Florida International University FIU Digital Commons

$7-1-2016$

\title{
The Effect of Stigma on Treatment Adherence among HIV-positive Alcohol Users in Haiti
}

Muni Rubens

Florida International University, mrube001@fiu.edu

DOI: 10.25148 /etd.FIDC000700

Follow this and additional works at: https://digitalcommons.fiu.edu/etd

\section{Recommended Citation}

Rubens, Muni, "The Effect of Stigma on Treatment Adherence among HIV-positive Alcohol Users in Haiti" (2016). FIU Electronic Theses and Dissertations. 2625.

https://digitalcommons.fiu.edu/etd/2625

This work is brought to you for free and open access by the University Graduate School at FIU Digital Commons. It has been accepted for inclusion in FIU Electronic Theses and Dissertations by an authorized administrator of FIU Digital Commons. For more information, please contact dcc@fiu.edu. 


\section{FLORIDA INTERNATIONAL UNIVERSITY}

Miami, Florida

THE EFFECT OF STIGMA ON TREATMENT ADHERENCE AMONG HIVPOSITIVE ALCOHOL USERS IN HAITI

A dissertation submitted in partial fulfillment of the

requirements for the degree of DOCTOR OF PHILOSOPHY

in

PUBLIC HEALTH

by

Muni Balakrishnan Rubens

2016 
To: Dean Tomás R. Guilarte

Robert Stempel College of Public Health and Social Work

This dissertation, written by Muni Balakrishnan Rubens, and entitled The Effect of Stigma on Treatment Adherence among HIV-positive Alcohol Users in Haiti, having been approved in respect to style and intellectual content, is referred to you for judgment.

We have read this dissertation and recommend that it be approved

$\begin{array}{r}\hline \text { H. Virginia McCoy } \\ \hline \text { Consuelo M. Beck-Sagué } \\ \hline \text { Florence George } \\ \hline \text { Jessy G. Dévieux, Major Professor }\end{array}$

Date of Defense: July 1, 2016

The dissertation of Muni Balakrishnan Rubens is approved.

Dean Tomás R. Guilarte Robert Stempel College of Public Health and Social Work

Dean Andrés G. Gil Vice President for Research and Economic Development and Dean of the University Graduate School

Florida International University, 2016 
(C) Copyright 2016 by Muni Balakrishnan Rubens

All rights reserved. 


\section{DEDICATION}

I dedicate this dissertation to my parents Girija and Balakrishnan, my dearest wife Sandhya (Pinky), my mentors Dr. Jessy G Dévieux, Dr. H. Virginia McCoy, Dr.

Consuelo M. Beck-Sagué, and Dr. Florence George and above all God the almighty Mookambika. 


\section{ACKNOWLEDGMENTS}

I express my sincere gratitude to all the people who made this dissertation a reality, especially my committee members who helped me all these years. Dr. Jessy G Dévieux, my Major Professor and Principal Investigator of the parent study, "Intervening with Haitian HIV-positive Alcohol Users: An Environmental Psychosocial Framework," a special appreciation for allowing me to use your data for the current study as well as the continual support in terms of funding and guidance over the years. The Parent study was supported by Grant R01AA018084 from the National Institute on Alcohol Abuse and Alcoholism (NIAAA). Dr. H. Virginia McCoy, all my admiration for your understanding, unrelenting encouragement and support. Dr. Consuelo M. Beck-Sagué, my sincere gratitude for your constructive opinions and limitless flow of ideas. Dr. Florence George, my respects for accommodating me amidst your busy schedule and your willingness to help and provide hours of unconditional support. Dr. Elena Bastida, Professor and Chair, Department of Health Promotion and Disease Prevention, my sincere thanks for prodding me to meet the deadlines, as well as funding and support through the department. I would also like to thank Dr. Michele Jean-Gilles for helping me extracting my data for the secondary analyses. My sincere gratitude to all my fellow Ph.D. students, especially Vekataraghavan Ramamoorthy and Anshul Saxena for their immense support in the entire process of this dissertation. Finally, I would also like to thank the University Graduate School, Florida International University for the Dissertation Year Fellowship. 


\title{
ABSTRACT OF THE DISSERTATION \\ THE EFFECT OF STIGMA ON TREATMENT ADHERENCE AMONG HIV POSITIVE ALCOHOL USERS IN HAITI
}

\author{
by \\ Muni Balakrishnan Rubens \\ Florida International University, 2016 \\ Miami, Florida \\ Professor Jessy G. Dévieux, Major Professor
}

Haiti reports the second highest prevalence of HIV among the Caribbean nations. People living with HIV/AIDS (PLWH) report stigmatic experiences, inadequate social support, depression, and anxiety, thereby affecting treatment adherence. This study examined the relationship between HIV-related stigma and treatment adherence, considering the effects of depression, anxiety, social support, and coping.

The current study is a secondary analysis of baseline data collected from 362 PLWH from Haiti. The measures included: Community Programs for Clinical Research on AIDS (CPCRA) adherence questionnaire; Perceived Stigma scale; Brief COPE questionnaire; State-Trait Anxiety Inventory (STAI); Centers for Epidemiological Studies Depression Scale (CES-D); and modified Medical Outcome Study Social Support Survey (mMOS-SSS). Descriptive statistics were used for demographic characteristics. T tests, Person correlations, multivariable linear regressions and structural equation modeling (SEM) were used for estimating the strength of associations and mediating effects.

Mean age of the sample was $35.72 \pm 8.50$ years and $37.0 \%$ were men. The mean self-reported treatment adherence was 93.1 percent. About $50.2 \%$ reported high levels of 
perceived stigma, $58.1 \%$ reported high levels of social support, $51.1 \%$ reported high levels of coping, $45.6 \%$ reported depression and $47.2 \%$ reported anxiety. Multivariable regression showed that treatment adherence was directly associated with quality of care satisfaction scores $($ Beta $=.032, \mathrm{p}=.041)$ and inversely associated with perceived stigma $($ Beta $=-0.049, \mathrm{p}=.031)$. Depression was directly associated with perceived stigmapublic view $($ Beta $=1.877, \mathrm{p}=.037)$ and inversely associated with tangible/informational social support $($ Beta $=1.877, \mathrm{p}=.020)$. SEM analyses showed significant associations between perceived sigma and coping $($ Beta $=.175, \mathrm{p}=.003)$, perceived sigma and anxiety $($ Beta $=.164, \mathrm{p}=.005)$, coping and anxiety $($ Beta $=.229, \mathrm{p}<.001)$, and anxiety and treatment adherence $($ Beta $=-.140, \mathrm{p}=.018)$. Maladaptive coping mediated the relationship between stigma and anxiety levels which in turn adversely affected treatment adherence.

In summary, HIV-related stigma was associated with lower levels of treatment adherence, and higher levels of depression and anxiety. These findings could be informative for future large scale studies on stigma, coping, anxiety and depression and planning effective interventions for improving treatment adherence. 


\section{TABLE OF CONTENTS}

CHAPTER

PAGE

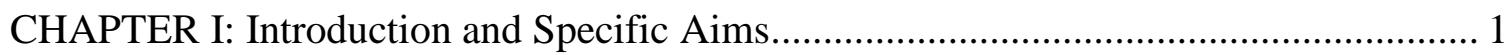

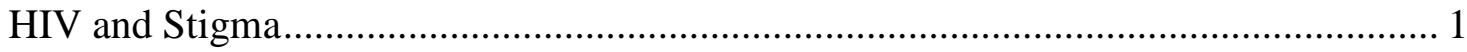

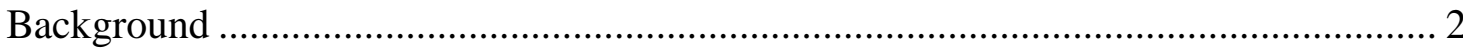

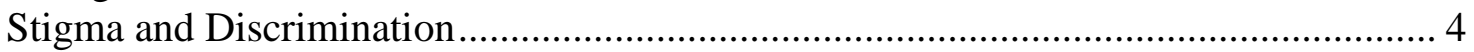

Multidimensional Aspects of HIV-Related Stigma …………...................................... 5

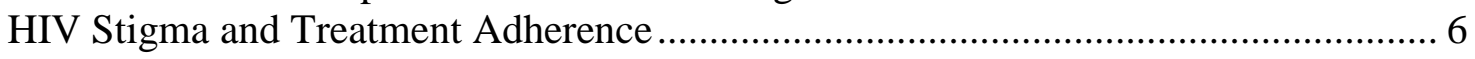

HIV-Related Stigma and Depression ................................................................ 7

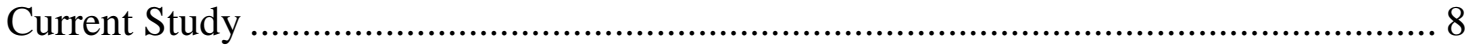

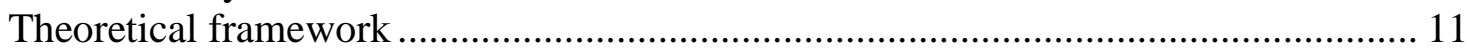

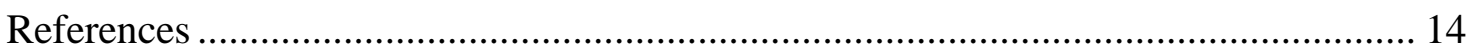

CHAPTER II: Literature Review........................................................................... 23

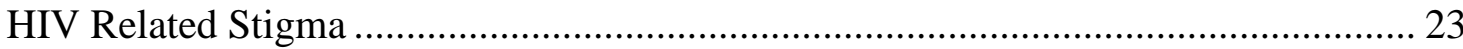

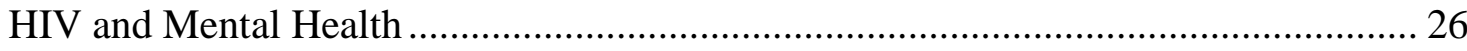

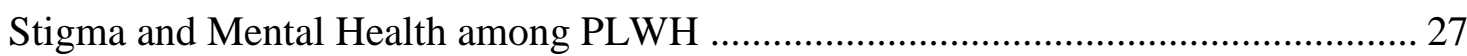

Anxiety, Stigma \& Treatment Adherence ………….................................................. 28

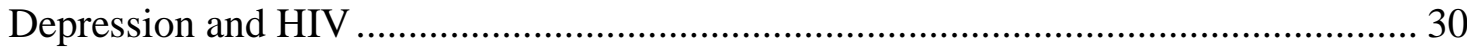

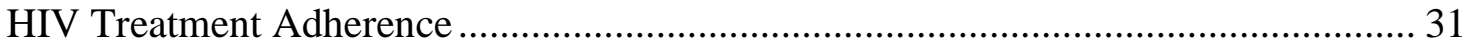

HIV Treatment Adherence and Mental Health ………........................................... 32

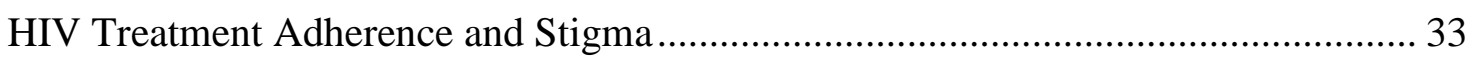

Alcohol Use and HIV Treatment Adherence ........................................................... 34

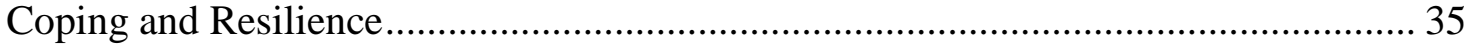

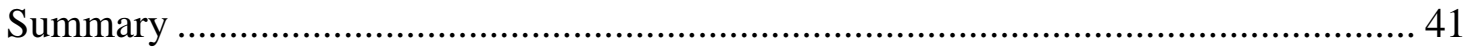

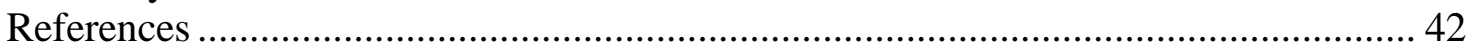

CHAPTER III: Relationship between HIV-Related Stigma and Treatment Adherence and the Mediating Effects of Coping Strategies in Alcohol Using PLWH in Haiti ......... 59

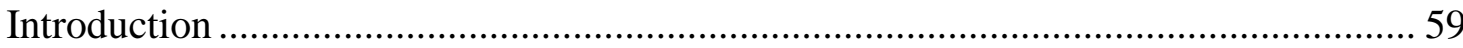

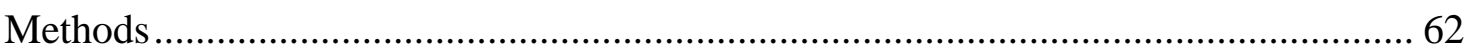

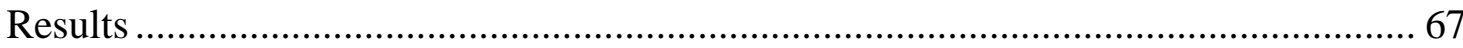

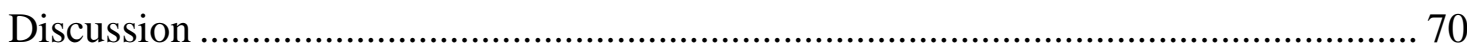

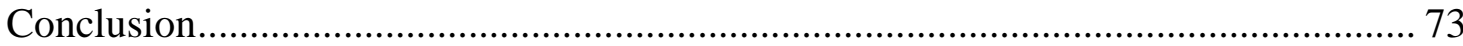

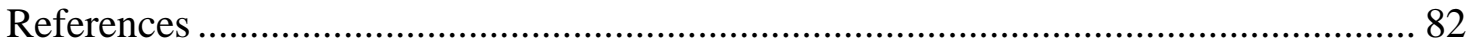

CHAPTER IV: Effects of Stigma and Anxiety on Treatment Adherence with

Maladaptive Coping as Mediator among HIV-Positive Alcohol Users in Haiti ............... 88

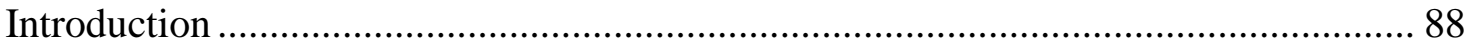

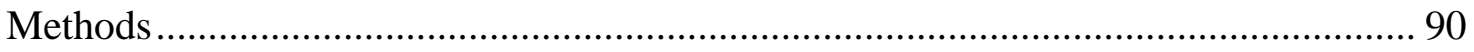

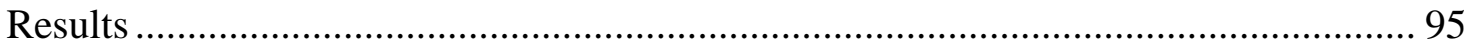

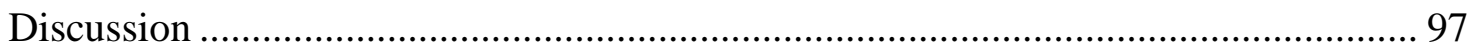

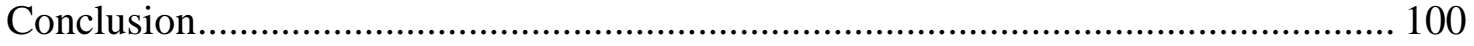


CHAPTER V: Relationships between Depression, Social Support and HIV-Related

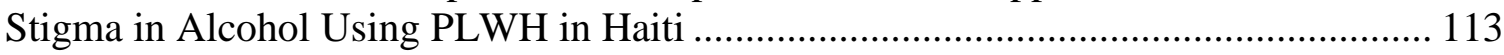

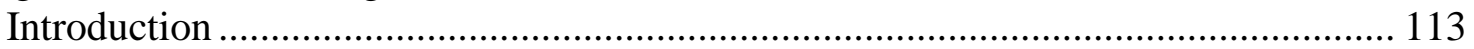

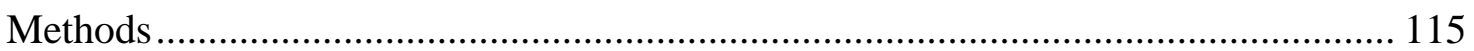

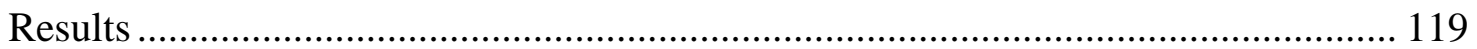

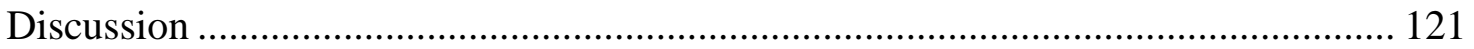

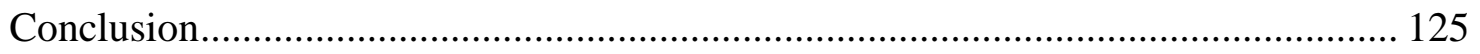

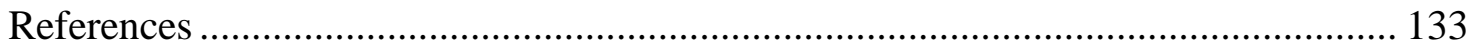

CHAPTER VI: Summary, Limitations and Future Extensions .................................. 138

Summary of the Study................................................................................... 138

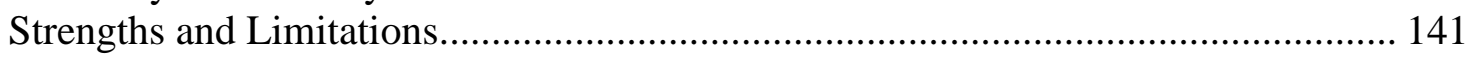

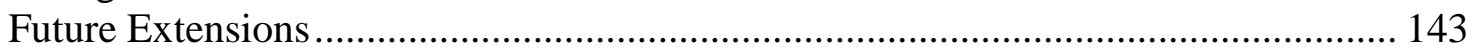

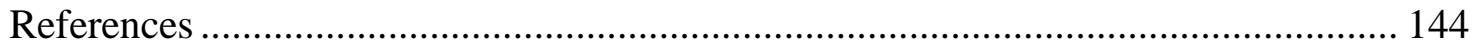

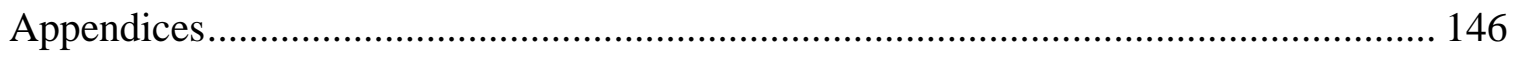

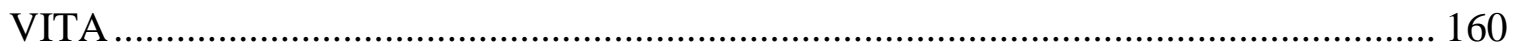




\section{LIST OF TABLES}

TABLE

PAGE

3.1. Demographic characteristics of the participants............................ 75

3.2. Participants' stigma by level of HIV treatment adherence.......................76

3.3. Participants' Brief COPE scores by level of HIV treatment adherence..............77

3.4. Reasons for not taking medication by participants with low HIV

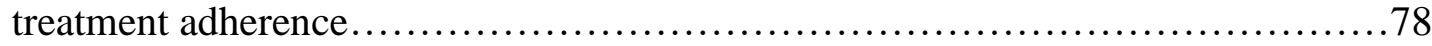

3.5. Correlation between adherence, perceived stigma, coping and satisfaction...........79

3.6. Multivariable linear regression predicting depression.........................80

4.1. Demographic characteristics of the participants............................ 101

4.2. Participants' stigma by anxiety level................................... 102

4.3. Participants' Brief COPE scores by anxiety level........................... 103

4.4. Participants' treatment adherence by anxiety level........................... 104

4.5. Correlation between anxiety, adherence, perceived stigma, and coping...........105

5.1. Demographic characteristics of the participants.............................127

5.2. Comparison of perceived stigma by mood related and attitudinal depression among participants............................................ 128

5.3. Comparison of social support by mood related and attitudinal depression among participants

5.4. Correlations among perceived stigma, depression, social support and demographic characteristics.

5.5. Multivariable linear regression predicting depression. 


\section{ABBREVIATIONS AND ACRONYMS}

$\begin{array}{ll}\text { ART } & \text { Antiretroviral Therapy } \\ \text { CBSM-A } & \text { Cognitive-Behavioral Stress Management - Adapted } \\ \text { CES-D } & \text { Centers for Epidemiological Studies Depression Scale } \\ \text { CDC } & \text { Centers for Disease Control and Prevention } \\ \text { CPCRA } & \text { Community Programs for Clinical Research on AIDS } \\ \text { GHESKIO } & \text { Groupe Haitien d'Etude du Sarcome de Kaposi et des Infections } \\ & \text { Opportunistes } \\ \text { IMB } & \text { Information-Motivation-Behavioral Skills Theory } \\ \text { IRB } & \text { Institutional Review Board } \\ \text { PLWH } & \text { People living with HIV/AIDS } \\ \text { mMOS-SSS } & \text { Modified Medical Outcome Study Social Support Survey } \\ \text { SEM } & \text { Structural Equation Modeling } \\ \text { STAI } & \text { State-Trait Anxiety Inventory } \\ \text { UNAIDS } & \text { Joint United Nations Programme on HIV/AIDS } \\ \text { WHO } & \text { World Health Organization }\end{array}$




\section{CHAPTER I: Introduction and Specific Aims}

\section{HIV and Stigma}

From the very onset of the pandemic, HIV/AIDS has been associated with increased stigma (Parker \& Aggleton, 2003; Scambler, 2003). HIV/AIDS has been associated with stigmatized groups such as men who have sex with men (MSMs), commercial sex workers and injection drug users (IDUs; Parker \& Aggleton, 2003). In spite of evidence of higher HIV transmission rates through heterosexual contacts globally, MSMs and IDUs have been implicated for acquiring and transmitting the disease (Lekas, Siegel, \& Leider, 2011; Liamputtong, 2013). Even among heterosexuals, HIV/AIDS has been stereotypically associated with commercial sex work, and women bear the brunt of stigmatization and discrimination. These discriminatory acts have in many instances violated human rights and extended to extreme forms of physical and mental abuse (Deacon et al., 2005). As Mann and Tarantola (1998) have suggested, "those who - before the arrival of HIV/AIDS - were socially marginalized, stigmatized or discriminated against, were found gradually and increasingly to bear the brunt of the HIV/AIDS epidemic. Human rights violations are now recognized to be primordial root causes of vulnerability to the epidemic" (Mann \& Tarantola, 1998, p. 8).

It has been repeatedly stated that HIV/AIDS because of its very nature of transmission initiates a high level of stigmatization and discrimination (Brimlow, Cook, \& Seaton, 2003; Lekas et al., 2011; Parker \& Aggleton, 2003). Thomas (2006) has described this process as a devaluation based on stereotyping and prejudice, where individuals tend to degrade those affected as "discreditable or unworthy, resulting in the person experiencing stigma becoming discounted or tainted" (Thomas, 2006, p. 3175). 
Stigma also includes the individual's fear and perceived threat about being discovered about the stigmatizing condition by the family or the community (Sivaram et al., 2009). Parker and Birdsall (2005) have explained this arm of stigma as prejudiced identity that sets apart affected individuals or groups because of their self-perceived and heightened negative perceptions and values towards their disease or condition (W. Parker \& Birdsall, 2005).

Deng and colleagues (2007) have also identified stigma as a social construct resulting from cultural, historical, social, and situational factors subjecting the affected individuals to feelings of shame or guilt. One of the major products of stigmatization is discrimination where a stigmatized individual is judged unfairly or unjustly due to the perception that the individual is at fault for his/her condition (Deng, Li, Sringernyuang, \& Zhang, 2007). HIV/AIDS has also been misconstrued as a disease that affects the individuals who have breached the moral and ethical standards of divine justice and threatened the very ethical and moral standards of the society (Zhou, 2007). Stigma may be expressed as verbal abuse, gossip, isolation, humiliation, rejection or neglect of individuals (Deng et al., 2007; Thomas, 2006). These manifestations may increase over time and become consolidated by ignorance, inaccurate information, and misconstrued perceptions about the disease by the infected population as well as the public (Apinundecha, Laohasiriwong, Cameron, \& Lim, 2007; Sweat \& Levin, 1995; Zhou, 2007).

\section{Background}

Since the first case of AIDS was identified in 1981 and human immunodeficiency virus (HIV) was identified as the causative agent, this disease has become a leading cause 
of mortality and morbidity worldwide (Centers for Disease Control and Prevention [CDC], 1981; Gallo et al., 1984). In the year 2013, global estimation showed that approximately 35 million people were living with HIV infection (World Health Organization [WHO], 2015a). Since the initial identification and characterization of the disease, about 78 million people have become infected and 39 million people have died from AIDS and related conditions (Joint United Nations Programme on HIV/AIDS [UNAIDS], 2014a). About 2.1 million people have become newly infected with HIV in the year 2013 (UNAIDS, 2014b).

Since the advent of antiretroviral medications, HIV infection has become a chronic disease with decreasing incidence and increasing prevalence. There were 29.8 million people living with HIV in 2001, and in 2014 the number has increased to 36.9 million. However, the global prevalence rate (percentage of people 15-49 years old who are infected) has leveled since 2001 and was $0.8 \%$ in 2014 (UNAIDS, 2015c). In the year 2013, about 12.9 million people were receiving some form of antiretroviral medication and constituted only $37 \%$ of all infected cases globally (UNAIDS, 2014d). According to the global estimates, about $\$ 19.1$ billion were spent on HIV/AIDS and related conditions in the year 2013 (Kaiser Family Foundation, 2014). This is a great burden on both developed as well as developing economies because more than $50 \%$ of these total expenses are directed towards underdeveloped nations with decreased productive capacity and increased HIV associated life loss years. Haiti is one such Caribbean nation with the second highest prevalence of HIV among Latin America and the Caribbean and also the highest number of people living with HIV (PLWH) in this geographical area. UNAIDS estimated that about 150,000 people are living with HIV in Haiti and 
prevalence among adults between 15-49 years is 2.2 percent (UNAIDS, 2013e). Haiti also reported 7,500 AIDS related deaths in 2012 (WHO, 2012b). The epidemiological severity of HIV/AIDS in Haiti is further complicated by many factors such as limited availability of antiretroviral therapy (ART), non-compliance to ART, substance abuse and stigma associated with the disease (Boulle \& Ford, 2007; Castro \& Farmer, 2005; Young, Wheeler, McCoy \& Weiser, 2014).

\section{Stigma and Discrimination}

Individuals coping with chronic illnesses have always been perceived as weak, dependent, or a burden on society. Many illnesses are associated with irresponsible or poor lifestyle choices (Millen \& Walker, 2000). HIV/AIDS is one such disease and research has consistently found that HIV/AIDS is far more stigmatizing than other chronic illnesses such as cancer, diabetes, heart disease or infectious diseases like tuberculosis and leprosy because of its association with homosexuality (Liamputtong, 2013).

The word stigma is derived from ancient Greek, meaning "mark" (Jones, 1987). Stigma has always produced negative impacts on the life, health and well-being of the individuals subjected to it (Liamputtong, Fanany, \& Verrinder, 2012). Stigma has its basis in "differences" in age, gender, race, socioeconomic status, disability, appearance, personality, illness, color, sexuality and specific behaviors which evoke panic, abhorrence, discontent or pity from individuals belonging to the same or other population groups (Whitehead, Carlisle, Watkins, \& Mason, 2001). The main element of stigmatization strategies includes social schism to create a "them and us" divide and lay a foundation for classification of individuals as "good and in favor" or "bad and out of 
favor" within a given socio-political setting (Foucault, 1973; Whitehead et al., 2001, p. 89).

Stigma also shows the phenomenon of self-perpetuation once the initiation of this socio-political schism occurs. The factors that aid in perpetuating stigma include prejudice, religious beliefs, social norms, superstition, ignorance, lack of knowledge and transmission of beliefs and thoughts across succeeding generations (Deacon, Stephney, \& Prosalendis, 2005). Sontag (1991) suggested that HIV/AIDS has been associated with the "sinful" and "evil," and PLWH are branded as "immoral" and "depraved" (Sontag, 1991, p. 90). As a consequence, they are socially unrecognized and considered as "not one of us" leading to discrimination (Whitehead et al., 2001, p. 126).

\section{Multidimensional Aspects of HIV-Related Stigma}

Though there are many arms of HIV-related stigma, they have been broadly classified into three subtypes (Bond, Chase, \& Aggleton, 2002; Thomas, 2006; Vanlandingham, Im-Em, \& Saengtienchai, 2005). 'Internalized stigma' occurs due to self-blame and self-deprecation by the individuals themselves because of their perceived beliefs and knowledge about the acquisition of the disease. 'Anticipated stigma' relates to the fear of being discriminated by willful or accidental disclosure of the disease condition resulting in constant avoidance or concealment of the disease, as well as the anxiety associated with the accidental disclosure of the disease. 'Enacted stigma' occurs because the individuals have experienced tangible discriminatory acts from non-infected individuals which could be actual or perceived. However, Parker and Aggleton (2003) have suggested that stigma may manifest in varied forms specific to the sociocultural context of the individuals, and the accompanying discrimination also varies across 
cultural diversities and complexities (Parker \& Aggleton, 2003). Zhou (2007)

recommends that sociocultural beliefs, moral beliefs and values within local contexts should always be considered to better understand the factors affecting stigma and discrimination in a given community. Stigma also changes temporally and therefore the currently accepted dimensions related to stigma will not absolutely represent the established dimensions in the past or the evolving dimensions in the future. Thus stigma and discrimination constitute a continuously evolving phenomenon (Zhou, 2007).

\section{HIV Stigma and Treatment Adherence}

ART has been the most critical determinant of control over HIV viral RNA and HIV/AIDS related conditions (Bangsberg et al., 2000; Bangsberg et al., 2001; Paterson et al., 2000). Many studies have positively associated ART adherence and cognitive processes such as knowledge, perception and health literacy (Maggiolo et al., 2002; Mehta, Moore, \& Graham, 1997). Recent studies have also associated lack of ART adherence with structural barriers such as geographic isolation, lack of transportation, food insecurity and lack of money and resources for treatment alternatives (Hardon et al., 2007; Kalofonos, 2010; Nagata et al., 2012; Pyne-Mercier et al., 2011; Taiwo et al., 2010; Weiser et al., 2010).

HIV/AIDS related stigma is another barrier that adversely affects many aspects of HIV-related care including HIV testing, HIV serostatus disclosure and ART adherence (Cree, Kay, Tisdall, \& Wallace, 2004). The process of enacted stigma and perceived stigma prevent the patient from seeking active medical services and force them towards concealing their seropositive status or refusing to be tested and treated (Bond et al., 2002; Thomas, 2006). Despite substantial evidence of stigma acting as a barrier in effective 
management of HIV in several populations worldwide, the mechanisms through which stigma compromises ART adherence in Haitian HIV positive alcohol users needs further explorations. This is an important gap in the literature which needs to be filled in order to improve treatment outcomes and the quality of life in these HIV positive patients.

\section{HIV-Related Stigma and Depression}

HIV-related stigma produces feelings of shame, guilt and concern regarding the disclosure, which in turn results in negatively perceived self-image. Such negative attitudes and perceptions can exacerbate mood disorders such as major depressive disorder, anxiety and panic attacks, and obsessive compulsive disorders (Chandra, Deepthivarma, Jairam, \& Thomas, 2003; Whetten, Reif, Whetten, \& Murphy-McMillan, 2008). HIV also produces feelings of self-loathing, guilt and shame among people diagnosed with the condition (Emlet, 2007). In extreme forms, these feelings could be transformed into intense depression and despair; PLWH often report extreme social withdrawal and acceptance of impending death (Hong, Anh, \& Ogden, 2004). When compared to the general population, PLWH report 2-3 times increased rates of depressive disorders (Mogga et al., 2006). This could be especially true in underdeveloped countries such as Haiti where the prevalence of depressive disorders is as high as $41.7 \%$ in the general population (Surkan et al., 2010; Wagenaar, Hagaman, Kaiser, McLean, \& Kohrt, 2012; Dévieux et al., 2013). Depressive disorders have been associated with many adverse health-related outcomes such as poor adherence to medications, faster progression to AIDS and poor quality of life in HIV positive patients (Ammassari et al., 2004; Bouhnik et al., 2005; Treisman \& Angelino, 2007; Malow et al., 2013). 
HIV-related stigma, gender, lower education, unemployment, compromised immune status, and increased rate of opportunistic infections are some of the variables associated with depression in HIV positive patients (Burack et al., 1993; Leserman et al., 2000; Olley, Seedat, Nei, \& Stein, 2004; Sherbourne et al., 2014; Simbayi et al., 2007). Additionally, HIV-related stigma adversely affects health service utilization and psychological well-being (Bond et al., 2002; Chesney \& Smith, 1999; Lichtenstein, Laska, \& Clair, 2002). In spite of profound effects on general well-being and quality of life, HIV-related stigma has often been overlooked in many scientific studies (MacQuarrie, Eckhaus, \& Nyblade, 2009). Similarly, major depressive disorders have also been associated with compromised immunological and virological variables such as lower CD4 counts and uncontrolled viral load (Olley et al., 2004). Major depressive disorders have been associated with female gender, younger age and unemployment status (Akena, Musisi, \& Kinyanda, 2010; Nakimuli-Mpungu, Musisi, Mpungu, \& Katabira, 2006). Many of these factors may have a bearing on treatment outcomes in PLWH.

\section{Current Study}

Using secondary data from the parent study titled "Intervening with Haitian HIV positive Alcohol Users: An Environmental Psychosocial Framework," the current dissertation examined the effect of stigma on HIV treatment adherence. This study examined the effects of HIV-related stigma on coping strategies affecting medication adherence and anxiety. In addition, this study also examined the relationship between depression and HIV-related stigma. The parent study was an adapted randomized controlled trial of a Cognitive-Behavioral Stress Management (CBSM-A) intervention for 
simultaneously enhancing safer sex practices, adherence to ART medication, and reducing alcohol or other drugs use, in a predominantly poor urban population in Haiti. The parent study included 389 alcohol using, HIV positive individuals. The experimental group was administered the CBSM-A, an adapted intervention guided by the Information-Motivation-Behavioral Skills (IMB) theory. The intervention used a smallgroup design for HIV positive alcohol-using populations, which also addressed their cognitive/self-management and coping barriers that could impede sustainable outcomes, particularly in resource-constrained settings such as Haiti. In the parent study, the CBSMA intervention was compared with a wait-list control group where participants received the intervention following their 6-month follow-up assessment.

The following aims and hypothesis were tested in this study:

Aim 1: To understand the relationship between HIV-related stigma and HIV treatment adherence in a sample of HIV positive alcohol users in Haiti.

Research Question 1: Does HIV-related stigma significantly affect HIV treatment adherence in a sample of PLWH in Haiti?

Hypothesis 1: Among PLWH, levels of HIV-related stigma will be significantly associated with levels of HIV treatment adherence.

Aim 2: To understand whether coping strategies act as a mediator between HIV-related stigma and HIV treatment adherence.

Research Question 2: Do coping strategies used to deal with HIV-related symptoms mediate the relationship between HIV-related stigma and HIV treatment adherence? 
Hypothesis 2: Among PLWH, coping strategies act as a mediator between HIV-related stigma and HIV treatment adherence.

Aim 3: To understand whether coping strategies act as a mediator between anxiety and HIV treatment adherence

Research Question 3: Do coping strategies used to deal with HIV-related symptoms mediate the relationship between anxiety and HIV treatment adherence?

Hypothesis 3: Among PLWH, coping strategies act as mediator between anxiety and HIV treatment adherence.

Aim 4: To understand the relationship between HIV-related stigma and depression Research Question 4: Does HIV-related stigma significantly affect depression in PLWH?

Hypothesis 4: Among PLWH, HIV-related stigma will be significantly associated with higher levels of depression.

Aim 5: To understand whether social support acts as a mediator between HIV related stigma and depression symptoms

Research Question 5: Does social support mediate the relationship between HIV related stigma and depression?

Hypothesis 5: Among PLWH, social support will act as a mediator between HIV related stigma and depression. 


\section{Theoretical framework}

Stress and coping theories provide frameworks to relate how individuals cope and react to psychologically stressful situations (Matthieu \& Ivanoff, 2006). Stigma represents a stressful psychological situation in which an individual internalizes negative beliefs, opinions and feelings towards himself/herself (Logie, Newman, Chakrapani, \& Shunmugam, 2012). Evidence indicates that PLWH often accept the stigma associated with their disease; this acceptance adversely influences their physical and mental health (Kalichman et al., 2009). Kalichman and colleagues (2009) reported that the stigma associated with HIV/AIDS could act as significant barriers towards prevention, testing and care. The study also showed that internalized HIV-related stigma was consistent across PLWH from geographically diverse locations such as South Africa, Swaziland and Atlanta, GA, U.S. This study also reported that the social stigma of HIV/AIDS follows the classic model of stigma identified by Goffman's seminal 1963 study. Goffman defined three dimensions of stigma relating to flaws in personal character and include: disgraced social identity; physical abnormalities or defects; and racial stigma (Goffman, 1963). Green (1995) in a street survey among 300 non-infected participants and 42 PLWH in Glasgow and Edinburgh documented these attributes in the general public (Green, 1995).

Stress theory dates back to Hans Selye's benchmark research and his book on the "Stress of Life" (Selye, 1956). A psychosocial stressor refers to the reaction of an individual to a response or stimulus that he/she perceives as a threat (Matthieu \& Ivanoff, 2006). The concept of HIV stigma falls under the definition of a psychosocial stressor. HIV stigma creates stress from the prejudiced attitudes and discrimination toward 
PLWH. Understanding the stress stimulus allows the ability to target interventions to deal with this response.

Coping theory encompasses the concept of the adaptation response in an individual to a stressful situation. Coping involves self-directing endeavors targeted towards diminishing the harmful effects of stressors (Varni, Miller, McCuin, \& Solomon, 2012). Coping strategies may involve approach (engagement) or avoidance (disengagement) responses to stressors. PLWH using disengagement coping to deal with stressors show a higher association with depression, anxiety and emotional distress; whereas PLWH employing engagement coping strategies demonstrate lesser depression and higher levels of satisfaction with life (Heckman, 2003).

HIV related stigma and coping mechanisms significantly affect many outcome variables such as HIV treatment adherence, HIV symptomatology and anxiety towards the disease condition. Furthermore, anxiety disorders among PLWH are eight times higher than in the general population (Varni et al., 2012). Anxiety and the symptoms of the disease are also negatively correlated with adherence to the medical regimen. In addition, another variable, social support, acts as a mediator for the relationship between depression and HIV related stigma (Rao et al., 2012). Because of the interrelationships between these variables, depression could also have significant adverse effects on HIV treatment adherence and anxiety. Figure 1 illustrates the all-encompassing model which was created to demonstrate this complex interrelationship. 
Figure 1. Stress-coping model demonstrating interrelationship of variables.

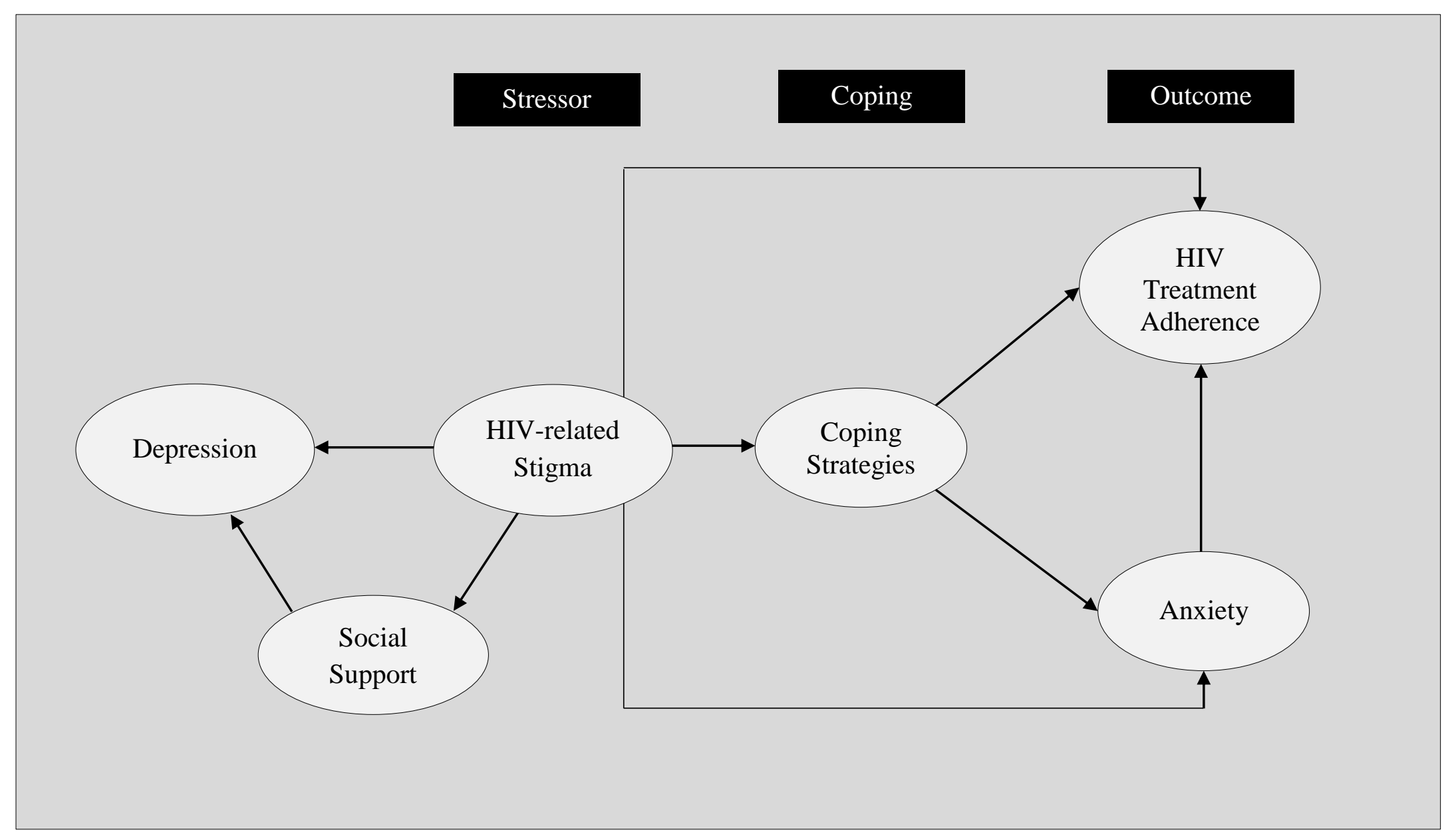




\section{References}

Akena, D., Musisi, S., \& Kinyanda, E. (2010). A comparison of the clinical features of depression in HIV-positive and HIV-negative patients in Uganda. African Journal of Psychiatry, 13(1), 43-51.

Ammassari, A., Antinori, A., Aloisi, M. S., Trotta, M. P., Murri, R., Bartoli, L., . . Starace, F. (2004). Depressive symptoms, neurocognitive impairment, and adherence to highly active antiretroviral therapy among HIV-infected persons. Psychosomatics, 45(5), 394-402.

Apinundecha, C., Laohasiriwong, W., Cameron, M. P., \& Lim, S. (2007). A community participation intervention to reduce HIV/AIDS stigma, Nakhon Ratchasima province, northeast Thailand. AIDS Care, 19(9), 1157-1165.

Bangsberg, D. R., Hecht, F. M., Charlebois, E. D., Zolopa, A. R., Holodniy, M., Sheiner, L., . . Moss, A. (2000). Adherence to protease inhibitors, HIV-1 viral load, and development of drug resistance in an indigent population. AIDS, 14(4), 357-366.

Bangsberg, D. R., Perry, S., Charlebois, E. D., Clark, R. A., Roberston, M., Zolopa, A. R., \& Moss, A. (2001). Non-adherence to highly active antiretroviral therapy predicts progression to AIDS. AIDS, 15(9), 1181-1183.

Baron, R. M., \& Kenny, D. A. (1986). The moderator-mediator variable distinction in social psychological research: Conceptual, strategic, and statistical considerations. Journal of Personality and Social Psychology, 51(6), 1173.

Bauman, L., Camacho, S., Westbrook, L., \& Forbes-Jones, E. (1997). Correlates of personal stigma and social stigma among mothers with HIV/AIDS. Paper presented at the National Conference on Women and HIV, Pasadena, CA.

Bauman, L., Silver, E., \& Camacho, S. (July, 2000). Stigma among mothers with HIV/AIDS. Paper presented at the XIII International AIDS Conference, Durban, South Africa.

Beck, A. T., \& Emery, G. (1979). Cognitive therapy of anxiety and phobic disorders. Philadelphia, PA: Center for Cognitive Therapy.

Bernstein, D. A., \& Borkovec, T. D. (1973). Progressive relaxation training: A manual for the helping professions. Champaign, IL: Research Press.

Bond, V., Chase, E., \& Aggleton, P. (2002). Stigma, HIV/AIDS and prevention of mother-to-child transmission in Zambia. Evaluation and Program Planning, 25(4), 347-356. 
Bouhnik, A.-D., Préau, M., Vincent, E., Carrieri, M. P., Gallais, H., Lepeu, G., . . Spire, B. (2005). Depression and clinical progression in HIV-infected drug users treated with highly active antiretroviral therapy. Antiviral Therapy, 10(1), 53-61.

Boulle, A., \& Ford, N. (2007). Scaling up antiretroviral therapy in developing countries: what are the benefits and challenges? Sexually Transmitted Infections, 83(7), 503505 .

Brimlow, D. L., Cook, J. S., \& Seaton, R. (2003). Stigma and HIV/AIDS: A review of the literature. Rockville, MD: US Department of Health and Human Services.

Burack, J. H., Barrett, D. C., Stall, R. D., Chesney, M. A., Ekstrand, M. L., \& Coates, T. J. (1993). Depressive symptoms and CD4 lymphocyte decline among HIVinfected men. JAMA, 270(21), 2568-2573.

Carver, C. S., Scheier, M. F., \& Weintraub, J. K. (1989). Assessing coping strategies: a theoretically based approach. Journal of Personality and Social Psychology, 56(2), 267.

Castro, A., \& Farmer, P. (2005). Understanding and addressing AIDS-related stigma: from anthropological theory to clinical practice in Haiti. American Journal of Public Health, 95(1), 53-59.

CDC/HRSA. (2011). Intervention for Seropositive Injection Drug Users, Research \& Evaluation (INSPIRE). Retrieved from http://hab.hrsa.gov/abouthab/special/inspire.html\#a

CDC. (1981). Kaposi's sarcoma and Pneumocystis pneumonia among homosexual menNew York City and California. MMWR Morbidity and Mortality Weekly Report, 30(25), 305-308

Chandra, P. S., Deepthivarma, S., Jairam, K., \& Thomas, T. (2003). Relationship of psychological morbidity and quality of life to illness-related disclosure among HIV-infected persons. Journal of Psychosomatic Research, 54(3), 199-203.

Chesney, M. A., \& Smith, A. W. (1999). Critical delays in HIV testing and care the potential role of stigma. American Behavioral Scientist, 42(7), 1162-1174.

Coleman, C. L., \& Holzemer, W. L. (1999). Spirituality, psychological well-being, and HIV symptoms for African Americans living with HIV disease. Journal of the Association of Nurses in AIDS Care, 10(1), 42-50.

Cree, V. E., Kay, H., Tisdall, K., \& Wallace, J. (2004). Stigma and parental HIV. Qualitative Social Work, 3(1), 7-24. 
Cutrona, C. E., \& Russell, D. W. (1987). The provisions of social relationships and adaptation to stress. Advances in Personal Relationships, 1(1), 37-67.

Deacon, H., Stephney, I., \& Prosalendis, S. (2005). Understanding HIV/AIDS stigma: A theoretical and methodological analysis. Cape Town, South Africa: HSRC Press.

Deng, R., Li, J., Sringernyuang, L., \& Zhang, K. (2007). Drug abuse, HIV/AIDS and stigmatisation in a Dai community in Yunnan, China. Social Science \& Medicine, 64(8), 1560-1571.

Dévieux, J. G., Malow, R. M., Attonito, J. M., Jean-Gilles, M., Rosenberg, R., Gaston, S., ... \& Deschamps, M. M. (2013). Post-traumatic stress disorder symptomatology and alcohol use among HIV-seropositive adults in Haiti. AIDS Care, 25(10), 1210-1218.

Emlet, C. A. (2007). Experiences of stigma in older adults living with HIV/AIDS: A mixed-methods analysis. AIDS Patient Care and STDs, 21(10), 740-752.

Fensterheim, H., \& Baer, J. L. (1975). Don't say yes when you want to say no. New York: NY: David McKay.

Foucault, M. (1973). The birth of the clinic: An archaeology of medical perception. Sheridan, London: Tavistock.

Gallo, R. C., Salahuddin, S. Z., Popovic, M., Shearer, G. M., Kaplan, M., Haynes, B. F., ... \& Safai, B. (1984). Frequent detection and isolation of cytopathic retroviruses (HTLV-III) from patients with AIDS and at risk for AIDS. Science, 224(4648), 500-503.

Goffman, E. (1963). Stigma: Notes on the management of spoiled identity. New York: NY: Simon \& Schuster.

Green, G. (1995). Attitudes towards people with HIV: Are they as stigmatizing as people with HIV perceive them to be? Social Science \& Medicine, 41(4), 557-568.

Hardon, A. P., Akurut, D., Comoro, C., Ekezie, C., Irunde, H. F., Gerrits, T., . . . Maridadi, J. (2007). Hunger, waiting time and transport costs: time to confront challenges to ART adherence in Africa. AIDS Care, 19(5), 658-665.

Heckman, T. G. (2003). The chronic illness quality of life (CIQOL) model: explaining life satisfaction in people living with HIV disease. Health Psychology, 22(2), 140147.

Holzemer, W. L., \& Uys, L. R. (2005). Managing AIDS stigma. Journal of Social Aspects of HIV/AIDS, 1(3), 165-174. 
Hong, K. T., Anh, N., \& Ogden, J. (2004). Understanding HIV and AIDS-related stigma and discrimination in Vietnam. Washington, DC: International Center for Research on Women.

Jones, C. P. (1987). Stigma: tattooing and branding in Graeco-Roman antiquity. Journal of Roman Studies, 77, 139-155.

Kaiser Family Foundation. (2014). The Global HIV/AIDS Epidemic. Retrieved from http://kff.org/global-health-policy/fact-sheet/the-global-hivaids-epidemic/

Kalichman, S. C., Amaral, C. M., White, D., Swetsze, C., Kalichman, M. O., Cherry, C., \& Eaton, L. (2012). Alcohol and adherence to antiretroviral medications: interactive toxicity beliefs among people living with HIV. Journal of the Association of Nurses in AIDS Care, 23(6), 511-520.

Kalichman, S. C., Simbayi, L. C., Cloete, A., Mthembu, P. P., Mkhonta, R. N., \& Ginindza, T. (2009). Measuring AIDS stigmas in people living with HIV/AIDS: the Internalized AIDS-Related Stigma Scale. AIDS Care, 21(1), 87-93.

Kalofonos, I. A. (2010). "All I eat is ARVs": the paradox of AIDS treatment interventions in central Mozambique. Medical Anthropology Quarterly, 24(3), $363-380$.

Kraaij, V., van der Veek, S. M., Garnefski, N., Schroevers, M., Witlox, R., \& Maes, S. (2008). Coping, goal adjustment, and psychological well-being in HIV-infected men who have sex with men. AIDS Patient Care and STDs, 22(5), 395-402.

Lekas, H.-M., Siegel, K., \& Leider, J. (2011). Felt and enacted stigma among HIV/HCVcoinfected adults the impact of stigma layering. Qualitative Health Research, 2l(9), 1205-1219.

Leserman, J., Petitto, J. M., Golden, R. N., Gaynes, B. N., Gu, H., Perkins, D. O., . . . Evans, D. L. (2000). Impact of stressful life events, depression, social support, coping, and cortisol on progression to AIDS. American Journal of Psychiatry, 157(8), 1221-1228.

Liamputtong, P. (2013). Women, motherhood and living with HIV/AIDS: A cross-cultural perspective. Dordrecht, Netherlands: Springer Netherlands.

Liamputtong, P., Fanany, R., \& Verrinder, G. (2012). Health, Illness and Wellbeing: Perspectives and Social Determinants. New York, NY: Oxford University Press.

Lichtenstein, B., Laska, M. K., \& Clair, J. M. (2002). Chronic sorrow in the HIV-positive patient: Issues of race, gender, and social support. AIDS Patient Care and STDs, 16(1), 27-38. 
Logie, C. H., Newman, P. A., Chakrapani, V., \& Shunmugam, M. (2012). Adapting the minority stress model: associations between gender non-conformity stigma, HIVrelated stigma and depression among men who have sex with men in South India. Social Science \& Medicine, 74(8), 1261-1268.

MacQuarrie, K., Eckhaus, T., \& Nyblade, L. (2009). HIV-related stigma and discrimination: A summary of recent literature. Geneva, Switzerland: UNAIDS.

Maggiolo, F., Ripamonti, D., Arici, C., Gregis, G., Quinzan, G., Camacho, G. A., . . Suter, F. (2002). Simpler regimens may enhance adherence to antiretrovirals in HIV-infected patients. HIV Clinical Trials, 3(5), 371-378.

Malow, R., Dévieux, J. G., Stein, J. A., Rosenberg, R., Jean-Gilles, M., Attonito, J., ... Pape, J. W. (2013). Depression, substance abuse and other contextual predictors of adherence to antiretroviral therapy (ART) among Haitians. AIDS and Behavior, 17(4), 1221-1230.

Mann, J., \& Tarantola, D. (1998). Responding to HIV/AIDS: a historical perspective. Health and Human Rights, 2(4), 5-8.

Mannheimer, S. B., Morse, E., Matts, J. P., Andrews, L., Child, C., Schmetter, B., ... Terry Beirn Community Programs for Clinical Research on AIDS. (2006). Sustained benefit from a long-term antiretroviral adherence intervention: results of a large randomized clinical trial. Journal of Acquired Immune Deficiency Syndromes, 43, S41-S47.

Matthieu, M. M., \& Ivanoff, A. (2006). Using stress, appraisal, and coping theories in clinical practice: assessments of coping strategies after disasters. Brief Treatment and Crisis Intervention, 6(4), 337.

Mehta, S., Moore, R. D., \& Graham, N. M. (1997). Potential factors affecting adherence with HIV therapy. AIDS, 11(14), 1665-1670.

Millen, N., \& Walker, C. (2000). Overcoming the stigma of chronic illness: Strategies for 'straightening out' a spoiled identity. Paper presented at the Sociological Sights/Sites, TASA 2000 Conference, Adelaide, Australia.

Mogga, S., Prince, M., Alem, A., Kebede, D., Stewart, R., Glozier, N., \& Hotopf, M. (2006). Outcome of major depression in Ethiopia Population-based study. The British Journal of Psychiatry, 189(3), 241-246. 
Nagata, J. M., Magerenge, R. O., Young, S. L., Oguta, J. O., Weiser, S. D., \& Cohen, C. R. (2012). Social determinants, lived experiences, and consequences of household food insecurity among persons living with HIV/AIDS on the shore of Lake Victoria, Kenya. AIDS Care, 24(6), 728-736.

Nakimuli-Mpungu, E., Musisi, S., Mpungu, S. K., \& Katabira, E. (2006). Primary mania versus HIV-related secondary mania in Uganda. The American Journal of Psychiatry, 163(8), 1349-1354.

Olley, B., Seedat, S., Nei, D., \& Stein, D. (2004). Predictors of major depression in recently diagnosed patients with HIV/AIDS in South Africa. AIDS Patient Care and STDs, 18(8), 481-487.

Parker, R., \& Aggleton, P. (2003). HIV and AIDS-related stigma and discrimination: a conceptual framework and implications for action. Social Science \& Medicine, 57(1), 13-24.

Parker, W., \& Birdsall, K. (2005). HIV/AIDS and faith-based organizations: A review. Retrieved from http://www.cadre.org.za/files/CADRE-Stigma-FBO.pdf

Paterson, D. L., Swindells, S., Mohr, J., Brester, M., Vergis, E. N., Squier, C., . . Singh, N. (2000). Adherence to protease inhibitor therapy and outcomes in patients with HIV infection. Annals of Internal Medicine, 133(1), 21-30.

Prado, G., Huang, S., Maldonado-Molina, M., Bandiera, F., Schwartz, S. J., de la Vega, P., ... Pantin, H. (2010). An empirical test of ecodevelopmental theory in predicting HIV risk behaviors among Hispanic youth. Health Education \& Behavior, 37(1), 97-114.

Pyne-Mercier, L. D., John-Stewart, G. C., Richardson, B. A., Kagondu, N. L., Thiga, J., Noshy, H., . . Chung, M. H. (2011). The consequences of post-election violence on antiretroviral HIV therapy in Kenya. AIDS Care, 23(5), 562-568.

Radloff, L. S. (1977). The CES-D scale a self-report depression scale for research in the general population. Applied Psychological Measurement, 1(3), 385-401.

Rao, D., Chen, W., Pearson, C., Simoni, J., Fredriksen-Goldsen, K., Nelson, K., . . . Zhang, F. (2012). Social support mediates the relationship between HIV stigma and depression/quality of life among people living with HIV in Beijing, China. International Journal of STD \& AIDS, 23(7), 481-484.

Saunders, J. B., Aasland, O. G., Babor, T. F., De la Fuente, J. R., \& Grant, M. (1993). Development of the alcohol use disorders identification test (AUDIT). WHO collaborative project on early detection of persons with harmful alcohol consumption-II. Addiction, 88, 791-804. 
Scambler, G. (2003). Sociology as applied to medicine. Edinburgh: Saunders.

Selye, H. (1956). The stress of life. New York, NY: McGraw-Hill.

Sherbourne, C. D., Hays, R. D., Fleishman, J. A., Vitiello, B., Magruder, K. M., Bing, E. G., ... Eggan, F. (2014). Impact of psychiatric conditions on health-related quality of life in persons with HIV infection. American Journal of Psychiatry, 157(2), 248-254.

Simbayi, L. C., Kalichman, S., Strebel, A., Cloete, A., Henda, N., \& Mqeketo, A. (2007). Internalized stigma, discrimination, and depression among men and women living with HIV/AIDS in Cape Town, South Africa. Social Science \& Medicine, 64(9), 1823-1831.

Sivaram, S., Zelaya, C., Srikrishnan, A., Latkin, C., Go, V., Solomon, S., \& Celentano, D. (2009). Associations between social capital and HIV stigma in Chennai, India: considerations for prevention intervention design. AIDS Education and Prevention, 21(3), 233-250.

Sontag, S. (1991). Illness as metaphor: AIDS and its metaphors. London: Penguin.

Spielberger, C., Gorsuch, R., \& Lushene, R. (1970). Manual for the state-trait anxiety inventory. Palo Alto, CA: Consulting Psychologists Press.

STATA. (2007). Stata Base Reference Manual, Release 10: College Station, TX: Stata Press.

Surkan, P. J., Mukherjee, J. S., Williams, D. R., Eustache, E., Louis, E., Jean-Paul, T., . . . Fawzi, M. C. S. (2010). Perceived discrimination and stigma toward children affected by HIV/AIDS and their HIV-positive caregivers in central Haiti. AIDS Care, 22(7), 803-815.

Sweat, M. D., \& Levin, M. (1995). HIV/AIDS knowledge among the US population. AIDS Education and Prevention, 7(4), 355-375.

Taiwo, B. O., Idoko, J. A., Welty, L. J., Otoh, I., Job, G., Iyaji, P. G., . . Murphy, R. L. (2010). Assessing the viorologic and adherence benefits of patient-selected HIV treatment partners in a resource-limited setting. Journal of Acquired Immune Deficiency Syndromes, 54(1), 85-92.

Terry Beirn Community Programs for Clinical Research on AIDS. (2003). Antiretroviral medication self-report: Form 646. 
Thomas, F. (2006). Stigma, fatigue and social breakdown: exploring the impacts of HIV/AIDS on patient and carer well-being in the Caprivi Region, Namibia. Social Science \& Medicine, 63(12), 3174-3187.

Treisman, G., \& Angelino, A. (2007). Interrelation between psychiatric disorders and the prevention and treatment of HIV infection. Clinical Infectious Diseases, 45(Supplement 4), S313-S317.

UNAIDS(a). (2014). World AIDS Day 2014 Report - Fact sheet. Retrieved from http://www.unaids.org/en/resources/campaigns/World-AIDS-Day-Report$\underline{\text { 2014/factsheet }}$

UNAIDS(b). (2014). Global Statistics. Retrieved from http://www.unaids.org/en/resources/campaigns/2014/2014gapreport/factsheet

UNAIDS(c). (2015). How AIDS Changed Everything. Retrieved from http://www.unaids.org/sites/default/files/media_asset/MDG6Report_en.pdf

UNAIDS(d). (2014). The Gap Report. Retrieved from http://www.unaids.org/sites/default/files/en/media/unaids/contentassets/document s/unaidspublication/2014/UNAIDS_Gap_report_en.pdf

UNAIDS(e). (2013). HIV and AIDS estimates: Haiti [Internet]. Retrieved from http://www.unaids.org/en/regionscountries/countries/haiti/

UNICEF. (2013). HIV/AIDS complete global database [Data file]. Retrieved from http://data.unicef.org/hiv-aids/global-trends

Vanlandingham, M. J., Im-Em, W., \& Saengtienchai, C. (2005). Community reaction to persons with HIV/AIDS and their parents: an analysis of recent evidence from Thailand. Journal of Health and Social Behavior, 46(4), 392-410.

Varni, S. E., Miller, C. T., McCuin, T., \& Solomon, S. E. (2012). Disengagement and engagement coping with HIV/AIDS stigma and psychological well-being of people with HIV/AIDS. Journal of Social and Clinical Psychology, 31(2), 123150.

Wagenaar, B. H., Hagaman, A. K., Kaiser, B. N., McLean, K. E., \& Kohrt, B. A. (2012). Depression, suicidal ideation, and associated factors: a cross-sectional study in rural Haiti. BMC Psychiatry, 12(1), 149.

Weiser, S. D., Tuller, D. M., Frongillo, E. A., Senkungu, J., Mukiibi, N., \& Bangsberg, D. R. (2010). Food insecurity as a barrier to sustained antiretroviral therapy adherence in Uganda. PLoS One, 5(4), e10340. 
Westbrook, L., \& Bauman, L. (1996). The perceived stigma of AIDS: Personal view and public view scales. Bronx, NY: Albert Einstein College of Medicine.

Whetten, K., Reif, S., Whetten, R., \& Murphy-McMillan, L. K. (2008). Trauma, mental health, distrust, and stigma among HIV-positive persons: implications for effective care. Psychosomatic Medicine, 70(5), 531-538.

Whitehead, E., Carlisle, C., Watkins, C., \& Mason, T. (2001). Stigma and social exclusion in healthcare. London: Routledge.

WHO(a). (2015). Global Health Observatory (GHO) data. Retrieved from http://www.who.int/gho/hiv/en/

WHO(b). (2012). Voluntary medical male circumcision for HIV prevention. Retrieved from http://www.who.int/hiv/topics/malecircumcision/fact_sheet/en/

Young, S., Wheeler, A. C., McCoy, S. I., \& Weiser, S. D. (2014). A review of the role of food insecurity in adherence to care and treatment among adult and pediatric populations living with HIV and AIDS. AIDS and Behavior, 18(5), 505-515.

Zhou, Y. R. (2007). "If you get AIDS... You have to endure it alone": Understanding the social constructions of HIV/AIDS in China. Social Science \& Medicine, 65(2), 284-295. 


\section{CHAPTER II: Literature Review}

From the very onset of HIV/AIDS in the early 1980s, this pandemic has been considered both a medical and social illness (Herek \& Capitanio, 1993; Letteney \& Laporte, 2004). Scambler (2003) stated that HIV/AIDS has always been "both medicalized as disease and moralized as stigma" (Scambler, 2003, p. 199). Ever since its identification, HIV/AIDS has provoked powerful reactions from the public such as prejudices against “sex, drugs, death and contagion” (Scambler, 2003, p. 199). This uniqueness has made HIV/AIDS an extremely stigmatizing disease. This literature review explores the different associations and components of HIV-related stigma and its adverse effects.

\section{HIV Related Stigma}

The conceptualization of stigma can be traced back to the work of Erving Goffman, who defined stigma as an "attribute that is deeply discrediting, reduces the stigmatized individual from a whole and usual person to a tainted, discounted one" (Goffman, 1963, p. 3). Building on this foundation, many researchers have successively discredited stigma as a social injustice that involves discriminatory behaviors and indirect harm to the stigmatized individual (Major \& O'Brien, 2005). Link and Phelan (2001) developed an integrative approach for defining stigma in terms of four core components: distinguishing and labeling human differences; cultural beliefs perpetuating negative stereotypes; categorization of labeled persons in order to develop separation mentality (i.e. "us" versus "them"); and finally, status loss and discrimination experienced by labeled persons resulting in social injustice (p. 367). This definition also encompasses the broader forces acting in the stigmatization process, particularly social, economic, and political (Link \& Phelan 2001, p. 367). Though personal responses to stigma significantly 
vary from individual to individual, self-stigma has been defined as the situation wherein individuals internalize and accept stigma-related devaluations and discriminations (Herek, 1990). The negative thoughts and feelings that result from these internalization processes lead to the creation of self-hatred and has been linked to increased depression, psychological distress, and decreased reliance on social support (Mak et al., 2007; Lee, Kochman, \& Sikkema, 2002).

HIV-related stigma constitutes one of the significant barriers adversely affecting treatment adherence and thereby increasing transmissions rates of the disease (Katz et al., 2013). HIV-related stigma has been identified as a social and structural phenomenon that involves stereotyping, status loss, and discrimination in many power structure settings existing in complex societies (Mahajan et al., 2008). Studies show that the most salient domains of HIV-stigma (that affect self-esteem and self-acceptance in PLWH) include blame, stereotypes, and fear of contagion (Sayles et al., 2007). Stigma is thus a complex social process (Earnshaw \& Caudoir, 2009), with varied and profound implications, particularly for PLWH (Lee, Kochman, Sikkema, 2002). HIV-related stigma has been linked to the creation and maintenance of social inequalities, often along the lines of race, class, gender, and sexual orientation (Parker \& Aggleton, 2003). This is additionally complicated by stigmas related to drug use, and homosexuality (Reidpath \& Chan, 2005; Crawford, 1996). Moreover, several studies have shown that HIV-related stigma is more intense when compared to the stigmas associated with other illnesses such as herpes, cancer, tuberculosis etc. (Peters et al., 1994). HIV-related stigma has significant effects not only on the diagnosed individuals, but also their family members (Bogart et al., 2008), their health workers and volunteers (Snyder et al., 1999). 
Earnshaw and Chaudoir (2009) developed the HIV Stigma Framework to understand the specifics as well as the effects of stigma experienced by PLWH. The HIV Stigma Framework proposes three distinct stigma mechanisms: internalized, anticipated, and enacted HIV stigma categories (Earnshaw \& Chaudoir, 2009). Many studies have utilized this framework to investigate stigmatic experiences among PLWH.

Internalized Stigma: The PLWH tend to endorse the negative feelings and beliefs of others and internalize these feelings to themselves thus leading to internalized stigma. In a study on internalized stigma, Lee, Kochman, and Sikkema (2002) found that the majority of those having internalized stigma were diagnosed more recently; were receiving less support and acceptance from their families; knew fewer people with HIV; and were less likely to participate in HIV support groups. People experiencing higher levels of internalized stigma worry more about spreading their infection to others and report higher levels of hopelessness, anxiety and other depressive symptoms (Lee, Kochman, Sikkema, 2002). Among PLWH, internalized stigma generates feelings of shame and guilt and the affected individuals see themselves as dirty/unclean and deserving of the negative outcomes enforced upon them (Earnshaw et al., 2013). Anticipated Stigma: HIV stigma also manifests as anticipated stigma, wherein PLWH anticipate negative attitudes, treatment complications, and acts of discrimination because of their very HIV positive status (Earnshaw et al., 2013). Research shows that experiencing this type of stigma is associated with increased physical illness (Quinn \& Chaudoir, 2009) and stress related symptoms (Pascoe \& Richman, 2009). Enacted Stigma: The third category, enacted stigma, includes the actual experiences of stereotyping, discrimination, social exclusion, and other forms of prejudices enforced by 
others on the person experiencing the stigmatic condition (Earnshaw, et al., 2013).

Enacted stigma among PLWH has been associated with poor health outcomes, in terms of both physical and psychological well-being (Earnshaw et al., 2015; Logie \& Gadalla, 2009). Enacted stigma has been associated with worsening HIV progression such as lower CD4 counts, uncontrolled viral load, opportunistic infections and faster progression to AIDS (Earnshaw et al., 2013; Holzemer et al., 2007). Despite advances in treatment and management of HIV/AIDS and ongoing educational campaigns, the misconceptions held by the public regarding the contagion still persist, leading to greater instances of enacted stigma (Ware, Wyatt, \& Tugenberg, 2006).

\section{HIV and Mental Health}

It has long been recognized that PLWH face significant psychosocial challenges often resulting in complex mental health issues (Catalan, Burgess, \& Klimes, 1995). Many researchers have also suggested that PLWH experience greater psychological distress when compared to the general population (Stutterheim et al., 2009). However, psychiatric illnesses among these patients have often being under reported (Gatz, Brownstein, \& Taylor, 2005). Many studies on the health challenges faced by PLWH identify mental health problems as one of the most common comorbidities associated with HIV (Edmiston, Passmore, Smith, \& Petoumenos, 2015; Kendall et al., 2014). After comparing clinico-psychological reports of PLWH over a period of 24 years, Adams and colleagues (2016) reported that though acute mental health syndromes and organic brain disorders have declined, depression and anxiety disorders (often chronic) have increased over the years. Additionally, new mental health problems related to recreational drug use and co-infections (e.g. HIV and Hepatitis C) are increasing among PLWH, justifying the 
continued need for increased mental health services for this population (Adams et al., 2016). Ironically, mental health research and treatment facilities for HIV positive patients are lacking, especially in resource limited settings such as Haiti (Dow et al., 2016; Klasen \& Crombag, 2012; Castro \& Farmer, 2005). The majority of PLWH are already vulnerable to mental health problems. PLWH living in resource limited settings have additionally elevated risks for anxiety disorders, PTSD, depression (Betancourt et al., 2014; Seth et al., 2014; Malow et al., 2013) and suicidal ideations (Marzuk et al., 1997) compared to the general population. PLWH in mid- to later-life also face specific challenges such as emotional distress and suicidal thoughts and require targeted and longterm interventions and psychiatric care (Kalichman et al., 2000; Heckman, 2000;

Heckman, 2002).

\section{Stigma and Mental Health among PLWH}

HIV-related stigma represents a significant risk factor for mental health problems among PLWH (Earnshaw \& Chaudoit, 2009). Research has consistently shown that higher levels of stigma are associated with lower levels of mental health in PLWH (Logie \& Gadall, 2009). HIV-based discrimination and prejudice have serious impacts on psychological health (Steward et al., 2011), with stigma experiences being linked to depression, anxiety, and risky sexual behaviors (Vanable et al. 2006; Preston et al., 2007). Some researchers have conceptualized that the psychological and emotional challenges such as illness, fear of death, poverty, and social isolation lead to "chronic sorrow" and stigma additionally aggravates these factors in PLWH (Lichtenstein, Laska, \& Clair, 2002). They have also recommended that stigma should be considered as a potential marker for psychiatric problems, specifically chronic depression. 
The effects of HIV-related stigma become additionally detrimental when multiple types of stigmas act in combination - for instance race- or sexual orientation-based stigma combined with fear of contagion stigma. Lelutiu-Weinberger and colleagues (2015) in their study on men who have sex with men (MSM) of color have highlighted the adverse effects of these types of combined stigmas. Their study showed that there are many adverse mental health outcomes associated with each individual type of stigma. The adverse outcomes associated with each specific stigma additively combine together when multiple stigmas are simultaneously acting on these individuals, thereby increasing their risks for mental, emotional, and psychological problems (Lelutiu-Weinberger et al., 2015; Balsam et al., 2011; Stirratt et al., 2008). The negative mental health outcomes of compounded stigmas have been reported in many minority populations. For example, minority PLWH in the U.S. who experienced discrimination due to age (Emlet et al., 2015; Emlet, 2006) or race (Singleton, et al. 2015) when compounded with other specific stigmas showed higher susceptibilities to mental health problems.

\section{Anxiety, Stigma \& Treatment Adherence}

The burden of social and physical coping mechanisms used by the PLWH to manage their diseased states are worsened due to stigma and discrimination experienced by this population (Colbert et al., 2010). Though there are many mental health problems experienced by this population, depression and anxiety predominate (Sunderland et al., 2010). Anxiety disorders among PLWH have been associated with stigma and discrimination and some studies have suggested that HIV-related stigma leads to social isolation, fear, and other negative emotional consequences exacerbating anxiety disorders (Fullilove, 1989). Stigma has been identified as a predisposing factor for many anxiety 
disorders (Katz \& Nevid, 2005). Affective disorders such as generalized anxiety disorder, panic disorder, major depressive disorder, post-traumatic stress disorder, and dysthymia are two to three times more common in PLWH experiencing higher levels of stigma (Safren et al., 2003; Adewuya et al., 2009). Among PLWH, the prevalence of anxiety disorders varies from $20 \%$ to as high as 47\% (Els et al. 1999; Celesia et al., 2013; Vitiello et al., 2003; Olagunju et al., 2012). While anxiety disorders may pre-exist among those diagnosed with HIV, it is generally exacerbated during stressful phases such as HIV diagnosis and coping, implicated largely in fear of death as well as HIV-related stigma. Emotional dysregulation among PLWH also contributes to greater anxiety and distress (Brandt et al., 2013). Moreover, HIV-related anxiety adversely affects general health outcomes in PLWH and has been associated with decreased life satisfaction scores, faster disease progression, and lower treatment adherence (Turner et al., 2003; Tucker et al., 2003; Tsao et al., 2004). Increased anxiety levels have been associated with sub-optimal treatment adherence in many studies (Panigrahi, Swain, \& Mohanty, 2015; Pappin, Wouters, \& Booysen, 2012; Celsia et al., 2010). Van Servellen and colleagues (2002) found that anxiety scores among HIV positive patients were significantly related to both self-reported non-adherence and clinically evaluated non-adherence. In another study, anxiety symptoms were associated with lower treatment adherence and compliance to ART schedules (Schönnesson et al., 2007). Even among PLWH without any diagnosed psychiatric illness, anxiety was found to be the most significant variable associated with sub-optimal treatment adherence (Schönnesson et al., 2007). This evidence strongly suggests that there is an adverse relationship between anxiety and HIV treatment adherence. Though there are many studies on the beneficial effects of reducing anxiety on 
treatment adherence in other populations (Kemppainen et al., 2006), similar studies are lacking in Haitian PLWH. There is still a considerable gap in the literature regarding the effects of discrimination and anxiety disorders on HIV treatment adherence in marginalized populations such as Haitian PLWH.

\section{Depression and HIV}

Depressive disorders constitute the most common mental illness among PLWH (Choi, 2013) and have significant effects on interpersonal relationships, employment, quality of life, treatment adherence and survival (Kibret \& Salilih, 2016). After being diagnosed with HIV, PLWH often struggle to adapt to the chronic disease condition, and suffer from depression and anxiety as they attempt to make sense of their current situation and come to terms with the social, mental, and physical challenges of the disease (Williams, et al., 2005; Green \& Smith, 2004). A meta-analysis done by Ciesla \& Roberts (2001) showed that the prevalence of major depressive disorders was nearly double among PLWH when compared to HIV-negative counterparts. Irrespective of these findings, studies continue to suggest that depression is under-diagnosed and underreported among PLWH (Rodkjaer, Laursen, Balle, \& Sodemann, 2010). Depression has also been associated with impaired immunological responses and higher mortality rates (Sumari-de Boer, Sprangers, Prins \& Nieuwkerk, 2012; Ironson et al., 2005). There is a definite need for understanding the prevalence of these disorders in PLWH. Bouhnik and colleagues (2005) suggested that depression on its own adversely affected clinical disease progression in PLWH, independent of the adverse effects of sub-optimal treatment adherence associated with depression. Cook et al. (2004) additionally found that AIDSrelated deaths were more likely among female PLWH with chronic depressive disorders 
after controlling for many other factors. Studies have also reported that there is a direct relationship between severity of clinical depression and clinical disease progression in PLWH which strengthens over time (Lyketsos et al., 1996; Wells et al., 1989).

\section{HIV Treatment Adherence}

Treatment adherence is a complex concept involving many domains: the patient; the disease; the medical care settings including treatment, relationship to caregivers, and the wider healthcare system; and the socio-cultural context (Ammassari et al., 2002). Due to its broad domains, it is very challenging to identify and target all the potential determinants of treatment adherence. Yet, it is crucial because many studies have recommended moderate to high levels of adherence to ART to achieve adequate control over the disease (Kobin \& Sheth, 2011; Parienti et al., 2008; Shuter et al., 2007). HIV treatment typically involves a complex regimen of several pills consumed multiple times in a day. Some of the factors influencing HIV treatment adherence include: memory; adverse effects of medications; regimen complexity; domestic responsibilities; availability and access to medications; existing comorbidities; psychiatric problems such as depression and anxiety; and subjective knowledge and awareness about the disease (Gifford et al., 2000). Because of several factors involved, it would be beneficial to consider treatment adherence from a biosocial perspective. In biosocial approaches, analyses and interpretations are based on broader considerations of both the clinical and social factors affecting adherence and the dynamic interactions of these processes over time (Singer, 2003). Gaining insight into the particular socio-cultural contexts in which HIV treatment is occurring, and acknowledging the dynamic nature of such contexts would be useful in developing a more grounded understanding of the multiple and 
evolving factors associated with adherence and non-adherence behaviors (Spire et al., 2002; Ickovics \& Meade, 2002). Treatment non-adherence among PLWH is thus a complicated and evolving issue of great importance. Non-adherence in HIV patients can lead to uncontrolled viral loads which in turn could increase the risk for sexual transmission as well as drug resistant viral strains (Lucas, 2005). Many studies have shown that effective and consistent adherence to ART decreases the risk of sexual transmission among sexual partners (Cohen et al., 2011).

\section{HIV Treatment Adherence and Mental Health}

As previously discussed, depression, anxiety and other mental health problems are highly prevalent among PLWH (Kilbourne et al., 2002) and have consistently been implicated for lower treatment adherence (Gonzalez et al., 2011; Turner et al., 2003). Non-adherence to HIV treatment is estimated to be three times greater among those with depression when compared to those without (DiMatteo, Lepper, \& Croghan, 2000). Some of the factors associated with depression that may contribute to non-adherence include: sense of hopelessness; negative expectations; and pessimistic thoughts. Additionally, depressed individuals often have decreased social interactions, which, in the context of treatment adherence, may limit their access to some of the contacts necessary for maintaining compliance (both emotional and practical; Starace et al., 2002). In a longitudinal study, it was found that participants who reported depression during the baseline visit showed a two-fold decrease in treatment adherence during the follow-up after adjusting for covariates, thus underscoring the dynamic rather than static relationship between depression and treatment adherence (Kacanek et al., 2010). Yun and colleagues (2005) showed that HIV patients who adhered to antidepressant medications 
also adhered to ART. However, this could have been due to higher adherence to all medications in general rather that the effects of anti-depressants on ART adherence. Similarly, in a large scale clinical study consisting of 3,359 PLWHs reporting depression, Horberg and associates (2008) found that greater adherence to selective serotonin reuptake inhibitor (SSRI) class of antidepressants was associated with improved HIV treatment adherence in terms of controlled viral load and recuperating CD4 T-cell counts. Many other studies have also reported improved HIV treatment adherence in PLWH receiving psychotherapeutic treatment (cognitive-behavioral therapy) for their depression (Safren et al., 2009; Weber et al., 2004; Kelly et al., 1993). A recent meta-analysis suggested that targeted and effective treatments for depression would not only positively impact adherence, but could also considerably improve quality of life and health outcomes in PLWH (Sin \& DiMatteo, 2014).

\section{HIV Treatment Adherence and Stigma}

Stigma has shown to have pervasive negative effects on multiple aspects of HIVrelated care such as willingness and decision to be tested (Chesney \& Smith, 1999), HIV status disclosure (Smith, Rossetto, \& Peterson, 2008; Steward et al., 2008), and seeking social and psychological support (Logie \& Gadalla, 2009; Mak et al., 2007). As outlined earlier, internalized stigma is often associated with maladaptive responses to social, mental and physical factors related to treatment adherence. In a review that examined both qualitative and quantitative variables related to stigma and HIV treatment adherence, it was found that HIV-related stigma adversely affected treatment adherence through many general and group-specific psychological processes. This review also reported that adaptive coping and social supports were crucial in determining the success achieved by 
participants in overcoming structural and economic barriers towards effective treatment adherence (Katz et al., 2013). In a cross sectional study of PLWH in Hong Kong, researchers also found that higher rates of self-perceived stigma were reported by those who intentionally did not adhere to treatment regimen when compared to those who adhered to treatment or those who unintentionally failed to adhere (Mo \& Mak, 2009). Experiences of stigma and discrimination have also been associated with increased odds of non-adherence in many other studies (Boyer et al., 2011; Li et al., 2010). In summary, the stress, social isolation, and diminished view of self, emanating from stigma lead to maladaptive repercussions against treatment regimens and achievable compliance (Adeyemi, Olubunmi, \& Oluseyi, 2011). In contrast to these findings, a number of studies have also reported that there is no significant association between stigma and HIV treatment adherence (Martinez et al., 2012; Kalichman et al., 2008).

\section{Alcohol Use and HIV Treatment Adherence}

In addition to stigma and mental health problems, alcohol and drug use have been identified as important factors affecting HIV treatment adherence (Lucas, 2011). Alcohol use constitutes the most consistent and widespread barrier to HIV treatment adherence (Gonzalez, Barinas, \& O’Cleirigh, 2011; Azar et al., 2010). Alcohol use is not only a significant cause of sub-optimal treatment adherence but also associated with worsening disease progression and compromised general well-being (Cook et al., 2001). It has been estimated that a quarter to half of all PLWH report moderate to higher levels of alcohol consumption, and many of them cross into the 'problem drinking' category defined as alcohol consumption "sufficiently large enough to lead to problems of health and social functioning, but do not necessarily meet Diagnostic and Statistical Manual of Mental 
Disorders, Fourth Edition criteria for alcohol abuse or dependence" (Cooke et al., 2001 p. 83). One study also reported that alcohol use was twice as common in those PLWH who reported cocaine or heroin use or reported lower educational status (Galvan et al., 2002).

Several studies have reported that alcohol use alone or in combination with drug use have significantly decreased treatment adherence (Chander, Lau, \& Moore, 2006; Cook et al., 2001). In a study of PLWH with history of alcohol use problems, semiannual assessments over a period of 30 months revealed that alcohol consumption constituted the most significant predictor of treatment non-adherence (Samet et al., 2004). This study also showed that adherence rates were significantly lower in those who continued to use alcohol when compared to recent abstainers (Samet et al., 2004). Alcohol consumption during ART resulted in medication lapses, missed doses, and ultimately, treatment failures in many studies (Hendershot et al., 2009; Braithwaite et al.,2007). Additionally, alcohol use resulted in memory and cognitive impairments which further affected treatment compliance (Braithwaite et al., 2005). Excessive alcohol consumption also affected treatment adherence by delaying follow-up visits, prescription renewals and medication pick-ups (Kalichman et al., 2007; Sankar et al., 2007).

\section{Coping and Resilience}

Being seropositive is an inherently stressful situation with far reaching mental and psychosocial consequences (Kelly et al., 1998). As medical advances continue to prolong the lives of PLWH, there is a greater need for understanding the adaptation and coping mechanisms employed by these patients. When faced with situations of acute/ongoing stress or the challenges of stigma and discrimination, individuals engage in coping processes that include behavioral as well as psychological adaptations aimed at 
overcoming the stressors or challenges (Taylor \& Stanton, 2007). The coping processes involve efforts to tolerate or overcome the stressful and painful effects of particular events (Folkman \& Lazarus, 1980). In the context of HIV infection, effective coping is said to require "conscious, purposeful behavior" which "determines the individual's ability to live successfully with the continuous and chronic assault of HIV" (Fife et al., 2008, p. 77). Studies have identified two general forms of coping: active (or approach coping) and passive (or avoidance coping; Moosa, Jeenah, \& Vorster, 2005; Smith et al., 2001). Active coping involves directly engaging with situations via problem-solving, information seeking, and cognitive restructuring processes, whereas passive coping involves denial and avoidance (Kotzé, et al., 2013).

While either one or both of these coping mechanisms may be employed randomly or in tandem, studies show that subjects employing active approaches have greater success rates in adapting to stressors and hence report fewer negative effects compared to those relying solely on passive avoidance strategies (Kim et al., 2010). Yeji and colleagues (2014), for example, found that one of the elements of avoidance coping strategies includes withdrawal from social contacts, which, in their study, increased the likelihood of depression. Other studies have similarly concluded that passive coping based on denial and avoidance is linked to higher rates of depression and even impaired treatment adherence (Lesserman et al., 1997). Passive coping has also been associated with increased sexual risk behaviors which could lead to increased transmission of the virus (Kelly et al., 1993). In contrast, a number of studies exploring coping mechanisms have found that active coping strategies improve quality of life (Vyavaharkar, Moneyham, Murdaugh, \& Tavakoli, 2011), nurture higher self-esteem (Trevino et al., 
2010; Stein \& Rotheram-Borus, 2004) and develop more positive affect (Deichert et al., 2008). Additionally, studies have also shown that active coping strategies have the potential to decrease psychological distress (Kraaij et al., 2008) and are associated with lower levels of substance use (Pence et al., 2008) and greater treatment adherence (Vervoort et al., 2009). Active coping is considered an adaptive or resilient strategy because it involves positive means of adaptation and enables beneficial recovery and resilience to significant stressors (Sinclair \& Wallston, 2004). Because of these beneficial effects, many studies have recommended increasing our collective knowledge about active coping strategies among PLWH and understanding the factors and resources influencing these strategies (Earnshaw et al., 2013b).

Resilience refers to the capacity of positive adaptation and effective coping when faced with stressors and adversities (Connor \& Davidson, 2003). The characteristics associated with resilience may be both individual (e.g. self-esteem, personality traits, coping style, spirituality, etc.) and social (e.g. supportive peer networks, relationship and support from family, friends etc.; Zhang et al., 2015). Among PLWH, stigma constitutes an important cause of stress, anxiety, panic and depression and PLWH are exposed and forced to cope with it. The notion of "resilience resources" was constructed to identify the modifiable and strength-based moderators that have effects on the coping mechanisms adopted by PLWH (Earnshaw et al., 2013b). Among these resources, social support and identity centrality constitute the two most crucial elements (Earnshaw, et al., 2015; Pascoe \& Smart Richman, 2009). 


\section{Social Support}

There is considerable literature about the fundamental role played by social support in improving mental and physical outcomes in PLWH (Degroote, Vogelaers, \& Vandijck, 2014). Social support (Wallston, Alagna, DeVellis, \& DeVellis, 1983) has been categorized into two broad domains: emotional/informational support (which includes the expression and exchange of positive feelings and emotions, particularly empathy, love, and trust) and instrumental/tangible support (which represents the more tangible forms, such as physical assistance or material goods and services; Earnshaw et al., 2015; Cho, Zunin, Chao, Heiby, \& McKoy, 2012; Taylor, 2011; Heaney \& Israel, 2008). Both of these social support components, emotional/informational support and instrumental/tangible social support, are identified as key resilience resources that moderate the relationship between stigma and stress (Earnshaw et al., 2015). Social support has been shown to reduce depression in PLWH (Asante, 2012; Vyavaharkar et al., 2011) and associated with lower levels of mental health problems (Lam, Naar-King, \& Wright, 2007; McDowell \& Serovich, 2007). The emotional/informational support received from family and friends contribute to the development of adaptive coping and improved treatment adherence among PLWH (McDowell \& Serovich, 2007; Ware, Wyatt, \& Tugenberg, 2006). Instrumental/tangible social support is particularly effective in coping with depression, improving treatment adherence, and retention in treatment facilities (Yeji et al., 2014). PLWH with greater access to instrumental/tangible social support experience less stigma-related stress which may ultimately protect them from adverse HIV symptoms (Earnshaw, 2015). In fact, Heywood and Lyons (2016) contend that any kind of support from any of the sources have significant beneficial effects on 
PLWH. Despite evidence of the beneficial effects of social support, some studies contend that factors beyond social support affect the relationship between HIV stigma and mental health (Breet, Kagee, \& Seedat, 2014). Supporting these contentions, some studies have also reported that there is no relationship between social support, stigma, stress and health outcomes (Logie et al., 2012; Pascoe \& Smart Richman, 2009).

\section{Identity Centrality}

Identity theorists have suggested that selfhood is defined by multiple, shifting identities which function as internalized positional markers that reflect our participation in any structured role relationship (Stryker \& Serpe, 1982). The various roles that we play over the course of our lives have significant impacts on our identities and amalgamate together to develop the self (Serpe, 1987). The salience of any given identity depends on the numbers, types, and strength of the social relationships associated with that identity, in the sense that the more a specific identity is invoked and enacted, the higher its salience (Serpe, 1987). Salience is closely related to another construct, "centrality", which refers to the extent to which a particular identity defines an individual's sense of self and who they are as a person (Quinn \& Earnshaw, 2011). For example, being diagnosed and living with HIV imposes an identity centrality that the affected person belongs to the HIV infected community. Some studies have postulated that the relative salience or centrality of HIV status, as a defining aspect of self, may have important implications for mental health and the coping strategies that individuals adopt as they deal with various forms of stigma (i.e. enacted, anticipated, internalized; Earnshaw, 2015; Baumgartner \& Niemi, 2013). Significant research has been conducted on the processes and events that shape the formation of identity centrality for any specific individual 
characteristic or trait. Among them, the identity centralities associated with gender and race constitute visible identities and can be molded to improve outcome variables such as treatment adherence, coping mechanisms, and resilience (Jamil, Harper, \& Fernandez, 2009; Phinney \& Chavira, 1992). Gender and race identities are associated with biological and developmental processes and constitutes stronger identities with beneficial roles. Many studies have also shown that harnessing such visible central identities improved mental health outcomes in PLWH (Mossakowski, 2003; Earnshaw, 2015). However, belonging to the HIV community does not generate a visible central identity as observed in gender and race, but instead produces a concealable stigmatized identity (CSI) (Quinn et al., 2014). Some studies have demonstrated that CSI is associated with higher levels of distress and discomfort (Quinn \& Chaudoir, 2009). The effects of HIV identity as a CSI are questionable due to extremely sparse research on this topic. Irrespectively, Harper and colleagues (2013) have proposed that a salient or centralized HIV identity may be associated with detrimental effects such as poor treatment adherence. They propose that when PLWH strongly identify with their HIV status, they become overwhelmed and experience a range of negative emotions that adversely affect treatment adherence (Harper et al., 2013). Due to the lack of rigorous and conclusive studies on identity centrality in HIV, conclusions regarding its effects on PLWH are questionable. Nevertheless, it is an important factor because development of an HIV identity impacts the salience of other identities and has far reaching implications on the overall process of making sense of the challenging experience and developing adaptive coping strategies (Baumgartner \& Niemi, 2013). 


\section{Summary}

The subsections of this review (HIV stigma, treatment adherence, social support, coping, depression and anxiety) represent a broad range of significant issues in the current field of HIV research. While there is substantial evidence to the hypotheses explored in this dissertation, contradictions exist in a number of key areas. In regards to the association between HIV and depressive disorders, for example, a majority of the studies demonstrated a clear relationship, and yet some studies report that HIV status was not associated with depression (Kelly et al., 1998; Rabkin, et al., 1997). Similarly, in regards to stigma and mental health, some studies have challenged the mediating role of social support in the relationship between HIV-related stigma and mental health (Breet, Kagee, \& Seedat, 2014). The relationship between internalized HIV stigma and medication adherence ranges from inversely strong (Rao et al., 2012; Sayles et al., 2007) to weak or no associations (Kalichman et al., 2008). The diversity in the strength of association between different outcome variables observed in different studies as well as the approaches, methodologies, and sampling contexts used across the literature suggest the need for further investigations. These investigations should be directed towards the intersections and interactions of multiple, simultaneously active components of HIV stigma, treatment adherence, social support, coping, depression and anxiety and their collective role in HIV care and well-being. 


\section{References}

Adams, C., Zacharia, S., Masters, L., Coffey, C., \& Catalan, P. (2016). Mental health problems in people living with HIV: changes in the last two decades: The London experience 1990-2014. AIDS Care, 28(sup1), 56-59.

Adewuya, A. O., Afolabi, M. O., Ola, B. A., Ogundele, O. A., Ajibare, A. O., Oladipo, B. F., \& Fakande, I. (2009). Post-traumatic stress disorder (PTSD) after stigma related events in HIV infected individuals in Nigeria. Social Psychiatry and Psychiatric Epidemiology, 44(9), 761-766.

Adeyemi, A., Olubunmi, F., \& Oluseyi, A. (2011). 206 Predictors of Adherence for Patients on Highly Active Antiretroviral Therapy in HIV Treatment Program. JAIDS Journal of Acquired Immune Deficiency Syndromes, 56, 88.

Aggleton, P., \& Parker, R. (2002). World AIDS Campaign 2002-3. A Conceptual Framework and Basis for Action. HIV/AIDS Stigma and Discrimination. UNAIDS, Geneva, Switzerland.

Asante, K. O. (2012). Social support and the psychological wellbeing of people living with HIV/AIDS in Ghana. African Journal of Psychiatry, 15(5), 340-345.

Azar, M. M., Springer, S. A., Meyer, J. P., \& Altice, F. L. (2010). A systematic review of the impact of alcohol use disorders on HIV treatment outcomes, adherence to antiretroviral therapy and health care utilization. Drug and Alcohol Dependence, 112(3), 178-193.

Balsam, K. F., Molina, Y., Beadnell, B., Simoni, J., \& Walters, K. (2011). Measuring multiple minority stress: the LGBT People of Color Microaggressions Scale. Cultural Diversity and Ethnic Minority Psychology, 17(2), 163-174.

Baumgartner, L. M., \& Niemi, E. (2013). The perceived effect of HIV/AIDS on other identities. The Qualitative Report, 18(8), 1-23.

Betancourt, T., Scorza, P., Kanyanganzi, F., Fawzi, M. C. S., Sezibera, V., Cyamatare, F., ... Kayiteshonga, Y. (2014). HIV and child mental health: a case-control study in Rwanda. Pediatrics, 134(2), e464-e472.

Bogart, L. M., Cowgill, B. O., Kennedy, D., Ryan, G., Murphy, D. A., Elijah, J., \& Schuster, M. A. (2008). HIV-related stigma among people with HIV and their families: a qualitative analysis. AIDS and Behavior, 12(2), 244-254. 
Bouhnik, A. D., Préau, M., Vincent, E., Carrieri, M. P., Gallais, H., Lepeu, G., ... Spire, B. (2005). Depression and clinical progression in HIV-infected drug users treated with highly active antiretroviral therapy. Antiviral Therapy, 10(1), 53-61.

Boyer, S., Clerc, I., Bonono, C. R., Marcellin, F., Bilé, P. C., \& Ventelou, B. (2011). Non-adherence to antiretroviral treatment and unplanned treatment interruption among people living with HIV/AIDS in Cameroon: Individual and healthcare supply-related factors. Social Science \& Medicine, 72(8), 1383-1392.

Braithwaite, R. S., McGinnis, K. A., Conigliaro, J., Maisto, S. A., Crystal, S., Day, N., ... Justice, A. C. (2005). A Temporal and Dose-Response Association Between Alcohol Consumption and Medication Adherence Among Veterans in Care. Alcoholism: Clinical and Experimental Research, 29(7), 1190-1197.

Braithwaite, R. S., Kozal, M. J., Chang, C. C. H., Roberts, M. S., Fultz, S. L., Goetz, M. B., ... \& Justice, A. C. (2007). Adherence, virological and immunological outcomes for HIV-infected veterans starting combination antiretroviral therapies. AIDS (London, England), 21(12), 1579-1589.

Brandt, C. P., Gonzalez, A., Grover, K. W., \& Zvolensky, M. J. (2013). The relation between emotional dysregulation and anxiety and depressive symptoms, painrelated anxiety, and HIV-symptom distress among adults with HIV/AIDS. Journal of Psychopathology and Behavioral Assessment, 35(2), 197-204.

Breet, E., Kagee, A., \& Seedat, S. (2014). HIV-related stigma and symptoms of posttraumatic stress disorder and depression in HIV-infected individuals: does social support play a mediating or moderating role? AIDS Care, 26(8), 947-951.

Castro, A., \& Farmer, P. (2005). Understanding and addressing AIDS-related stigma: from anthropological theory to clinical practice in Haiti. American Journal of Public Health, 95(1), 53-59.

Catalan, J., Burgess, A., \& Klimes, I. (1995). Psychological medicine of HIV infection. Oxford: Oxford University Press.

Celesia, B. M., Nigro, L., Pinzone, M. R., Coco, C., La Rosa, R., Bisicchia, F., ... Palermo, F. (2013). High prevalence of undiagnosed anxiety symptoms among HIV-positive individuals on cART: a cross-sectional study. European Review of Medical Pharmacological Science, 17(15), 2040-2046.

Celesia, B. M., Coco, C. A., Bisicchia, F., Pellicanò, G., Nunnari, G., Mughini, M. T., ... \& Russo, R. (2010). Anxiety disorders and adherence to HAART. In XVIII International AIDS Conference. [Abstract TUPE0192]. 
Chander, G., Lau, B., \& Moore, R. D. (2006). Hazardous alcohol use: a risk factor for non-adherence and lack of suppression in HIV infection. Journal of Acquired Immune Deficiency Syndromes, 43(4), 411-417.

Chesney, M. A., \& Smith, A. W. (1999). Critical delays in HIV testing and care the potential role of stigma. American Behavioral Scientist, 42(7), 1162-1174.

Choi, J. Y. (2013). Mental health of HIV-infected patients: a severe, but overlooked problem. Infection \& Chemotherapy, 45(2), 239-240.

Ciesla, J. A., \& Roberts, J. E. (2001). Meta-analysis of the relationship between HIV infection and risk for depressive disorders. American Journal of Psychiatry, $158(5), 725-730$.

Cohen, M. S., Chen, Y. Q., McCauley, M., Gamble, T., Hosseinipour, M. C., Kumarasamy, N., ... \& Godbole, S. V. (2011). Prevention of HIV-1 infection with early antiretroviral therapy. New England Journal of Medicine, 365(6), 493-505.

Colbert, A. M., Kim, K. H., Sereika, S. M., \& Erlen, J. A. (2010). An examination of the relationships among gender, health status, social support, and HIV-related stigma. Journal of the Association of Nurses in AIDS Care, 21(4), 302-313.

Cook, J. A., Grey, D., Burke, J., Cohen, M. H., Gurtman, A. C., Richardson, J. L., ... Hessol, N. A. (2004). Depressive symptoms and AIDS-related mortality among a multisite cohort of HIV-positive women. American Journal of Public Health, 94(7), 1133-1140.

Cook, R. L., Sereika, S. M., Hunt, S. C., Woodward, W. C., Erlen, J. A., \& Conigliaro, J. (2001). Problem drinking and medication adherence among persons with HIV infection. Journal of General Internal Medicine, 16(2), 83-88.

Crawford, A. M. (1996). Stigma Associated with AIDS: A Meta-Analysis1. Journal of Applied Social Psychology, 26(5), 398-416.

Degroote, S., Vogelaers, D., \& Vandijck, D. M. (2014). What determines health-related quality of life among people living with HIV: an updated review of the literature. Archives of Public Health, 72(1), 1-10.

Deichert, N. T., Fekete, E. M., Boarts, J. M., Druley, J. A., \& Delahanty, D. L. (2008). Emotional support and affect: Associations with health behaviors and active coping efforts in men living with HIV. AIDS and Behavior, 12(1), 139-145. 
DiMatteo, M. R., Lepper, H. S., \& Croghan, T. W. (2000). Depression is a risk factor for noncompliance with medical treatment: meta-analysis of the effects of anxiety and depression on patient adherence. Archives of Internal Medicine, 160(14), 2101-2107.

Dow, D. E., Turner, E. L., Shayo, A. M., Mmbaga, B., Cunningham, C. K., \& O'Donnell, K. (2016). Evaluating mental health difficulties and associated outcomes among HIV-positive adolescents in Tanzania. AIDS Care, 3, 1-9.

Earnshaw, V. A., Lang, S. M., Lippitt, M., Jin, H., \& Chaudoir, S. R. (2015). HIV stigma and physical health symptoms: do social support, adaptive coping, and/or identity centrality act as resilience resources? AIDS and Behavior, 19(1), 41-49.

Earnshaw, V. A., Smith, L. R., Chaudoir, S. R., Amico, K. R., \& Copenhaver, M. M. (2013). HIV stigma mechanisms and well-being among PLWH: a test of the HIV stigma framework. AIDS and Behavior, 17(5), 1785-1795.

Earnshaw, V. A., Bogart, L. M., Dovidio, J. F., \& Williams, D. R. (2013b). Stigma and racial/ethnic HIV disparities: Moving toward resilience. American Psychologist, 68(4), 225-236.

Earnshaw, V. A., \& Chaudoir, S. R. (2009). From conceptualizing to measuring HIV stigma: a review of HIV stigma mechanism measures. AIDS and Behavior, 13(6), 1160-1177.

Edmiston, N., Passmore, E., Smith, D. J., \& Petoumenos, K. (2015). Multimorbidity among people with HIV in regional New South Wales, Australia. Sexual Health, $12(5), 425-432$.

Els, C., Boshoff, W., Scott, C., Strydom, W., Joubert, G., \& Van Der Ryst, E. (1999). Psychiatric co-morbidity in South African HIV/AIDS patients. South African Journal of Medicine, 89(9), 992-995.

Emlet, C. A., Brennan, D. J., Brennenstuhl, S., Rueda, S., Hart, T. A., \& Rourke, S. B. (2015). The impact of HIV-related stigma on older and younger adults living with HIV disease: does age matter? AIDS Care, 27(4), 520-528.

Emlet, C. A. (2006). "You're awfully old to have this disease": Experiences of stigma and ageism in adults 50 years and older living with HIV/AIDS. The Gerontologist, 46(6), 781-790. 
Farber, E. W., Schwartz, J. A., Schaper, P. E., Moonen, D. J., \& McDaniel, J. S. (2000). Resilience factors associated with adaptation to HIV disease. Psychosomatics, 41(2), 140-146.

Fife, B. L., Scott, L. L., Fineberg, N. S., \& Zwickl, B. E. (2008). Promoting adaptive coping by persons with HIV disease: evaluation of a patient/partner intervention model. Journal of the Association of Nurses in AIDS Care, 19(1), 75-84.

Folkman, S., \& Lazarus, R. S. (1980). An analysis of coping in a middle-aged community sample. Journal of Health and Social Behavior, 21(3), 219-239.

Fullilove, M. T. (1989). Anxiety and stigmatizing aspects of HIV infection. Journal of Clinical Psychiatry, 50(11, Suppl), 5-8.

Galvan, F. H., Bing, E. G., Fleishman, J. A., London, A. S., Caetano, R., Burnam, M. A., ... \& Shapiro, M. (2002). The prevalence of alcohol consumption and heavy drinking among people with HIV in the United States: results from the HIV Cost and Services Utilization Study. Journal of Studies on Alcohol, 63(2), 179-186.

Gatz, M., Brounstein, P., \& Taylor, J. (2005). Serving the needs of women with cooccurring disorders and a history of trauma: Special issue introduction. Journal of Community Psychology, 33(4), 373-378.

Gifford, A. L., Bormann, J. E., Shively, M. J., Wright, B. C., Richman, D. D., \& Bozzette, S. A. (2000). Predictors of self-reported adherence and plasma HIV concentrations in patients on multidrug antiretroviral regimens. JAIDS Journal of Acquired Immune Deficiency Syndromes, 23(5), 386-395.

Goffman, E. (1963). Stigma: Notes on the Management of Spoiled Identity. Englewood Cliffs, NJ: Prentice Hall.

Gonzalez, A., Barinas, J., \& O’Cleirigh, C. (2011). Substance use: impact on adherence and HIV medical treatment. Current HIV/AIDS Reports, 8(4), 223-234.

Gonzalez, J. S., Batchelder, A. W., Psaros, C., \& Safren, S. A. (2011). Depression and HIV/AIDS treatment nonadherence: a review and meta-analysis. Journal of Acquired Immune Deficiency Syndromes (1999), 58(2), 181-187.

Green, G., \& Smith, R. (2004). The psychosocial and health care needs of HIV-positive people in the United Kingdom: a review. HIV Medicine, 5(s1), 4-46. 
Harper, G. W., Fernandez, I. M., Bruce, D., Hosek, S. G., \& Jacobs, R. J. (2013). The role of multiple identities in adherence to medical appointments among gay/bisexual male adolescents living with HIV. AIDS and Behavior, 17(1), 213223.

Heaney, C. A., \& Israel, B. A. (2008). Social networks and social support. In K. Glanz, B. K. Rimer, \& K. Viswanath (Eds.), Health behavior and health education: Theory, research, and practice (pp. 24-36). San Francisco, CA: Jossey-Bass.

Heckman, T. G., Heckman, B. D., Kochman, A., Sikkema, K. J., Suhr, J., \& Goodkin, K. (2002). Psychological symptoms among persons 50 years of age and older living with HIV disease. Aging \& Mental Health, 6(2), 121-128.

Heckman, T. G., Kochman, A., Sikkema, K. J., Kalichman, S. C., Masten, J., \& Goodkin, K. (2000). Late middle-aged and older men living with HIV/AIDS: race differences in coping, social support, and psychological distress. Journal of the National Medical Association, 92(9), 436-444.

Hendershot, C. S., Stoner, S. A., Pantalone, D. W., \& Simoni, J. M. (2009). Alcohol use and antiretroviral adherence: review and meta-analysis. Journal of Acquired Immune Deficiency Syndromes, 52(2), 180-202.

Herek, G. M. (1990). Illness, stigma, and AIDS. In P. T. Costa, Jr., \& G. R. VandenBos (Eds.), Psychological aspects of serious illness: Chronic conditions, fatal diseases, and clinical care (pp. 107-150). Washington, DC: American Psychological Association.

Herek, G. M., \& Capitanio, J. P. (1993). Public reactions to AIDS in the United States: a second decade of stigma. American Journal of Public Health, 83(4), 574-577.

Heywood, W., \& Lyons, A. (2016). HIV and Elevated Mental Health Problems: Diagnostic, Treatment, and Risk Patterns for Symptoms of Depression, Anxiety, and Stress in a National Community-Based Cohort of Gay Men Living with HIV. AIDS and Behavior, (online). doi: 10.1007/s10461-016-1324-y.

Holzemer, W. L., Uys, L. R., Chirwa, M. L., Greeff, M., Makoae, L. N., Kohi, T. W., ... Wantland, D. (2007). Validation of the HIV/AIDS Stigma Instrument-PLWA (HASI-P). AIDS Care, 19(8), 1002-1012. 
Horberg, Michael Alan, et al. "Effects of depression and selective serotonin reuptake inhibitor use on adherence to highly active antiretroviral therapy and on clinical outcomes in HIV-infected patients." JAIDS Journal of Acquired Immune Deficiency Syndromes, 47(3), (2008): 384-390.

Ickovics, J. R., \& Meade, C. S. (2002). Adherence to antiretroviral therapy among patients with HIV: a critical link between behavioral and biomedical sciences. Journal of Acquired Immune Deficiency Syndromes, 31(Suppl 3), S98-102.

Ironson, G., O’Cleirigh, C., Fletcher, M. A., Laurenceau, J. P., Balbin, E., Klimas, N., ... Solomon, G. (2005). Psychosocial factors predict CD4 and viral load change in men and women with human immunodeficiency virus in the era of highly active antiretroviral treatment. Psychosomatic Medicine, 67(6), 1013-1021.

Kacanek, D., Jacobson, D. L., Spiegelman, D., Wanke, C., Isaac, R., \& Wilson, I. B. (2010). Incident depression symptoms are associated with poorer HAART adherence: A longitudinal analysis from the Nutrition for Healthy Living (NFHL) study. Journal of Acquired Immune Deficiency Syndromes, 53(2), 266-272.

Kalichman, S. C., Amaral, C. M., White, D., Swetsze, C., Pope, H., Kalichman, M. O., ... Eaton, L. (2009). Prevalence and clinical implications of interactive toxicity beliefs regarding mixing alcohol and antiretroviral therapies among people living with HIV/AIDS. AIDS Patient Care and STDs, 23(6), 449-454.

Kalichman, S. C., Pope, H., White, D., Cherry, C., Amaral, C. M., Swetzes, C., ,.. Kalichman, M. O. (2008). The association between health literacy and HIV treatment adherence: further evidence from objectively measured medication adherence. Journal of the International Association of Physicians in AIDS Care, 7(6), 317-323.

Kalichman, S. C., Heckman, T., Kochman, A., Sikkema, K., \& Bergholte, J. (2000). Depression and thoughts of suicide among middle-aged and older persons living with HIV-AIDS. Psychiatric Services, 5(7), 903-907.

Katz, I. T., Ryu, A. E., Onuegbu, A. G., Psaros, C., Weiser, S. D., Bangsberg, D. R., \& Tsai, A. C. (2013). Impact of HIV-related stigma on treatment adherence: systematic review and meta-synthesis. Journal of the International AIDS Society, 16(Suppl 2):18640.

Katz, S. \& Nevid, J.S. (2005). Risk factors associated with posttraumatic stress disorder symptomatology in HIV-infected women. AIDS Patient Care STDS, 19(2), 110120. 
Kelly, J. A., Murphy, D. A., Bahr, G. R., Koob, J. J., Morgan, M. G., Kalichman, S. C., ... St Lawrence, J. S. (1993). Factors associated with severity of depression and high-risk sexual behavior among persons diagnosed with human immunodeficiency virus (HIV) infection. Health Psychology, 12(3), 215-219.

Kelly, B., Raphael, B., Judd, F., Perdices, M., Kernutt, G., Burnett, P., ... \& Burrows, G. (1998). Posttraumatic stress disorder in response to HIV infection. General Hospital Psychiatry, 20(6), 345-352.

Kelly, J.A., Murphy, D.A., Bahr, G.R., Koob, J. J., Brasfield, T. L., ...... Bernstein, B. M. (1993). Outcome of cognitive-behavioral and support group brief therapies for depressed, HIV-infected persons. American Journal of Psychiatry, 150(1), 16791686.

Kemppainen, J. K., Eller, L. S., Bunch, E., Hamilton, M. J., Dole, P., Holzemer, W., ... Nokes, K. M. (2006). Strategies for self-management of HIV-related anxiety. AIDS Care, 18(6), 597-607.

Kendall, C. E., Wong, J., Taljaard, M., Glazier, R. H., Hogg, W., Younger, J., \& Manuel, D. G. (2014). A cross-sectional, population-based study measuring comorbidity among people living with HIV in Ontario. BMC Public Health, 14, 161.

Kibret, G. D., \& Salilih, S. Z. (2016). Prevalence and Associated Factors of Depression among HIV Infected Patients in Debre Markos Town Northwest Ethiopia. International Journal of Emergency Mental Health and Human Resilience, 17(4), 714-716.

Kilbourne, A. M., Justice, A. C., Rollman, B. L., McGinnis, K. A., Rabeneck, L., Weissman, S., ... \& Rodriguez-Barradas, M. (2002). Clinical importance of HIV and depressive symptoms among veterans with HIV infection. Journal of General Internal Medicine, 17(7), 512-520.

Kim, J., Han, J. Y., Shaw, B., McTavish, F., \& Gustafson, D. (2010). The roles of social support and coping strategies in predicting breast cancer patients' emotional wellbeing testing mediation and moderation models. Journal of Health Psychology, 15(4), 543-552.

Klasen, H., \& Crombag, A. C. (2013). What works where? A systematic review of child and adolescent mental health interventions for low and middle income countries. Social Psychiatry and Psychiatric Epidemiology, 48(4), 595-611. 
Kobin, A. B., \& Sheth, N. U. (2011). Levels of adherence required for virologic suppression among newer antiretroviral medications. Annals of Pharmacotherapy, 45(3), 372-379.

Kotzé, M., Visser, M., Makin, J., Sikkema, K., \& Forsyth, B. (2013). Psychosocial variables associated with coping of HIV-positive women diagnosed during pregnancy. AIDS and Behavior, 17(2), 498-507.

Kraaij, V., van der Veek, S. M., Garnefski, N., Schroevers, M., Witlox, R., \& Maes, S. (2008). Coping, goal adjustment, and psychological well-being in HIV-infected men who have sex with men. AIDS patient care and STDs, 22(5), 395-402.

Lam, P. K., Naar-King, S., \& Wright, K. (2007). Social support and disclosure as predictors of mental health in HIV-positive youth. AIDS Patient Care and STDs, 21(1), 20-29.

Lee, R. S., Kochman, A., \& Sikkema, K. J. (2002). Internalized stigma among people living with HIV-AIDS. AIDS and Behavior, 6(4), 309-319.

Lelutiu-Weinberger, C., Gamarel, K. E., Golub, S. A., \& Parsons, J. T. (2015). Racebased differentials in the impact of mental health and stigma on HIV risk among young men who have sex with men. Health Psychology,34(8), 847-856.

Letteney, S., \& Laporte, H. H. (2004). Deconstructing stigma: Perceptions of HIVseropositive mothers and their disclosure to children. Social Work in Health Care, 38(3), 105-123.

Li, L., Lee, S. J., Wen, Y., Lin, C., Wan, D., \& Jiraphongsa, C. (2010). Antiretroviral therapy adherence among patients living with HIV/AIDS in Thailand. Nursing \& Health Sciences, 12(2), 212-220.

Lichtenstein, B., Laska, M. K., \& Clair, J. M. (2002). Chronic sorrow in the HIV-positive patient: Issues of race, -gender, and social support. AIDS patient care and STDs, 16(1), 27-38.

Link, B.G., and Phelan, J.C. (2001). Conceptualizing stigma. Annual Review of Sociology, 27, 363-385.

Logie, C. H., Newman, P. A., Chakrapani, V., \& Shunmugam, M. (2012). Adapting the minority stress model: associations between gender non-conformity stigma, HIVrelated stigma and depression among men who have sex with men in South India. Social Science \& Medicine, 74(8), 1261-1268. 
Logie C. \& Gadalla, T.M. (2009). Meta-analysis of health and demographic correlates of stigma towards people living with HIV. AIDS Care, 21, 742-753.

Lucas, G. M. (2011). Substance abuse, adherence with antiretroviral therapy, and clinical outcomes among HIV-infected individuals. Life Sciences, 88(21), 948-952.

Lucas, G. M. (2005). Antiretroviral adherence, drug resistance, viral fitness and HIV disease progression: a tangled web is woven. Journal of Antimicrobial Chemotherapy, 55(4), 413-416.

Lyketsos, C. G., Hoover, D. R., Guccione, M., Dew, M. A., Wesch, J. E., Bing, E. G., \& Treisman, G. J. (1996). Changes in depressive symptoms as AIDS develops. American Journal of Psychiatry, 153(11), 1430-1437.

McDowell, T. L., \& Serovich, J. M. (2007). The effect of perceived and actual social support on the mental health of HIV-positive persons. AIDS Care, 19(10), 12231229.

Mahajan, A. P., Sayles, J. N., Patel, V. A., Remien, R. H., Ortiz, D., Szekeres, G., \& Coates, T. J. (2008). Stigma in the HIV/AIDS epidemic: a review of the literature and recommendations for the way forward. AIDS (London, England), 22(Suppl 2), S67-79.

Major, B., \& O'Brien, L. T. (2005). The social psychology of stigma. Annu. Rev. Psychol., 56, 393-421.

Mak, W.W., Cheung, R.Y., Law, R.W., Woo, J., Li, P.C., Chung, R.W. (2007). Examining attribution model of self-stigma on social support and psychological well-being among people with HIV+/AIDS. Social Science \& Medicine, 64(8), 1549-1559.

Malow, R., Dévieux, J. G., Stein, J. A., Rosenberg, R., Jean-Gilles, M., Attonito, J., ... Pape, J. W. (2013). Depression, substance abuse and other contextual predictors of adherence to antiretroviral therapy (ART) among Haitians. AIDS and Behavior, $17(4), 1221-1230$.

Martinez, J., Harper, G., Carleton, R. A., Hosek, S., Bojan, K., Clum, G., \& Ellen, and the Adolescent Medicine Trials Network, J. (2012). The impact of stigma on medication adherence among HIV-positive adolescent and young adult females and the moderating effects of coping and satisfaction with health care. AIDS Patient Care and STDs, 26(2), 108-115. 
Marzuk, P.M., Tardiff, K., Leon A, et al. (1997). HIV seroprevalence among suicide victims in New York City, 1991-1993. American Journal of Psychiatry, 154, 1720-1725.

Mo, P.K. \& Mak, W.W. (2009). Intentionality of medication non-adherence among individuals living with HIV/AIDS in Hong Kong. AIDS Care, 21(6), 785-95.

Moosa, M., Jeenah, F., \& Vorster, M. (2005). HIV in South Africa - Depression and CD4 count. South African Journal of Psychiatry, 11(1), 12-15.

Mossakowski, K. N. (2003). Coping with perceived discrimination: does ethnic identity protect mental health? Journal of Health and Social Behavior, 44(3), 318-331.

Noto, T., Vecchiet, J., Monforte, H. D. A., \& Wu, A. W. (2002). Correlates and predictors of adherence to highly active antiretroviral therapy: overview of published literature. JAIDS Journal of Acquired Immune Deficiency Syndromes, 51, 8123-5127.

Olagunju, A. T., Adeyemi, J. D., Ogbolu, R. E., \& Campbell, E. A. (2012). A study on epidemiological profile of anxiety disorders among people living with HIV/AIDS in a Sub-Saharan Africa HIV Clinic. AIDS and Behavior, 16(8), 2192-2197.

Padurariu, M., Ciobica, A., Persson, C., \& Stefanescu, C. (2011). Self-stigma in psychiatry: Ethical and biopsycho-social perspectives. Revista Romana De Bioetica, 9(1), 76-82.

Panigrahi, M., Swain, T. R., \& Mohanty, S. (2015). Nonadherence to anti-HIV medication is associated with higher level of anxiety: Experience from a tertiary care hospital of Odisha. Indian Journal of Pharmacology, 47(6), 672.

Pappin, M., Wouters, E., \& Booysen, F. L. (2012). Anxiety and depression amongst patients enrolled in a public sector antiretroviral treatment programme in South Africa: a cross sectional study. BMC Public Health, 12, 244.

Parienti, J. J., Das-Douglas, M., Massari, V., Guzman, D., Deeks, S. G., Verdon, R., \& Bangsberg, D. R. (2008). Not all missed doses are the same: sustained NNRTI treatment interruptions predict HIV rebound at low-to-moderate adherence levels. PloS One, 3(7), e2783.

Parker, R., \& Aggleton, P. (2003). HIV and AIDS-related stigma and discrimination: a conceptual framework and implications for action. Social Science \& Medicine, 57(1), 13-24. 
Pascoe, E. A., \& Smart Richman, L. (2009). Perceived discrimination and health: a metaanalytic review. Psychological Bulletin, 135(4), 531-554.

Pence, B. W., Thielman, N. M., Whetten, K., Ostermann, J., Kumar, V., \& Mugavero, M. J. (2008). Coping strategies and patterns of alcohol and drug use among HIVinfected patients in the United States Southeast. AIDS patient care and STDs, 22(11), 869-877.

Peters, L., den Boer, D. J., Kok, G., and Schaalma, H. P. (1994). Public reactions towards people with AIDS: An attributional analysis. Patient Education and Counseling, 24(3), 323-335.

Phinney, J. S., \& Chavira, V. (1992). Ethnic identity and self-esteem: An exploratory longitudinal study. Journal of Adolescence, 15(3), 271-281.

Preston, D. B., D'augelli, A. R., Kassab, C. D., \& Starks, M. T. (2007). The relationship of stigma to the sexual risk behavior of rural men who have sex with men. AIDS Education \& Prevention, 19(3), 218-230.

Quinn, D. M., Williams, M. K., Quintana, F., Gaskins, J. L., Overstreet, N. M., Pishori, A., ... \& Chaudoir, S. R. (2014). Examining effects of anticipated stigma, centrality, salience, internalization, and outness on psychological distress for people with concealable stigmatized identities. PloS One, 9(5), e96977.

Quinn, D.M., \& Earnshaw, V.A. (2011). Understanding concealable stigmatized identities: the role of identity in psychological, physical, and behavioral outcomes. Social Issues and Policy Review, 5(1),160-90.

Quinn, D. M., \& Chaudoir, S. R. (2009). Living with a concealable stigmatized identity: the impact of anticipated stigma, centrality, salience, and cultural stigma on psychological distress and health. Journal of Personality and Social Psychology, 97(4), 634.

Rao, D., Feldman, B. J., Fredericksen, R. J., Crane, P. K., Simoni, J. M., Kitahata, M. M., \& Crane, H. M. (2012). A structural equation model of HIV-related stigma, depressive symptoms, and medication adherence. AIDS and Behavior, 16(3), 711716.

Rabkin, J. G., Ferrando, S. J., Jacobsberg, L. B., \& Fishman, B. (1997). Prevalence of axis I disorders in an AIDS cohort: a cross-sectional, controlled study. Comprehensive Psychiatry, 38(3), 146-154. 
Reidpath, D. D., \& Chan, K. Y. (2005). A method for the quantitative analysis of the layering of HIV-related stigma. AIDS Care, 17(4), 425-432.

Rodkjaer, L., Laursen, T., Balle, N., \& Sodemann, M. (2010). Depression in patients with HIV is under-diagnosed: a cross-sectional study in Denmark. HIV Medicine, 11(1), 46-53.

Safren, S., Gershuny, B., \& Hendriksen, E. (2003). Symptoms of posttraumatic stress and death anxiety in persons with HIV and medication adherence difficulties. AIDS Patient Care and STDs, 17(12), 65764.

Safren, S. A., O'Cleirigh, C., Tan, J. Y., Raminani, S. R., Reilly, L. C., Otto, M. W., \& Mayer, K. H. (2009). A randomized controlled trial of cognitive behavioral therapy for adherence and depression (CBT-AD) in HIV-infected individuals. Health Psychology, 28(1), 1-10.

Samet, J. H., Horton, N. J., Meli, S., Freedberg, K. A., \& Palepu, A. (2004). Alcohol consumption and antiretroviral adherence among HIV-infected persons with alcohol problems. Alcoholism: Clinical and Experimental Research, 28(4), 572577.

Sankar, A., Wunderlich, T., Neufeld, S., \& Luborsky, M. (2007). Sero-positive African Americans' beliefs about alcohol and their impact on anti-retroviral adherence. AIDS and Behavior, 11(2), 195-203.

Sayles, J. N., Ryan, G. W., Silver, J. S., Sarkisian, C. A., \& Cunningham, W. E. (2007). Experiences of social stigma and implications for healthcare among a diverse population of HIV positive adults. Journal of Urban Health, 84(6), 814-828.

Scambler, G. (2003). Sociology as applied to medicine. Edinburgh: Saunders.

Schönnesson, L. N., Williams, M. L., Ross, M. W., Bratt, G., \& Keel, B. (2007). Factors associated with suboptimal antiretroviral therapy adherence to dose, schedule, and dietary instructions. AIDS and Behavior, 11(2), 175-183.

Serpe, R. T. (1987). Stability and change in self: A structural symbolic interactionist explanation. Social Psychology Quarterly, 50(1), 44-55.

Seth, P., Kidder, D., Pals, S., Parent, J., Mbatia, R., Chesang, K., ... Bachanas, P. (2014). Psychosocial functioning and depressive symptoms among HIV-positive persons receiving care and treatment in Kenya, Namibia, and Tanzania. Prevention Science, 15(3), 318-328. 
Shuter, J., Sarlo, J.A., Kanmaz, T.J., Rode, R.A., Zingman, B.S. (2007). HIV-infected patients receiving lopinavir/ritonavir-based antiretroviral therapy achieve high rates of virologic suppression despite adherence rates less than 95\%. Journal of Acquired Immune Deficiency Syndrome, 45(1), 4-8.

Sin, N. L., \& DiMatteo, M. R. (2014). Depression treatment enhances adherence to antiretroviral therapy: a meta-analysis. Annals of Behavioral Medicine, 47(3), 259-269.

Sinclair, V. G., \& Wallston, K. A. (2004). The development and psychometric evaluation of the Brief Resilient Coping Scale. Assessment, 11(1), 94-101.

Singleton, J. L., Raunig, M., Brunsteter, H., Desmond, M., \& Rao, D. (2015). Identity, Physical Space, and Stigma Among African American Men Living with HIV in Chicago and Seattle. Journal of Racial and Ethnic Health Disparities, 2(4), 548555 .

Singer, M., \& Clair, S. (2003). Syndemics and public health: Reconceptualizing disease in bio-social context. Medical Anthropology Quarterly, 17(4), 423-441.

Smith, L., Feaster, D. J., Prado, G., Kamin, M., Blaney, N., \& Szapocznik, J. (2001). The psychosocial functioning of HIV+ and HIV- African American recent mothers. AIDS and Behavior, 5(3), 219-231.

Smith, R., Rossetto, K., \& Peterson, B. L. (2008). A meta-analysis of disclosure of one's HIV positive status, stigma and social support. AIDS Care, 20(10), 1266-1275.

Snyder, M., Omoto, A., and Crain, L. (1999). Punished for their good deeds: Stigmatization of AIDS volunteers. American Behavioral Scientist, 42(7), 11751192

Spire, B., Duran, S., Souville, M., Leport, C., Raffi, F., \& Moatti, J. P. (2002). Adherence to highly active antiretroviral therapies (HAART) in HIV-infected patients: from a predictive to a dynamic approach. Social Science \& Medicine, 54(10), 14811496.

Starace, F., Ammassari, A., Trotta, M. P., Murri, R., De Longis, P., Izzo, C., ... \& Antinori, A. (2002). Depression is a risk factor for suboptimal adherence to highly active antiretroviral therapy. Journal of Acquired Immune Deficiency Syndromes, 31(Suppl 3), S136-9.

Stein, J. A., \& Rotheram-Borus, M. J. (2004). Cross-sectional and longitudinal associations in coping strategies and physical health outcomes among HIVpositive youth. Psychology \& Health, 19(3), 321-336. 
Steward W. T., Chandy S., Singh G., Panicker S. T., Osmand T. A., Heylen E., \& Ekstrand M. L. (2011). Depression is not an inevitable outcome of disclosure avoidance: HIV stigma and mental health in a cohort of HIV-infected individuals from southern India. Psychology, Health \& Medicine, 16(1), 74-85.

Steward, W. T., Herek, G. M., Ramakrishna, J., Bharat, S., Chandy, S., Wrubel, J., \& Ekstrand, M. L. (2008). HIV-related stigma: adapting a theoretical framework for use in India. Social Science \& Medicine, 67(8), 1225-1235.

Stirratt, M. J., Meyer, I. H., Ouellette, S. C., \& Gara, M. A. (2008). Measuring identity multiplicity and intersectionality: Hierarchical classes analysis (HICLAS) of sexual, racial, and gender identities. Self and Identity, 7(1), 89-111.

Stryker, S., \& Serpe, R. T. (1982). Commitment, identity salience, and role behavior: Theory and research examples. In W. Ickes \& E. S. Knowles (Eds.), Personality, roles, and social behavior (pp. 199-218). New York: Springer.

Stutterheim, S. E., Pryor, J. B., Bos, A. E., Hoogendijk, R., Muris, P., \& Schaalma, H. P. (2009). HIV-related stigma and psychological distress: the harmful effects of specific stigma manifestations in various social settings. AIDS, 23(17), 23532357.

Sumari-de Boer, I. M., Sprangers, M. A., Prins, J. M., \& Nieuwkerk, P. T. (2012). HIV stigma and depressive symptoms are related to adherence and virological response to antiretroviral treatment among immigrant and indigenous HIV infected patients. AIDS and Behavior, 16(6), 1681-1689.

Sunderland, M., Mewton, L., Slade, T., \& Baillie, A. J. (2010). Investigating differential symptom profiles in major depressive episode with and without generalized anxiety disorder: true co-morbidity or symptom similarity? Psychological Medicine, 40(07), 1113-1123.

Taylor, S. E., \& Stanton, A. L. (2007). Coping resources, coping processes, and mental health. Annual Review of Clinical Psychology, 3, 377-401.

Trevino, K. M., Pargament, K. I., Cotton, S., Leonard, A. C., Hahn, J., Caprini-Faigin, C. A., \& Tsevat, J. (2010). Religious coping and physiological, psychological, social, and spiritual outcomes in patients with HIV/AIDS: Cross-sectional and longitudinal findings. AIDS and Behavior, 14(2), 379-389.

Tsao, J., Dobalian, A., \& Naliboff, B. (2004). Panic disorder and pain in a national sample of persons living with HIV. Pain, 109(1-2), 172-180. 
Tucker, J., Burnam, A., Sherbourne, C., Fuan-Yue, K., \& Gifford, A. (2003). Substance use and mental health correlates of nonadherence to antiretroviral medications in a sample of patients with human immunodeficiency virus infection. American Journal of Medicine, 114(7), 573-580.

Turner, B. J., Laine, C., Cosler, L., \& Hauck, W. W. (2003). Relationship of Gender, Depression, and Health Care Delivery with Antiretroviral Adherence in HIVinfected Drug Users. Journal of General Internal Medicine, 18(4), 248-257.

van Servellen, G., Chang, B., Garcia, L., \& Lombardi, E. (2002). Individual and system level factors associated with treatment non-adherence in human immunodeficiency virusinfected men and women. AIDS Patient Care STDS, 16(6), 269-281.

Vanable, P. A., Carey, M. P., Blair, D. C., \& Littlewood, R. A. (2006). Impact of HIVrelated stigma on health behaviors and psychological adjustment among HIVpositive men and women. AIDS and Behavior, 10(5), 473-482.

Vervoort, S. C., Grypdonck, M. H., De Grauwe, A., Hoepelman, A. I., \& Borleffs, J. C. (2009). Adherence to HAART: processes explaining adherence behavior in acceptors and nonacceptors. AIDS Care, 21(4), 431-438.

Vitiello, B., Burnam, M. A., Bing, E. G., Beckman, R., \& Shapiro, M. F. (2003). Use of psychotropic medications among HIV-infected patients in the United States. American Journal of Psychiatry, 160(3), 547-554.

Vyavaharkar, M., Moneyham, L., Corwin, S., Tavakoli, A., Saunders, R., \& Annang, L. (2011). HIV-disclosure, social support, and depression among HIV-infected African American women living in the rural southeastern United States. AIDS Education and Prevention, 23(1), 78-90.

Wallston, B. S., Alagna, S. W., DeVellis, B. M., \& DeVellis, R. F. (1983). Social support and physical health. Health Psychology, 2(4), 367-391.

Ware, N. C., Wyatt, M. A., \& Tugenberg, T. (2006). Social relationships, stigma and adherence to antiretroviral therapy for HIV/AIDS. AIDS Care, 18(8), 904-910.

Weber, R., Christen, L., Christen, S., Tschopp, S., Znoj, H., Schneider, C., ... Swiss HIV Cohort Study. (2004). Effect of individual cognitive behaviour intervention on adherence to antiretroviral therapy: prospective randomized trial. Antiviral Therapy, 9(1), 85-96.

Wells, K. B., Stewart, A., Hays, R. D., Burnam, M. A., Rogers, W., Daniels, M., ... Ware, J. (1989). The functioning and well-being of depressed patients: results from the Medical Outcomes Study. JAMA, 262(7), 914-919. 
Williams, P., Narciso, L., Browne, G., Roberts, J., Weir, R., \& Gafni, A. (2005). The prevalence, correlates, and costs of depression in people living with HIV/AIDS in Ontario: Implications for service directions. AIDS Educational Preview, 17(2), 119-130.

Yeji, F., Klipstein-Grobusch, K., Newell, M. L., Hirschhorn, L. R., Hosegood, V., \& Bärnighausen, T. (2014). Are social support and HIV coping strategies associated with lower depression in adults on antiretroviral treatment? Evidence from rural KwaZulu-Natal, South Africa. AIDS Care, 26(12), 1482-1489.

Yun, L. W., Maravi, M., Kobayashi, J. S., Barton, P. L., \& Davidson, A. J. (2005). Antidepressant treatment improves adherence to antiretroviral therapy among depressed HIV-infected patients. JAIDS Journal of Acquired Immune Deficiency Syndromes, 38(4), 432-438.

Zhang, L., Li, X., Qiao, S., Zhou, Y., Shen, Z., Tang, Z., ... Stanton, B. (2015). The mediating role of individual resilience resources in stigma-health relationship among people living with HIV in Guangxi, China. AIDS Care, 27(10), 13171325. 


\section{CHAPTER III: Relationship between HIV-Related Stigma and Treatment Adherence and the Mediating Effects of Coping Strategies in Alcohol Using PLWH in Haiti}

\section{Introduction}

Advancements in HIV-related treatment and care have significantly improved and extended the lives of people living with HIV (PLWH) (Bor, Herbst, Newell, \& Bärnighausen, 2013). Despite these medical advances, progress in the social sphere has been very limited. Stigma, the social phenomenon involving labeling, stereotyping, and discrimination has been identified as one of the primary barriers to the provision of adequate care and support for PLWH (Morris et al., 2014)

The social stigma associated with HIV continues to exact devastating consequences on its victims (Tsai, 2013). Research shows that HIV-related stigma is far more intense when compared to the stigmas associated with other illnesses such as herpes, cancer, tuberculosis etc. (Earnshaw \& Kalichman, 2013). HIV-related stigma has significant effects not only on the diagnosed individuals, but also their family members, their health workers and volunteers (Ha, Chuc, Hien, Larsson, \& Pharris, 2013; Bogart et al., 2008). HIV-related stigma has been associated with broader social inequalities, becoming further entrenched by the compounded layering of existing stigmas related to drug use, and homosexuality (Reidpath \& Chan, 2005; Takács, Kelly, P Tóth, Mocsonaki \& Amirkhanian, 2013; Rudolph et al., 2012; Onyebuchi-Iwudibia \& Brown, 2014). HIVrelated stigma experiences are consistently associated with poor mental and physical health outcomes - including anxiety and depression, increased risky sexual behaviors, lower self-esteem, lower CD4 counts and higher levels of viral load (Bunn, Solomon, 
Miller, \& Forehand, 2007; Storholm et al., 2013; Earnshaw, Smith, Chaudoir, Amico, \& Copenhaver, 2013; Holzemer et al., 2007; Preston, D'Augelli, Kassab, \& Starks, 2007). Though many distinct forms of HIV-related stigma have been identified, perceived stigma has been associated with significant adverse effects in PLWH (Earnshaw \& Chaudoir, 2009). Those experiencing higher levels of perceived stigma are at increased risk of transmitting their infection to others, and display elevated levels of depression, anxiety, and helplessness (Lee, Kochman, Sikkema, 2002; Earnshaw, Bogart, Dovidio \& Williams, 2013).

Given the well documented negative effects of stigma experiences among PLWH, coping mechanisms have become a focus of substantial research. Coping has been defined as ongoing behavioral and cognitive efforts to manage and overcome taxing demands connected to stressful, painful, and difficult situations (Chida \& Vedhara, 2007). Coping has been conceptualized as a crucial process mediating the antecedent and subsequent outcomes of psychological stress. While multiple categories of coping strategies have been identified, the two most common groupings are adaptive coping (directly engaging with situations via problem-solving, information seeking, cognitive restructuring, etc.) and maladaptive coping (engaging in denial and avoidance; Kotzé, Visser, Makin, Sikkema \& Forsyth, 2013). Studies consistently show that adaptive coping strategies result in more positive outcomes, including higher quality of life, selfesteem, decreased psychological distress, lower frequency of substance use, and greater treatment adherence (Vervoort et al., 2009; Vyavaharkar et al., 2011; Trevino et al., 2010; Kraaij et al., 2008; Pence et al., 2008). In contrast, maladaptive coping leads to poor quality of life, higher anxiety, decreased physical functioning, and greater 
psychological distress (Kraaij et al., 2008; Brook \& Willoughby, 2016; Ferreira-Valente, Pais-Ribeiro \& Jensen, 2014; Joyce et al., 2015). Maladaptive coping also predicts faster disease progression and could affect mortality (McIntosh et al., 2015).

The relationship between HIV related stigma, coping and treatment adherence is extremely relevant because many studies have recommended moderate to high levels of treatment adherence in order to ensure adequate control over the disease (Kobin \& Sheth, 2011; Parienti et al., 2008; Shuter, Sarlo, Kanmaz, Rode \& Zingman, 2007). Treatment non-adherence can result in uncontrolled viral load, (increasing the risk of sexual transmission), non-recuperating CD4 counts (faster progression to AIDS), and significant drug resistant viral strains (Weiser, Palar, Frongillo, Tsai \& Kumbakumba, 2014; Nachega et al., 2011). Therefore, understanding the factors affecting treatment adherence is crucial. Treatment adherence is influenced by a range of psycho-social factors. Some of the factors influencing HIV treatment adherence include: memory; adverse effects of medications; regimen complexity; domestic responsibilities; availability and access to medications; existing comorbidities; psychiatric problems such as depression and anxiety; and subjective knowledge and awareness about the disease (Kardas, Lewek \& Matyjaszczyk, 2013). Stigma and coping mechanisms are important psycho-social factors affecting treatment adherence in PLWH (Lyimo et al., 2014). In a study by Rintamaki and colleagues (2006), it was observed that participants experiencing higher levels of stigma were 3.3 times more likely to report sub-optimal treatment adherence. Similarly, a meta-analysis done by Katz et al. (2013), reports that stigma undermines social support and adaptive coping and thus compromises treatment adherence among PLWH. Thus, stress, social isolation, and diminished view of self that result from perceived stigma have 
many negative repercussions when it comes to adhering to prescribed medical treatment for HIV. Furthermore, coping mechanisms have the potentials to alleviate many of these repercussions. Clearly, HIV-related stigma, coping strategies, and adherence intersect in complex and mutually consequential ways. This study, therefore, aims to clarify the relationships among these factors by exploring their effects within HIV positive alcohol users living in Haiti. The study also examined the association between health care satisfaction and treatment adherence, which is an important individual-level factor in the clinical setting which could affect treatment adherence.

\section{Methods}

\section{Study Design and Population}

The current study utilized a secondary analysis of data from the parent study titled, "Intervening with Haitian HIV positive Alcohol Users: An Environmental Psychosocial Framework." The parent study was a randomized controlled trial that examined the effectiveness of the adapted CBSM-A intervention in simultaneously reducing risk behaviors, improving ART adherence and mood. Participants were provided information on HIV disease and its treatment, including currently available ART medications, the negative effects of substance use and high-risk sexual behavior on the immune system and health status, and the nature of stress, coping responses and resources. The skill building aspects of the parent study included: teaching anxiety reduction skills such as progressive muscle relaxation, relaxing imagery and autogenics; modifying maladaptive cognitive appraisals using cognitive restructuring; enhancing interpersonal conflict resolution skills and anger expression via anger management and assertion training; and providing a supportive group environment and increasing 
utilization of social support networks. Data collection for the parent study occurred at the GHESKIO (Groupe Haitien d'Etude du Sarcome de Kaposi et des Infections

Opportunistes) Centers in Port-au-Prince, Haiti. The CBSM-A intervention was designed to include a combination of problem-focused (e.g., active coping and planning) and emotion-focused (e.g., relaxation training, seeking emotional support) coping strategies.

The parent study included participants who were: between 18 and 60 years of age; fluent in spoken Haitian Creole; documented HIV seropositivity; reported at least one episode of unprotected anal or vaginal sex in the past 90 days; reported recent alcohol consumption; were not cognitively impaired at the time of recruitment; and did not show symptoms of any major psychiatric disorder. The current study included subjects who participated in baseline assessments before the beginning of randomization and intervention. The institutional review board (IRB) at Florida International University approved this secondary analysis study in September, 2015.

\section{Measures}

\section{HIV Treatment Adherence}

HIV treatment adherence was measured using the Community Programs for Clinical Research on AIDS (CPCRA) Antiretroviral Medication Self-Report questionnaire (Form 646; Terry Beirn Community Programs for Clinical Research on AIDS, 2003; see Appendix II). This questionnaire uses a global 7-day recall and has slots for recording drug name, drug code, number of pills per dose, number of doses per day, and total number of pills per day. For each of the prescribed medications, the questionnaire records whether the patients took "all," "most," "about half," "very few," or "none" of their pills during the preceding seven days. Adherence to each medication is 
calculated based on the percentages assigned to each of these responses, which include: “all” (100\%); "most” (80\%); "about half" (50\%); "few” (20\%); and “none” (0\%). Total adherence is calculated as the mean of the total scores of all the individual medications and constitutes a continuous variable ranging from 0-100 percent. In this study, participants were categorized into those who reported $\geq 95 \%$ adherence to all medications (high treatment adherence) and those who reported $<95 \%$ treatment adherence (low treatment adherence). Previous studies have reported $\geq 95 \%$ adherence rates as ideal treatment adherence (Mannheimer et al., 2006).

The questionnaire also includes a checklist of ten possible reasons why the antiretroviral doses were missed, which include: side effects; pill burden; forgetfulness; being away from home; concerns about confidentiality; difficulties with dietary requirements; and confusion. However, these questions could be asked to only those participants who reported missed medications. Therefore, in this study, descriptive statistics were used to understand the reasons for non-adherence.

\section{Stigma of HIV/AIDS}

HIV/AIDS related stigma was measured using the Perceived Stigma of HIV/AIDS scale (Bauman, Camacho, Westbrook, \& Forbes-Jones, 1997; Bauman, Silver, \& Camacho, 2000; Westbrook \& Bauman, 1996; see Appendix I). This scale measures stigma in terms of two components - internalized stigma and externalized stigma. In order to measure these two parameters, the questionnaire includes two subsections - personal view and public view. The personal view subscale includes questions related to shame, guilt, blame, embarrassment, and poor self-worth due to HIV. The public view subscale includes questions related to participant's perception about 
social stigma, for example, what the respondent thinks about other people's attitudes and beliefs towards his/her disease condition. The questions in the subscales are both positively and negatively phrased to increase the specificity of the responses. Both subscales have 24 questions measured on a four-point Likert-type scale $(1=$ strongly agree to $4=$ strongly disagree). The total score of each subscale ranges between 24 and 96 and higher scores represent higher levels of stigma. Cronbach's alpha of the instrument was 0.869 .

\section{Coping}

Coping strategies were measured using the Brief COPE questionnaire (Carver, 1997; see Appendix IV). The Brief COPE questionnaire includes 28 questions classified into 14 components with two questions per component. Each question is measured using a 4-point scale ( 1 = I have not been doing this at all; 2 = I've been doing this a little bit; 3 $=$ I've been doing this a medium amount; and $4=\mathrm{I}$ have been doing this a lot). The 14 components include: self-distraction, active coping, denial, substance use, use of emotional support, use of instrumental support, behavioral disengagement, venting, positive reframing, planning, humor, acceptance, religion, and self- blame. Based on evidence that these factors tend to be either generally adaptive or problematic, the 14 components are further classified into two domains: adaptive coping or maladaptive coping (Carver, 1997). The adaptive coping domain contains eight components with possible scores of 0 to 48 , and higher scores signify greater levels of adaptive coping. This domain includes the following components: active coping, planning, positive reframing, acceptance, humor, religion, using emotional support, and using instrumental support. The maladaptive coping domain contains six components with possible scores of 
0 to 36 , and higher scores signify greater levels of maladaptive coping. This domain includes the following components: self-distraction; denial; venting; substance use; behavioral disengagement; and self-blame. Cronbach's alpha of the instrument was 0.907 .

\section{Satisfaction with the Quality of Care}

Satisfaction with quality of care received by the participants was assessed by asking, "How satisfied were you with the quality of care you received at the visit?" and measured using a 4-point scale $(1=$ very satisfied; 2 = satisfied; $3=$ unsatisfied; and $4=$ very unsatisfied).

\section{Data Analyses}

IBM SPSS Statistics (Version 23) and IBM SPSS Analysis of Moment Structures (AMOS; Version 23) were used for data analysis (Armonk, NY: IBM Corp.). Frequencies, means, standard deviations, $\mathrm{t}$ tests, chi-square tests and Fisher's exact tests were used to describe the demographic characteristics. Independent samples tests were used to compare perceived stigma and coping variables between those reporting low versus high treatment adherence. In addition, the reasons for non-adherence to medications were described using percentages among participants with less than complete $(<100 \%)$ treatment adherence. Pearson correlations were used to find associations between treatment adherence, and the domains of perceived stigma (personal view and public view), coping variables (adaptive coping and maladaptive coping), and satisfaction with quality of care scores. Multivariable linear regressions were used to estimate the predictors of treatment adherence with demographics, stigma and coping domains and satisfaction with quality of care scores as independent variables. In the 
regressions analysis, crude models were used initially and subsequently adjusted for associated covariates. The covariates were also tested for significant associations with the outcome variable using bivariate analysis before being incorporated into the final model. To increase the validity of the model, multicollinearity among covariates was tested prior to regression analyses. Adjusted models included non-missing values for all independent variables included in the models. Structural equation modeling (SEM) was used to test the hypothesis of whether the relationship between stigma and HIV treatment adherence variables were mediated by coping variables. SEM accounts for multiple interactive relationships and variances and explores for directional associations between them leading to delineation of the mediators (Grimm \& Yarnold, 2000; Kline, 1998). In the analysis, maximum-likelihood estimation was used for the AMOS modules. Statistical significance was set at $p<0.05$ for all the analyses.

\section{Results}

\section{Demographic and socio-economic characteristics}

A total of 285 participants who reported taking medications were included in the secondary analyses and $122(42.8 \%)$ were men (Table 1$)$. The mean age of the cohort was $36.43 \pm 8.62($ Mean \pm SD) years. About $59 \%$ of the participants had a 6 th grade or less education. Approximately $60 \%$ reported that they were married and about $59.2 \%$ were unemployed. The majority of the participants reported having primary care physicians $(91.2 \%)$.

\section{Stigma and HIV treatment adherence}

Participants with higher HIV treatment adherence reported significantly lower levels of perceived stigma scores $(p=.049$; Table 2$)$. However, there were no significant 
differences between low versus high treatment adherence with respect to perceived stigma-personal view and perceived stigma-public view. Satisfaction with quality of care scores were significantly greater in those reporting high adherence to treatment. There was also significant difference in age, educational levels and marital status between those reporting low versus high treatment adherence.

\section{Coping scores and HIV treatment adherence}

There were no significant differences in total coping scores between participants reporting higher versus lower treatment adherence (Table 3). However, with respect to total maladaptive coping scores, participants reporting low treatment adherence scored significantly higher than participants reporting high treatment adherence $(p=.021)$. Similarly, with respect to the individual components of maladaptive coping, substance use $(p=.018)$ and behavioral disengagement $(p=.011)$, the low treatment adherence group scored significantly higher. However, with respect to the individual components of adaptive coping, use of instrumental support $(p=.047)$, the high treatment adherence group scored significantly higher.

\section{Reason for not taking medication}

A significant number of participants (48.8\%) reported problems taking pills at specified times (Table 4). This was followed by forgetting to take the pills (42.5\%) and not wanting others to notice taking medications (38.8\%).

\section{Relationship between adherence, perceived stigma, coping and satisfaction}

Significant negative correlations were observed between treatment adherence, and total perceived stigma $(\mathrm{r}=-.119, p<0.05)$, and maladaptive coping domain of coping strategies $(\mathrm{r}=-.129, p<0.05)$. Irrespective of the associations between treatment 
adherence and total perceived stigma, the individual domains of perceived stigma personal view and public view - did not show any association with treatment adherence. Total coping scores also did not show any significant association with treatment adherence. Significant positive correlations were observed between treatment adherence and satisfaction with quality of care scores $(r=.157, p<0.01$; Table 4).

\section{Predictors of HIV treatment adherence}

In the adjusted multivariable linear regression model perceived stigma $($ Beta $=$ $.049, p=.031)$, showed significant negative associations with treatment adherence, whereas, satisfaction with quality of care scores (Beta $=.032, p=.041$ ) showed positive association with treatment adherence. However, there were no associations between maladaptive coping and treatment adherence.

\section{Mediation analysis}

In the mediation analysis, coefficients were simultaneously estimated for all the variables that showed significant associations in bivariate analyses including treatment adherence, perceived stigma and maladaptive coping. However, there were no significant association between these variables in the mediator analyses. Figure 1 shows the path diagram for these variables. In this model, there were significant negative associations between perceived stigma and treatment adherence $($ Beta $=-.208, p=.016)$ and maladaptive coping and treatment adherence (Beta $=-.180, p=.037$ ). However, there were no associations between perceived stigma and maladaptive coping (Beta $=.029, p=$ .740). These observations suggest that the effect of stigma on HIV treatment adherence is not mediated by maladaptive coping. 


\section{Discussion}

Results of this study show that perceived stigma and quality of care satisfaction scores were significant predictors of HIV treatment adherence among alcohol using PLWH in Haiti. Mediation analyses, however, showed that maladaptive coping did not act as a mediator between perceived stigma and treatment adherence. This could be due to the stronger effects of perceived stigma on treatment adherence.

The mean adherence in this study was $93.1 \%$, and this included $100 \%$ adherence reported by $71.9 \%$ of the cohort. About $72.3 \%$ of the participants reported $\geq 95 \%$ adherence. This is comparable to many other studies done among PLWH in similar resource limited settings. For example, in a Ugandan study done by Byakika-Tusiime and colleagues (2005), > 95\% adherence was reported by $68 \%$ of the participants. Likewise, a study in Senegal reported 91\% adherence for all participants (Lanièce et al., 2003). Achieving higher levels of adherence to a remarkably complex regimen is not only challenging but also demanding for both patients and caregivers (Johnson, Heckman, Hansen, Kochman \& Sikkema, 2009; Murphy, Roberts, Martin, Marelich \& Hoffman, 2000). Despite meticulous efforts by healthcare professionals, PLWH continue to miss doses, misinterpret medication schedules and misrepresent adherence levels (Gust et al., 2011). The high levels of adherence observed in this study could be attributed to the meticulous efforts done by the staff at the GHESKIO centers in Haiti.

The finding that treatment adherence was inversely associated with perceived stigma scores is consistent with many other studies done in other PLWH populations. For example, in a cross-sectional study of 204 American PLWH, adherence measured through Patient Medication Adherence Questionnaire (PMAQ) was inversely associated 
with internalized stigma and disclosures of HIV status (Waite, Paasche-Orlow, Rintamaki, Davis \& Wolf, 2008) Similarly, in a South African study, adherence measured through ACTG Adherence Instrument was adversely associated with fear of stigma (Spire et al., 2002). In this study, though the total perceived stigma scores showed significant negative associations with treatment adherence, there were no associations between the two domains of total perceived stigma - personal view and public view and treatment adherence.

In this study, maladaptive coping was not associated with treatment adherence. However, in a previous study done in the same population, Malow et al. (2013), reported that maladaptive coping indirectly affected treatment adherence through mediating variables such as greater depression and negative attitudes about medications. However, in the current study we did not measure depression and negative attitudes about medications, thereby limiting the conclusions of this study. Irrespective of these findings, a number of studies reported that maladaptive coping was associated with adverse outcomes in HIV including treatment adherence. In a study by McIntosh et al. (2015), maladaptive coping was associated with higher rates of disease progression and faster occurrence of AIDS symptoms. Maladaptive coping was also associated with increased sexual risk behaviors which could lead to higher disease transmission rates (Sánchez, Rice, Stein, Milburn \& Rotheram-Borus, 2010). In a study by Johnson and colleagues (2009), maladaptive coping had significant adverse effects on social support variables such as social well-being, and support from family/friends which contributed to negative effects such as depression, anxiety and lower psychological well-being scores, which in turn indirectly affected adherence to ART. 
In the current study, there were positive associations between quality of care satisfaction scores and treatment adherence. Similarly, in a study done by Martinez et al. (2012), health care satisfaction significantly moderated (alleviated) the adverse effects of stigma on treatment adherence and the effects strengthened over time. Many other studies have demonstrated the beneficial effects of health care satisfaction on treatment adherence (Bennett, Fuertes, Keitel \& Phillips, 2011; Martinez et al., 2012; Barbosa, Balp, Kulich, Germain \& Rofail, 2012). Satisfaction with heath care is associated with trusting, positive, and working relationships between patients and health care providers including availability during times of urgency, needs and illness (Urowitz \& Deber, 2008). Some of the factors associated with improved health care satisfaction scores include comprehensiveness, competence, continuity of care, consistency, and compassion demonstrated by the health care personnel during clinical encounters (Williams \& Friedland, 1997).

In this study, the two most common reasons for non-adherence included inability to comply with complex medication schedules and forgetfulness. Both of these reasons have been identified as common causes for nonadherence in many studies (Adefolalu \& Nkosi, 2013; Byakika-Tusiime et al., 2005). Some of the reasons for forgetting their medications include frequent residential changes, changes in living patterns, or travelling for a living (Vervloet, 2012). Some studies have suggested the beneficial effects of adherence counseling in providing assistance to PLWH in terms of follow-up visit reminders, treatment diaries, pill boxes and alarmed pill bottles. For example, in a study among female PLWH in Kenya, adherence significantly improved with such efforts (Frick, Lavreys, Mandaliya \& Kreiss, 2001). 
There were some limitations to this study. The study participants were recruited from the GHESKIO centers, which provide comprehensive health care services, free of charge, to socioeconomically underprivileged communities in Haiti. Participants in this study could have differed significantly from PLWH who have limited access to the GHESKO centers due to several structural barriers. Thus, the results of this study cannot be generalized to the entire population of PLWH from Haiti. The current study was a secondary analysis of baseline data collected for the parent study. This could have caused some surrogate information biases in the current study. The data is self-reported, and participants were HIV positive alcohol users, which may increase recall bias and social desirability biases could have affected the findings of this study. Because of the crosssectional nature of the study, causal associations could not be determined and because of lack of HIV-negative comparison group the effects of other confounders could not be eliminated.

\section{Conclusion}

PLWH experience considerable levels of internalized and externalized stigma to which they react using coping strategies. In this cross-sectional study of HIV positive alcohol users in Haiti, we found that perceived stigma was adversely associated with treatment adherence, whereas health care satisfaction was positively associated with treatment adherence. These findings suggest that adherence enhancing interventions should consider HIV-related stigma and health care satisfaction levels. Additional factors such as difficulty following complicated schedules, forgetfulness and confidentiality for medications should be addressed in such interventions. 


\section{Acknowledgements}

I would like to thank Dr. Jessy G. Dévieux, my major professor, for providing access to the parent study data repository, as well as her entire research group especially Dr. Michele Jean-Gilles for heling me extracting the data. I would also like to thank Dr. H. Virginia McCoy, Dr. Consuelo M. Beck-Sagué, and Dr. Florence George for the intellectual content of this manuscript. I acknowledge the valuable support provided by the University Graduate School, Florida International University, in terms of Doctoral Year Fellowship. Above all, I am very grateful to the GHESKIO Centers, Port-au-Prince, Haiti, who collaborated enthusiastically for this project. 
Table 3.1. Demographic characteristics of the participants

\begin{tabular}{|c|c|c|c|c|}
\hline \multirow{2}{*}{ Characteristics } & \multicolumn{2}{|c|}{ HIV treatment adherence } & \multirow{2}{*}{$p$ value } & \multirow{2}{*}{ 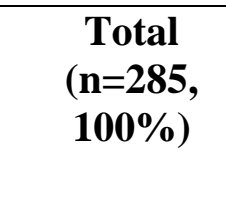 } \\
\hline & $\begin{array}{c}\text { Low } \\
(\mathbf{n}=79, \\
27.7 \%) \\
\end{array}$ & $\begin{array}{c}\text { High } \\
(\mathrm{n}=206, \\
\mathbf{7 2 . 3 \%})\end{array}$ & & \\
\hline Age* & $34.46 \pm 8.05$ & $37.23 \pm 8.75$ & .015 & $36.43 \pm 8.62$ \\
\hline Gender & & & .307 & \\
\hline Male & $30(38.0 \%)$ & $92(44.7 \%)$ & & $122(42.8 \%)$ \\
\hline Female & $49(62.0 \%)$ & $114(55.3 \%)$ & & $163(57.2 \%)$ \\
\hline Education* & & & .022 & \\
\hline $6^{\text {th }}$ grade or less & $36(48.0 \%)$ & $127(63.2 \%)$ & & $163(59.1 \%)$ \\
\hline $\begin{array}{l}\text { Some high school or } \\
\text { higher }\end{array}$ & $39(62.0 \%)$ & $74(36.8 \%)$ & & $113(40.9 \%)$ \\
\hline Marital status** & & & .009 & \\
\hline $\begin{array}{l}\text { Single or living as } \\
\text { single }\end{array}$ & $41(51.9 \%)$ & $72(35.0 \%)$ & & $113(39.6 \%)$ \\
\hline Married & $38(48.1 \%)$ & $134(65.0 \%)$ & & $172(60.4 \%)$ \\
\hline Employment & & & .286 & \\
\hline Full time job & $1(2.0 \%)$ & $4(3.7 \%)$ & & $5(3.2 \%)$ \\
\hline Seasonal job & $11(22.4 \%)$ & $27(25.0 \%)$ & & $38(24.2 \%)$ \\
\hline Unemployed & $28(57.1 \%)$ & $65(60.2 \%)$ & & $93(59.2 \%)$ \\
\hline Student & $3(6.1 \%)$ & $1(0.9 \%)$ & & $4(2.5 \%)$ \\
\hline Incapacitated & $1(2.0 \%)$ & $0(0 \%)$ & & $1(0.6 \%)$ \\
\hline Other & $5(10.2 \%)$ & $11(10.2 \%)$ & & $16(10.2 \%)$ \\
\hline Income & & & .857 & \\
\hline$<\$ 150$ & $9(30.0 \%)$ & $25(26.0 \%)$ & & $34(27.0 \%)$ \\
\hline$\$ 151-1,000$ & $10(33.3 \%)$ & $37(38.5 \%)$ & & $47(37.3 \%)$ \\
\hline$>\$ 1,000$ & $11(36.7 \%)$ & $34(35.4 \%)$ & & $45(35.7 \%)$ \\
\hline Primary care & & & .151 & \\
\hline Yes & $69(87.3 \%)$ & $191(92.7 \%)$ & & $260(91.2 \%)$ \\
\hline No & $10(12.7 \%)$ & $15(7.3 \%)$ & & $25(8.8 \%)$ \\
\hline $\begin{array}{l}\text { Satisfaction with quality } \\
\text { of care* }\end{array}$ & $3.12 \pm 0.89$ & $3.36 \pm 0.04$ & .016 & $3.29 \pm 0.73$ \\
\hline
\end{tabular}

Note: $P$ value corresponds to independent samples $\mathrm{t}$ test, chi-square test or Fisher's exact test

${ }^{*} p<.05 ; * * p<.01 ; * * * p<.001$ 
Table 3.2. Participants' stigma by level of HIV treatment adherence

\begin{tabular}{lllll}
\hline \multirow{2}{*}{ Stigma } & \multicolumn{2}{c}{ HIV treatment adherence } & \multirow{2}{*}{$\boldsymbol{p}$ value } & \multirow{2}{*}{ Total } \\
\cline { 2 - 4 } & \multicolumn{1}{c}{ Low } & \multicolumn{1}{c}{ High } & & \\
\hline Personal & $54.82 \pm 7.96$ & $54.48 \pm 8.25$ & .752 & $54.57 \pm 8.13$ \\
Public & $54.75 \pm 9.29$ & $54.02 \pm 10.62$ & .592 & $54.15 \pm 10.30$ \\
Total & $109.58 \pm 14.64$ & $108.24 \pm 17.55$ & .049 & $108.54 \pm 16.79$ \\
\hline$* p<.05 ; * * p<.01 ; * * * p<.001$ & & &
\end{tabular}


Table 3.3. Participants' Brief COPE scores by level of HIV treatment adherence

\begin{tabular}{|c|c|c|c|c|}
\hline \multirow[t]{2}{*}{ Brief COPE } & \multicolumn{2}{|c|}{ HIV treatment adherence } & \multirow[t]{2}{*}{$p$ value } & \multirow[t]{2}{*}{ Total } \\
\hline & Low & High & & \\
\hline \multicolumn{5}{|l|}{ Adaptive coping } \\
\hline Positive reframing & $5.06 \pm 1.79$ & $5.00 \pm 1.76$ & .815 & $5.02 \pm 1.77$ \\
\hline Use of instrumental support* & $4.75 \pm 1.64$ & $5.21 \pm 1.95$ & .047 & $5.12 \pm 1.88$ \\
\hline Religion & $5.80 \pm 1.61$ & $5.95 \pm 1.71$ & .502 & $5.94 \pm 1.68$ \\
\hline Use of emotional support & $4.92 \pm 1.80$ & $4.87 \pm 1.73$ & .850 & $4.90 \pm 1.75$ \\
\hline Acceptance & $5.18 \pm 1.65$ & $4.98 \pm 1.66$ & .375 & $5.03 \pm 1.65$ \\
\hline Planning & $5.44 \pm 1.52$ & $5.32 \pm 1.67$ & .568 & $5.36 \pm 1.62$ \\
\hline Active coping & $5.36 \pm 1.73$ & $5.08 \pm 1.81$ & .241 & $5.16 \pm 1.80$ \\
\hline Humor & $4.81 \pm 1.67$ & $4.73 \pm 1.79$ & .742 & $4.77 \pm 1.76$ \\
\hline Total adaptive coping & $41.35 \pm 8.82$ & $41.18 \pm 9.31$ & .892 & $41.33 \pm 9.16$ \\
\hline \multicolumn{5}{|l|}{ Maladaptive coping } \\
\hline Self-distraction & $5.23 \pm 1.78$ & $4.78 \pm 1.73$ & .054 & $5.02+1.78$ \\
\hline Denial & $5.17 \pm 1.60$ & $4.92 \pm 1.84$ & .298 & $4.98 \pm 1.79$ \\
\hline Substance use ${ }^{*}$ & $5.13 \pm 2.25$ & $4.44 \pm 2.09$ & .018 & $4.65 \pm 2.15$ \\
\hline Behavioral disengagement* & $5.92 \pm 1.90$ & $5.24 \pm 1.95$ & .011 & $4.92 \pm 1.74$ \\
\hline Venting & $5.15 \pm 1.76$ & $5.05 \pm 1.80$ & .668 & $5.07 \pm 1.77$ \\
\hline Self-blame & $5.23 \pm 1.78$ & $4.78 \pm 1.73$ & .204 & $5.39 \pm 1.94$ \\
\hline Total maladaptive coping* & $32.26 \pm 7.25$ & $29.78 \pm 8.21$ & .021 & $30.44 \pm 7.99$ \\
\hline Total coping & $73.61 \pm 14.76$ & $70.97 \pm 15.80$ & .193 & $71.78 \pm 15.50$ \\
\hline
\end{tabular}

$* p<.05 ; * * p<.01 ; * * * p<.001$ 
Table 3.4. Reasons for not taking medication by participants with low HIV treatment adherence

\begin{tabular}{ll}
\hline Reason & \multicolumn{1}{c}{$\mathbf{n ( \% )}$} \\
\hline I feel worse when I take the pills & $17(21.3 \%)$ \\
There are too many pills to take & $15(18.8 \%)$ \\
I forget to take the pills & $34(42.5 \%)$ \\
I ran out of pills & $4(5.0 \%)$ \\
I don't think I need the pills & $14(17.5 \%)$ \\
I was away from home & $25(31.3 \%)$ \\
I did not want others to notice & $31(38.8 \%)$ \\
I am too busy & $18(22.5 \%)$ \\
I had problems taking pills at specified times (with & $39(48.8 \%)$ \\
meals, on empty stomach, etc.) & \\
I was confused or uncertain about how to take the pills & $10(12.5 \%)$ \\
\hline
\end{tabular}
$* p<.05 ; * * p<.01 ; * * * p<.001$ 
Table 3.5. Correlation between adherence, perceived stigma, coping and satisfaction

\begin{tabular}{|c|c|c|c|c|c|c|c|c|}
\hline & 1 & 2 & 3 & 4 & 5 & 6 & 7 & 8 \\
\hline 1.Adherence & --- & & & & & & & \\
\hline 2.Personal view & -.042 & --- & & & & & & \\
\hline 3.Public view & -.106 & $.313 * *$ & --- & & & & & \\
\hline 4.Perceived stigma & $-.119 *$ & $.612 * *$ & $.703 * *$ & --- & & & & \\
\hline 5. Adaptive coping & -.025 & $-.227 * *$ & $-.182 * *$ & $-.222 * *$ & --- & & & \\
\hline 6. Maladaptive coping & $-.129 *$ & -.077 & -.071 & -.066 & $.632 * *$ & --- & & \\
\hline 7. Total coping & -.081 & $-.174 * *$ & $-.144 *$ & $-.165 * *$ & $.917 * *$ & $.889 * *$ & --- & \\
\hline 8. Satisfaction & $.157 * *$ & -.081 & -.049 & -.025 & -.003 & -.084 & -.045 & --- \\
\hline
\end{tabular}


Table 3.6. Multivariable linear regression predicting depression

\begin{tabular}{lllll}
\hline Independent variables & Estimate & $\begin{array}{c}\text { Standard } \\
\text { error }\end{array}$ & Beta & $\boldsymbol{p}$ value \\
\hline Age & 0.002 & 0.001 & 0.082 & 0.184 \\
Sex & -0.007 & 0.024 & -0.02 & 0.753 \\
Education & -0.038 & 0.017 & -0.142 & 0.921 \\
Marital status & 0.044 & 0.023 & 0.113 & 0.061 \\
Satisfaction* & 0.032 & 0.016 & 0.123 & 0.041 \\
Maladaptive coping & -0.002 & 0.001 & -0.091 & 0.133 \\
Stigma* & -0.049 & 0.023 & -0.131 & 0.031 \\
\hline
\end{tabular}

$* p<.05 ; * * p<.01 ; * * * p<.001$

Adjusted R-squared value $=.24$ 
Figure 3.1. Path diagram to describe the interrelationship between HIV related stigma, coping and HIV treatment adherence

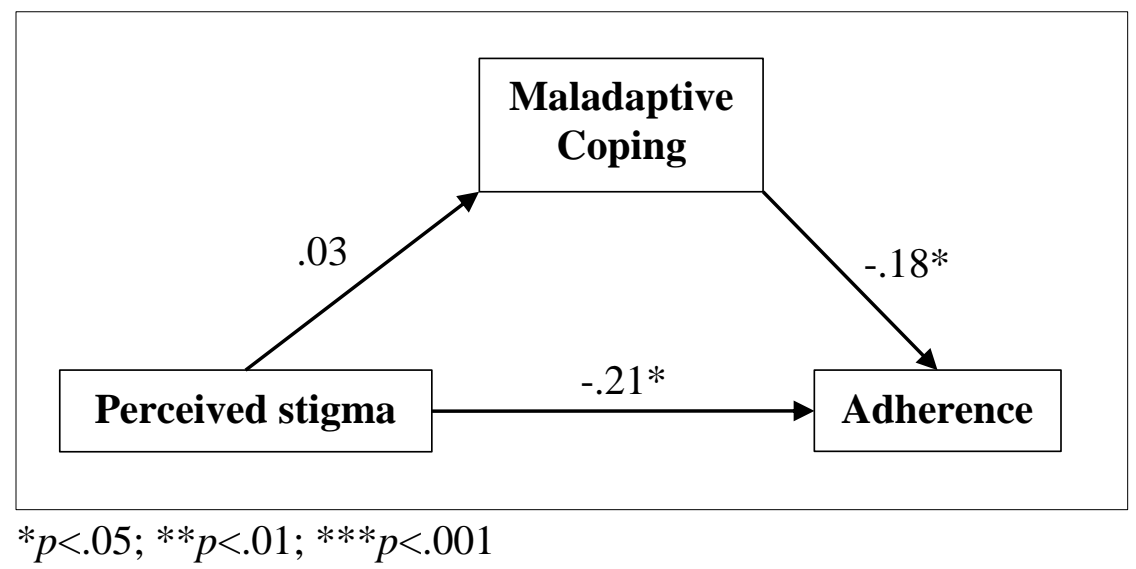




\section{References}

Adefolalu, A. O., \& Nkosi, Z. Z. (2013). The complex nature of adherence in the management of HIV/AIDS as a chronic medical condition. Diseases, 1(1), 18-35.

Barbosa, C. D., Balp, M. M., Kulich, K., Germain, N., \& Rofail, D. (2012). A literature review to explore the link between treatment satisfaction and adherence, compliance, and persistence. Patient Prefer Adherence, 6, 39-48.

Bauman, L., Camacho, S., Westbrook, L., \& Forbes-Jones, E. (1997). Correlates of personal stigma and social stigma among mothers with HIV/AIDS. Paper presented at the National Conference on Women and HIV, Pasadena, CA.

Bauman, L., Silver, E., \& Camacho, S. (July, 2000). Stigma among mothers with HIV/AIDS. Paper presented at the XIII International AIDS Conference, Durban, South Africa.

Bennett, J. K., Fuertes, J. N., Keitel, M., \& Phillips, R. (2011). The role of patient attachment and working alliance on patient adherence, satisfaction, and healthrelated quality of life in lupus treatment. Patient Education and Counseling, 85(1), 53-59.

Bogart, L. M., Cowgill, B. O., Kennedy, D., Ryan, G., Murphy, D. A., Elijah, J., \& Schuster, M. A. (2008). HIV-related stigma among people with HIV and their families: a qualitative analysis. AIDS and Behavior, 12(2), 244-254.

Bor, J., Herbst, A. J., Newell, M. L., \& Bärnighausen, T. (2013). Increases in adult life expectancy in rural South Africa: valuing the scale-up of HIV treatment. Science, 339(6122), 961-965.

Brook, C. A., \& Willoughby, T. (2016). Social anxiety and alcohol use across the university years: Adaptive and maladaptive groups. Developmental Psychology, 52(5), 835.

Bunn, J. Y., Solomon, S. E., Miller, C., \& Forehand, R. (2007). Measurement of stigma in people with HIV: A reexamination of the HIV Stigma Scale. AIDS Education \& Prevention, 19(3), 198-208.

Byakika-Tusiime, J., Oyugi, J. H., Tumwikirize, W. A., Katabira, E. T., Mugyenyi, P. N., \& Bangsberg, D. R. (2005). Adherence to HIV antiretroviral therapy in HIV+ Ugandan patients purchasing therapy. International journal of STD \& AIDS, 16(1), 38-41.

Carver, C. S. (1997). You want to measure coping but your protocol's too long: Consider the Brief COPE. International Journal of Behavioral Medicine, 4(2), 92-100. 
Chida, Y., \& Vedhara, K. (2009). Adverse psychosocial factors predict poorer prognosis in HIV disease: a meta-analytic review of prospective investigations. Brain, Behavior, and Immunity, 23(4), 434-445.

Earnshaw, V. A., \& Chaudoir, S. R. (2009). From conceptualizing to measuring HIV stigma: a review of HIV stigma mechanism measures. AIDS and Behavior, 13(6), 1160-1177.

Earnshaw, V. A., \& Kalichman, S. C. (2013). Stigma experienced by people living with HIV/AIDS. In Stigma, Discrimination and Living with HIV/AIDS (pp. 23-38). P. Liamputtong (Ed.). Springer Netherlands.

Earnshaw, V. A., Bogart, L. M., Dovidio, J. F., \& Williams, D. R. (2013). Stigma and racial/ethnic HIV disparities: Moving toward resilience. American Psychologist, 68(4), 225.

Earnshaw, V. A., Smith, L. R., Chaudoir, S. R., Amico, K. R., \& Copenhaver, M. M. (2013). HIV stigma mechanisms and well-being among PLWH: a test of the HIV stigma framework. AIDS and Behavior, 17(5), 1785-1795.

Ferreira-Valente, M. A., Pais-Ribeiro, J. L., \& Jensen, M. P. (2014). Associations between psychosocial factors and pain intensity, physical functioning, and psychological functioning in patients with chronic pain: A cross-cultural comparison. The Clinical Journal of Pain, 30(8), 713-723.

Frick, P. A., Lavreys, L., Mandaliya, K., \& Kreiss, J. K. (2001). Impact of an alarm device on medication compliance in women in Mombasa, Kenya. International Journal of STD \& AIDS, 12(5), 329-333.

Grimm, L. G., \& Yarnold, P. R. (2000). Reading and understanding MORE multivariate statistics. American psychological association.

Gust, D. A., Mosimaneotsile, B., Mathebula, U., Chingapane, B., Gaul, Z., Pals, S. L., \& Samandari, T. (2011). Risk factors for non-adherence and loss to follow-up in a three-year clinical trial in Botswana. PLoS One, 6(4), e18435.

Ha, P. N., Chuc, N. T. K., Hien, H. T., Larsson, M., \& Pharris, A. (2013). HIV-related stigma: Impact on healthcare workers in Vietnam. Global Public Health, 8(sup1), S61-S74.

Holzemer, W. L., Uys, L. R., Chirwa, M. L., Greeff, M., Makoae, L. N., Kohi, T. W., ... Wantland, D. (2007). Validation of the HIV/AIDS Stigma Instrument-PLWA (HASI-P). AIDS Care, 19(8), 1002-1012. 
Johnson, C. J., Heckman, T. G., Hansen, N. B., Kochman, A., \& Sikkema, K. J. (2009). Adherence to antiretroviral medication in older adults living with HIV/AIDS: a comparison of alternative models. AIDS Care, 21(5), 541-551.

Joyce, P., Yaptangco, M., Semana, S., Buscaino, E., Thompson, V., Cochrane, K., ... Rosenberg, A. (2015). The association of personal resilience with stress, coping, and diabetes outcomes in adolescents with type 1 diabetes. Journal of Health Psychology, 20(9), 1196-1206.

Kardas, P., Lewek, P., \& Matyjaszczyk, M. (2013). Determinants of patient adherence: a review of systematic reviews. Front Pharmacol, 4, 91.

Katz, I. T., Ryu, A. E., Onuegbu, A. G., Psaros, C., Weiser, S. D., Bangsberg, D. R., \& Tsai, A. C. (2013). Impact of HIV-related stigma on treatment adherence: systematic review and meta-synthesis. Journal of the International AIDS Society, 16(3 Suppl 2), 18640.

Kline, R. B. (1998). Principles and practice of structural equation modeling. New York: Guilford Press.

Kobin, A. B., \& Sheth, N. U. (2011). Levels of adherence required for virologic suppression among newer antiretroviral medications. Annals of Pharmacotherapy, 45(3), 372-379.

Kotzé, M., Visser, M., Makin, J., Sikkema, K., \& Forsyth, B. (2013). Psychosocial variables associated with coping of HIV-positive women diagnosed during pregnancy. AIDS and Behavior, 17(2), 498-507.

Kraaij, V., van der Veek, S. M., Garnefski, N., Schroevers, M., Witlox, R., \& Maes, S. (2008). Coping, goal adjustment, and psychological well-being in HIV-infected men who have sex with men. AIDS Patient Care and STDs, 22(5), 395-402.

Lee, R. S., Kochman, A., \& Sikkema, K. J. (2002). Internalized stigma among people living with HIV-AIDS. AIDS and Behavior, 6(4), 309-319.

Lyimo, R. A., Stutterheim, S. E., Hospers, H. J., de Glee, T., van der Ven, A., \& de Bruin, M. (2014). Stigma, disclosure, coping, and medication adherence among people living with HIV/AIDS in Northern Tanzania. AIDS Patient Care and STDs, 28(2), 98-105.

Malow, R., Dévieux, J. G., Stein, J. A., Rosenberg, R., Jean-Gilles, M., Attonito, J., ... Pape, J. W. (2013). Depression, substance abuse and other contextual predictors of adherence to antiretroviral therapy (ART) among Haitians. AIDS and Behavior, 17(4), 1221-1230. 
Mannheimer, S. B., Morse, E., Matts, J. P., Andrews, L., Child, C., Schmetter, B., ... Terry Beirn Community Programs for Clinical Research on AIDS. (2006). Sustained benefit from a long-term antiretroviral adherence intervention: results of a large randomized clinical trial. Journal of Acquired Immune Deficiency Syndromes, 43, S41-S47.

Martinez, J., Harper, G., Carleton, R. A., Hosek, S., Bojan, K., Clum, G., \& Ellen, and the Adolescent Medicine Trials Network, J. (2012). The impact of stigma on medication adherence among HIV-positive adolescent and young adult females and the moderating effects of coping and satisfaction with health care. AIDS Patient Care and STDs, 26(2), 108-115.

McIntosh, R. C., Hurwitz, B. E., Antoni, M., Gonzalez, A., Seay, J., \& Schneiderman, N. (2015). The ABCs of trait anger, psychological distress, and disease severity in HIV. Annals of Behavioral Medicine, 49(3), 420-433.

Morris, J. L., Lippman, S. A., Philip, S., Bernstein, K., Neilands, T. B., \& Lightfoot, M. (2014). Sexually transmitted infection related stigma and shame among African American male youth: Implications for testing practices, partner notification, and treatment. AIDS Patient Care and STDs, 28(9), 499-506.

Murphy, D. A., Roberts, K. J., Martin, D. J., Marelich, W., \& Hoffman, D. (2000). Barriers to antiretroviral adherence among HIV-infected adults. AIDS Patient Care and STDs, 14(1), 47-58.

Nachega, J. B., Marconi, V. C., van Zyl, G. U., Gardner, E. M., Preiser, W., Hong, S. Y., ... \& Gross, R. (2011). HIV treatment adherence, drug resistance, virologic failure: evolving concepts. Infectious Disorders-Drug Targets, 11(2), 167-174.

Onyebuchi-Iwudibia, O., \& Brown, A. (2014). HIV and depression in Eastern Nigeria: The role of HIV-related stigma. AIDS Care, 26(5), 653-657.

Parienti, J. J., Das-Douglas, M., Massari, V., Guzman, D., Deeks, S. G., Verdon, R., \& Bangsberg, D. R. (2008). Not all missed doses are the same: sustained NNRTI treatment interruptions predict HIV rebound at low-to-moderate adherence levels. PloS One, 3(7), e2783.

Pence, B. W., Thielman, N. M., Whetten, K., Ostermann, J., Kumar, V., \& Mugavero, M. J. (2008). Coping strategies and patterns of alcohol and drug use among HIVinfected patients in the United States Southeast. AIDS Patient Care and STDs, 22(11), 869-877.

Preston, D. B., D'augelli, A. R., Kassab, C. D., \& Starks, M. T. (2007). The relationship of stigma to the sexual risk behavior of rural men who have sex with men. AIDS Education \& Prevention, 19(3), 218-230. 
Reidpath, D. D., \& Chan, K. Y. (2005). A method for the quantitative analysis of the layering of HIV-related stigma. AIDS Care, 17(4), 425-432.

Rintamaki, L. S., Davis, T. C., Skripkauskas, S., Bennett, C. L., \& Wolf, M. S. (2006). Social stigma concerns and HIV medication adherence. AIDS Patient Care \& STDs, 20(5), 359-368.

Rudolph, A. E., Davis, W. W., Quan, V. M., Ha, T. V., Minh, N. L., Gregowski, A., ... Go, V. (2012). Perceptions of community-and family-level injection drug user (IDU)-and HIV-related stigma, disclosure decisions and experiences with layered stigma among HIV-positive IDUs in Vietnam. AIDS Care, 24(2), 239-244.

Sánchez, M., Rice, E., Stein, J., Milburn, N. G., \& Rotheram-Borus, M. J. (2010). Acculturation, coping styles, and health risk behaviors among HIV positive Latinas. AIDS and Behavior, 14(2), 401-409.

Shuter, J., Sarlo, J. A., Kanmaz, T. J., Rode, R. A., \& Zingman, B. S. (2007). HIVinfected patients receiving lopinavir/ritonavir-based antiretroviral therapy achieve high rates of virologic suppression despite adherence rates less than 95\%. JAIDS Journal of Acquired Immune Deficiency Syndromes, 45(1), 4-8.

Spire, B., Duran, S., Souville, M., Leport, C., Raffi, F., \& Moatti, J. P. (2002). Adherence to highly active antiretroviral therapies (HAART) in HIV-infected patients: from a predictive to a dynamic approach. Social Science \& Medicine, 54(10), 14811496.

Storholm, E. D., Halkitis, P. N., Kupprat, S. A., Hampton, M. C., Palamar, J. J., BrennanIng, M., \& Karpiak, S. (2013). HIV-related stigma as a mediator of the relation between multiple-minority status and mental health burden in an aging HIVpositive population. Journal of HIV/AIDS \& Social Services, 12(1), 9-25.

Takács, J., Kelly, J. A., P Tóth, T., Mocsonaki, L., \& Amirkhanian, Y. A. (2013). Effects of stigmatization on gay men living with HIV/AIDS in a Central-Eastern European context: a qualitative analysis from Hungary. Sexuality Research and Social Policy, 10(1), 24-34.

Terry Beirn Community Programs for Clinical Research on AIDS. (2003). Antiretroviral medication self-report: Form 646.

Trevino, K. M., Pargament, K. I., Cotton, S., Leonard, A. C., Hahn, J., Caprini-Faigin, C. A., \& Tsevat, J. (2010). Religious coping and physiological, psychological, social, and spiritual outcomes in patients with HIV/AIDS: Cross-sectional and longitudinal findings. AIDS and Behavior, 14(2), 379-389. 
Tsai, A. C., Bangsberg, D. R., Kegeles, S. M., Katz, I. T., Haberer, J. E., Muzoora, C., ... Weiser, S. D. (2013). Internalized stigma, social distance, and disclosure of HIV seropositivity in rural Uganda. Annals of Behavioral Medicine, 46(3), 285-294.

Urowitz, S., \& Deber, R. (2008). How consumerist do people want to be? Preferred role in decision-making of individuals with HIV/AIDS. Healthcare Policy, 3(3).

Vervloet, M., Linn, A. J., van Weert, J. C., De Bakker, D. H., Bouvy, M. L., \& Van Dijk, L. (2012). The effectiveness of interventions using electronic reminders to improve adherence to chronic medication: a systematic review of the literature. Journal of the American Medical Informatics Association, 19(5), 696-704.

Vervoort, S. C., Grypdonck, M. H., De Grauwe, A., Hoepelman, A. I., \& Borleffs, J. C. (2009). Adherence to HAART: processes explaining adherence behavior in acceptors and non-acceptors. AIDS Care, 21(4), 431-438.

Vyavaharkar, M., Moneyham, L., Corwin, S., Tavakoli, A., Saunders, R., \& Annang, L. (2011). HIV-disclosure, social support, and depression among HIV-infected African American women living in the rural southeastern United States. AIDS Education and Prevention, 23(1), 78.

Waite, K. R., Paasche-Orlow, M., Rintamaki, L. S., Davis, T. C., \& Wolf, M. S. (2008). Literacy, social stigma, and HIV medication adherence. Journal of General Internal Medicine, 23(9), 1367-1372.

Weiser, S. D., Palar, K., Frongillo, E. A., Tsai, A. C., \& Kumbakumba, E. (2014). Longitudinal assessment of associations between food insecurity, antiretroviral adherence and HIV treatment outcomes in rural Uganda. AIDS (London, England), 28(1), 115.

Westbrook, L., \& Bauman, L. (1996). The perceived stigma of AIDS: Personal view and public view scales. Bronx, NY: Albert Einstein College of Medicine.

Williams, A., \& Friedland, G. (1997). Adherence, compliance, and HAART. AIDS Clinical Care, 9(7), 51. 


\section{CHAPTER IV: Effects of Stigma and Anxiety on Treatment Adherence with Maladaptive Coping as Mediator among HIV-Positive Alcohol Users in Haiti}

\section{Introduction}

HIV is a global health problem, and despite significant advancements in treatment and prevention strategies, it remains one of the most stigmatized diseases worldwide. Among PLWH, stigma contributes to considerable emotional and psychological distress (Stutterheim et al., 2011) and acts as one of the greatest barriers to adequate treatment and control (Katz, et al., 2013). As a social and structural phenomenon involving stereotyping, status loss, and discrimination, stigma represents a significant risk factor for mental health problems among PLWH (Mahajan et al., 2008; Earnshaw \& Chaudoir, 2009). HIV-related stigma has been consistently associated with increased anxiety, depression, PTSD, alcoholism, drug use and other psychiatric disorders (Dévieux et al., 2013; Kamen et al., 2015; Yi et al., 2015).

There are several studies which show that PLWH experience greater levels of dysfunctional personality and negative affective disorders (Olley, et al., 2015; Houston, Sandfort, Watson, \& Caton, 2013). There are three streams of empirical evidence that associate HIV/AIDS with affective disorders. The first stream of evidence consists of studies that demonstrate remarkably higher levels of stress in PLWH (McIntosh \& Rosselli, 2012; Kalichman \& Grebler, 2010). These stressors are associated with physical, social, and medical aspects of the disease itself (Orban et al., 2010). The second stream of evidence comes from studies which show that PLWH additionally experience higher levels of life stressors not directly related to the disease. For example, abuse history, domestic violence, and poor socioeconomic status (Jewkes, Dunkle, Nduna \& 
Shai, 2010). The third stream of evidence comes from studies which show that PLWH inherently have increased susceptibility to psychiatric disorders due to unknown factors when compared to HIV-negative individuals within the same populations (Mayston, Kinyanda, Chishinga, Prince \& Patel, 2012). Though the associations between HIV and anxiety have been relatively less documented when compared to other psychiatric disorders, a few studies have shown significant associations between HIV infection and post-traumatic stress disorders, generalized anxiety disorders, and panic disorders (Vranceanu et al., 2008; Myer et al., 2008). This evidence shows that there is a greater need to address anxiety disorders especially in a resource-limited nation like Haiti. Coping is defined as efforts to deal with demands taxing or exceeding the resources of the person (Lazarus \& Folkman, 1984). Coping includes constant behavioral and cognitive efforts to manage and overcome the stressful demands connected to traumatic, painful, or difficult situations (Chida \& Vedhara, 2007). Ever since the emergence of the epidemic, a number of studies have documented the beneficial effects of coping on stress and illness (McIntosh \& Rosselli, 2012). Folkman (1997) demonstrated that coping mechanisms were associated with positive mind states in PLWH. Though several types of coping have been identified in the literature, two forms predominate - adaptive coping and maladaptive coping. Adaptive coping includes direct engagement strategies such as problem-solving, information seeking, and cognitive restructuring, whereas maladaptive coping includes patterns of denial and avoidance (Kotzé, et al., 2013). Adaptive coping is a resilient strategy because it involves positive means of adaptation and enables beneficial recovery and recuperation (Sinclair \& Wallston, 2004). Research in this area also concludes that the meaning ascribed to HIV 
varies between individuals and so various coping strategies may be differentially effective. Thus, coping interventions for PLWH may be most effective when tailored to individual life contexts and appraisals of PLWH with respect to their disease (Moskowitz $\&$ Wrubel, 2005).

Many studies have recommended moderate to high levels of treatment adherence in order to ensure adequate control over the disease (Kobin \& Sheth, 2011; Parienti et al., 2008; Shuter et al., 2007). Treatment non-adherence can result in uncontrolled viral load, (increasing the risk of sexual transmission), non-recuperating CD4 counts (faster progression to AIDS), and significant drug resistant viral strains (Weiser, Palar, Frongillo, Tsai \& Kumbakumba, 2014; Nachega et al., 2011). Therefore, understanding the factors affecting treatment adherence is crucial. A number of studies have shown adverse associations between anxiety disorders and treatment adherence in PLWH (Springer, Dushaj \& Azar, 2012). Given the consequential effects of stigma and coping mechanisms on anxiety disorders and their combined effects on treatment adherence, the current study aims to explore these associations in a sample of HIV positive alcohol users in Haiti.

\section{Methods}

\section{Study Design and Population}

The current study was a secondary analysis of data from the parent study titled, "Intervening with Haitian HIV positive Alcohol Users: An Environmental Psychosocial Framework." The parent study was a randomized controlled trial that examined the effectiveness of the adapted CBSM-A intervention in simultaneously reducing risk behaviors, improving ART adherence, and mood. Participants were provided 
information on HIV disease and its treatment, including currently available ART medications, the negative effects of substance use and high-risk sexual behavior on the immune system and health status, and the nature of stress and coping responses and resources. The skill building aspects of the parent study included: teaching anxiety reduction skills such as progressive muscle relaxation, relaxing imagery and autogenics; modifying maladaptive cognitive appraisals using cognitive restructuring; enhancing interpersonal conflict resolution skills and anger expression via anger management and assertion training; and providing a supportive group environment and increase utilization of social support networks. Data collection for the parent study occurred at the GHESKIO (Groupe Haitien d'Etude du Sarcome de Kaposi et des Infections Opportunistes) Centers in Port-au-Prince, Haiti. The CBSM-A intervention was designed to include a combination of problem-focused (e.g., active coping and planning) and emotion-focused (e.g., relaxation training, seeking emotional support) coping strategies.

The parent study included participants who were: between 18 and 60 years of age; fluent in spoken Haitian Creole; documented HIV seropositivity; reported at least one episode of unprotected anal or vaginal sex in the past 90 days; reported recent alcohol consumption; were not cognitively impaired at the time of recruitment; and did not show symptoms of any major psychiatric disorder. The current study included subjects who participated in baseline assessments before the beginning of randomization and the interventional The institutional review board (IRB) at Florida International University approved this secondary data analysis study in September, 2015. 


\section{Measures}

\section{State Anxiety}

State anxiety was assessed using the State-Trait Anxiety Inventory (STAI), Form Y-1 (Spielberger, Gorsuch \& Lushen, 1970; see Appendix V). STAI has two sections Form Y-1 and Form Y-2. The first section of the inventory (Form Y-1) includes 20 questions which measure transitory state anxiety levels in terms of a 4-point Likert scale ( $1=$ not at all; $2=$ somewhat; $3=$ moderately so; and $4=$ very much so $)$. The total state anxiety scores are obtained by adding the scores for each of the 20 questions and range between 20 and 80 . Higher scores signify greater levels of state anxiety. A cutting point of 39-40 has been suggested to indicate clinically significant symptoms for the state anxiety scale (Knight et al., 1983; Addolorato et al., 1999). The second section of the inventory (Form Y-2) also includes 20 questions which measure long term trait anxiety. However, trait anxiety levels change over extremely long periods of time and cannot be used for relatively short studies (Julian, 2011). The parent study did not measure trait anxiety levels due to the same reason. Cronbach's alpha of the instrument was 0.744 .

\section{Stigma of HIV/AIDS}

HIV/AIDS related stigma was measured using the Perceived Stigma of HIV/AIDS scale (Bauman, Camacho, Westbrook, \& Forbes-Jones, 1997; Bauman, Silver, \& Camacho, 2000; Westbrook \& Bauman, 1996; see Appendix I). This scale measures stigma in terms of two components - internalized stigma (personal view) and externalized stigma (public view). In order to measure these two parameters, the questionnaire includes two subsections - personal view and public view. The personal view subscale includes questions related to shame, guilt, blame, embarrassment, and poor 
self-worth due to HIV. The public view subscale includes questions related to participant's perception about social stigma, for example, what the respondent thinks about other people's attitudes and beliefs towards his/her disease condition. The questions in the subscales are both positively and negatively phrased to increase the specificity of the responses. Both subscales have 24 questions measured by four-point Likert-type scale $(1=$ strongly agree to $4=$ strongly disagree $)$. The total score of each subscale ranges between 24 and 96 and higher scores represent higher levels of stigma. Cronbach's alpha of the instrument was 0.869 .

\section{Coping}

Coping strategies were measured using the Brief COPE questionnaire (Carver, 1997; see Appendix IV). The Brief COPE questionnaire includes 28 questions classified into 14 components with two questions per component. Each question is measured using a 4-point scale ( 1 = I have not been doing this at all; 2 = I've been doing this a little bit; 3 $=$ I've been doing this a medium amount; and $4=\mathrm{I}$ have been doing this a lot). The 14 components include: self-distraction, active coping, denial, substance use, use of emotional support, use of instrumental support, behavioral disengagement, venting, positive reframing, planning, humor, acceptance, religion, and self- blame. Based on evidence that these factors tend to be either generally adaptive or problematic, the 14 components are further classified into two domains: adaptive coping or maladaptive coping (Carver, 1997). The adaptive coping domain contains eight components with possible scores of 0 to 48 , and higher scores signify greater levels of adaptive coping. This domain includes the following components: active coping, planning, positive reframing, acceptance, humor, religion, using emotional support, and using instrumental 
support. The maladaptive coping domain contains six components with possible scores of 0 to 36 , and higher scores signify greater levels of maladaptive coping. This domain includes the following components: self-distraction; denial; venting; substance use; behavioral disengagement; and self-blame. Cronbach's alpha of the instrument was 0.907 .

\section{HIV Treatment Adherence}

HIV treatment adherence was measured using the Community Programs for Clinical Research on AIDS (CPCRA) Antiretroviral Medication Self-Report questionnaire (Form 646; Terry Beirn Community Programs for Clinical Research on AIDS, 2003; see Appendix II). This questionnaire uses a global 7-day recall and has slots for recording drug name, drug code, number of pills per dose, number of doses per day, and total number of pills per day (Appendix II). For each of the prescribed medications, the questionnaire records, whether the patients took "all," "most," "about half," "very few," or "none" of their pills during the preceding seven days. Adherence to each medication is calculated based on the percentages assigned to each of these responses, which include: “all” (100\%); "most” (80\%); “about half” (50\%); “few" (20\%); and "none" $(0 \%)$. Total adherence is calculated as the mean of the total scores of all the individual medications and constitutes a continuous variable ranging from 0-100 percent. In this study, adherence was considered as a continuous variable.

\section{Data Analyses}

IBM SPSS Statistics (Version 23) and IBM SPSS Analysis of Moment Structures (AMOS; Version 23) were used for data analysis (Armonk, NY: IBM Corp.).

Frequencies, means, standard deviations, t tests, chi-square tests and Fisher's exact tests 
were used to describe the demographic characteristics. Independent samples tests were used to compare perceived stigma and coping variables between those reporting higher versus lower levels of anxiety. Pearson correlations were used to find associations between anxiety levels, treatment adherence, the domains of perceived stigma (personal view and public view), and coping variables (adaptive coping and maladaptive coping). Structural equation modeling (SEM) was used to test the hypothesis whether the relationship between stigma and anxiety levels was mediated by the coping variable and whether there were any combined effects on treatment adherence. SEM accounts for multiple interactive relationships and variances and explores for directional associations between them leading to delineation of the mediators (Grimm \& Yarnold, 2000; Kline, 1998). For analysis, maximum-likelihood estimations were used for the AMOS modules. Statistical significance was set at $p<0.05$ for all the analyses.

\section{Results}

\section{Demographic and socio-economic characteristics}

A total of 285 participants who reported taking medications were included in the secondary analyses and $42.3 \%$ were men (Table 1 ). The mean age of the cohort was $36.43 \pm 8.62($ Mean \pm SD) years. About $59 \%$ of the participants had 6th grade or lesser levels education. About $60 \%$ reported that they were married and $59.6 \%$ were unemployed. The majority of the participants reported having primary care physicians $(90.2 \%)$. There were significant differences in age and gender between those reporting low versus high levels of anxiety. 


\section{Stigma and anxiety levels}

There were no significant differences with respect to personal view, public view as well as total perceived stigma between those reporting low versus high levels of anxiety (Table 2).

\section{Coping scores and anxiety levels}

Participants who reported higher levels of anxiety also reported significantly higher levels of total coping ( $p<.001$; Table 3). Participants who reported higher levels of anxiety reported higher levels of maladaptive coping $(p<.001)$. However, there were no significant differences in adaptive coping scores between participants reporting low versus high levels of anxiety. Participants who reported higher levels of anxiety also reported higher levels of planning, active coping, self-distraction, denial, substance use, behavioral disengagement, venting, and self-blame components of the questionnaire (Table 3).

\section{Treatment adherence and anxiety levels}

There were significant differences in treatment adherence between participants reporting low versus high levels of anxiety. Participants who reported higher levels of anxiety reported significantly lower levels of treatment adherence ( $p=.011$; Table 4$)$.

\section{Relationship between anxiety, adherence, perceived stigma, and coping mechanisms}

Significant negative correlations were observed between anxiety levels and treatment adherence $(\mathrm{r}=-.141, p<0.05)$, and total coping scores $(\mathrm{r}=-.167, p<0.01$; Table 5). Significant positive correlations were observed between anxiety levels and total perceived stigma $(\mathrm{r}=.123, p<0.05)$, perceived stigma-public view $(\mathrm{r}=.132, p<0.05)$ and maladaptive coping $(\mathrm{r}=.398, p<0.01)$. 


\section{Mediation analysis}

In the mediation analysis, coefficients were simultaneously estimated for all the variables that showed significant associations in bivariate analyses including perceived stigma, maladaptive coping, anxiety levels, and treatment adherence. There were significant associations between perceived sigma and maladaptive coping (Beta $=.175, p$ $=.003)$, perceived sigma and anxiety $($ Beta $=.164, p=.005)$, maladaptive coping and anxiety $($ Beta $=.229, p<.001)$, and anxiety and treatment adherence $($ Beta $=-.140, p=$ .018). Figure 1 shows the path diagram for these variables. These observations suggest that maladaptive coping acted as a mediator on the relationship between stigma and anxiety levels which in turn had significant effects on treatment adherence.

\section{Discussion}

Many studies have shown that stigma was associated with poor mental and physical health outcomes, such as, anxiety and depression, increased risk seeking behaviors, and adverse disease progression parameters such as lower CD4 counts and higher viral load (Storholm et al., 2013; Earnshaw, Smith, Chaudoir, Amico, \& Copenhaver, 2013; Holzemer et al., 2007). In the present study, there were significant

associations between perceived stigma and anxiety levels. Results show that maladaptive coping strategies significantly mediated the associations between stigma and anxiety levels and in turn adversely affected treatment adherence.

PLWH experience varying levels of anxiety disorders as reported in associated studies and range between $7 \%$ in some studies to as high as $82 \%$ in others (Kemppainen et al., 2003; Morrison et al., 2011). In a study done among 1,125 PLWH in the Southeastern United States, prevalence of anxiety disorders was as high as $39 \%$ (Pence, 
Miller, Whetten, Eron \& Gaynes, 2006). Similarly, a survey done among 85 PLWH in the South Africa showed that high levels of anxiety were reported by $52.9 \%$ of the participants (Kagee \& Martin, 2010). Akin to these findings, this study reported high levels of anxiety in $47.2 \%$ of the participants.

In this study, maladaptive coping adversely mediated the effects of stigma on anxiety levels. However, adaptive coping did not show any such effects. Similar findings were reported in another study, where disengagement coping (maladaptive coping) aggravated anxiety and depressive symptoms (Varni, Miller, McCuin, \& Solomon, 2012). Higher levels of maladaptive coping and lower levels of adaptive coping were associated with higher levels of anxiety symptoms (Gonzalez, Solomon, Zvolensky, \& Miller, 2009). Contrasting these findings, a study done among Australian PLWH showed that adaptive coping was not associated with HIV-related stigma and anxiety (Pakenham \& Rinaldis, 2001). The variety of these conflicting findings suggest that the relationship between stigma, anxiety and coping is very complex. Many different aspects of mental functioning are affected by the stressors associated with the HIV-related stigma. A number of different coping mechanisms are used to overcome these stressors (O’Donnell et al., 2013; Gore-Felton et al., 2013). Thus, the preponderance of either one of these factors (stressor versus coping) may affect the outcome variables such as anxiety levels. This explains why adaptive coping may be beneficial in lowering anxiety (Pakenham \& Rinaldis, 2001), or may not show any association as observed in this study. The same assumptions can be extrapolated to maladaptive coping, which showed adverse associations with anxiety in this study. Coping mechanisms are inherently different with regards to their impact on anxiety symptoms. Future interventions should therefore 
consider not only the type of coping, but also their associations with different aspects of mental well-being. This could be achieved through improved assessment of perceived stigma and anxiety provoking factors.

In this study, anxiety levels were adversely associated with treatment adherence. A number of studies have shown adverse associations between anxiety disorders and treatment adherence in several PLWH populations. For example, in a study done among 85 female PLWH from New York City, many different components of anxiety were adversely associated with treatment adherence (Willie, Overstreet, Sullivan, Sikkema, \& Hansen, 2015). In a multivariable analysis of 358 Italian PLWH, it was found that anxiety symptoms were significantly associated with treatment non-adherence (Ammassari et al., 2001). In a longitudinal study of 193 Swedish PLWH, Nilsson Schönnesson and colleagues (2007) reported that anxiety measured by the Brief Symptom Inventory, significantly predicted suboptimal treatment adherence. Similarly, in a Brazilian study among 293 PLWH, severe anxiety predicted treatment non-adherence after adjusting for education, employment, and substance use in the past 4 weeks (Campos, Guimarães, \& Remien, 2010). These findings support the relevance of this study, where associations were found between stigma, coping mechanisms and anxiety levels, and their combined effects on treatment adherence.

Irrespective of these findings, there were some limitations to this study. This study was cross-sectional and causal associations could not be determined. The study also lacked an HIV-negative comparison group and therefore there could be many confounders affecting these findings. The participants were privileged to have comprehensive health care services from the GHESKIO centers in Haiti. They could have 
been significantly different from other PLWH in Haiti who had limited access to these services due to several reasons. This would compromise some of the external validity of the findings. The current study was a secondary analysis of baseline data collected for the parent study, leading to surrogate information biases. The data is self-reported, and participants were HIV positive alcohol users, which may have increased recall bias, and social desirability biases could have affected the findings of this study.

\section{Conclusion}

In summary, this study showed that the maladaptive coping strategies adversely mediated the relationship between stigma and anxiety symptoms. However, the beneficial mediating effect of adaptive coping on these factors was not evident. Furthermore, these adverse effects in turn potentiated the adverse effect of anxiety on treatment adherence. Thus, this study suggests that future intervention should aim at teaching PLWH to decrease their maladaptive coping strategies while dealing with HIV-related stigma. This could decrease their anxiety symptoms and improve their treatment adherence.

\section{Acknowledgements}

I would like to thank Dr. Jessy G. Dévieux, my major professor, for providing access to the parent study data repository, as well as her entire research group especially Dr. Michele Jean-Gilles for heling me extracting the data. I would also like to thank Dr. H. Virginia McCoy, Dr. Consuelo M. Beck-Sagué, and Dr. Florence George for the intellectual content of this manuscript. I acknowledge the valuable support provided by the University Graduate School, Florida International University, in terms of Doctoral Year Fellowship. Above all, I am very grateful to the GHESKIO Centers, Port-au-Prince, Haiti, who collaborated enthusiastically for this project. 
Table 4.1. Demographic characteristics of the participants

\begin{tabular}{|c|c|c|c|c|}
\hline \multirow[t]{2}{*}{ Characteristics } & \multicolumn{2}{|c|}{ Anxiety } & \multirow[t]{2}{*}{$p$ value } & \multirow{2}{*}{$\begin{array}{c}\text { Total } \\
(\mathrm{n}=285 \\
100 \%)\end{array}$} \\
\hline & $\begin{array}{c}\text { Low } \\
(\mathbf{n}=151 \\
\mathbf{5 2 . 8 \%})\end{array}$ & $\begin{array}{c}\text { High } \\
(\mathrm{n}=134, \\
47.2 \%)\end{array}$ & & \\
\hline $\operatorname{Age}^{*}$ & $37.80 \pm 8.77$ & $34.91 \pm 8.25$ & .005 & $36.43 \pm 8.62$ \\
\hline Gender & & & .008 & \\
\hline Male & $75(49.7 \%)$ & $45(34.1 \%)$ & & $120(42.3 \%)$ \\
\hline Female & $76(50.3 \%)$ & $89(65.9 \%)$ & & $165(57.7 \%)$ \\
\hline Education* & & & .869 & \\
\hline $6^{\text {th }}$ grade or less & $86(59.3 \%)$ & $77(58.3 \%)$ & & $163(58.8 \%)$ \\
\hline $\begin{array}{l}\text { Some high } \\
\text { school or higher }\end{array}$ & $59(40.7 \%)$ & $55(41.7 \%)$ & & $114(41.2 \%)$ \\
\hline Marital status* & & & .202 & \\
\hline $\begin{array}{l}\text { Single or living } \\
\text { as single }\end{array}$ & $66(43.7 \%)$ & $49(36.3 \%)$ & & $115(40.2 \%)$ \\
\hline Married & $85(56.3 \%)$ & $85(63.7 \%)$ & & $170(59.8 \%)$ \\
\hline Employment & & & .096 & \\
\hline Full time job & $1(1.5 \%)$ & $4(4.4 \%)$ & & $5(3.2 \%)$ \\
\hline Seasonal job & $22(33.8 \%)$ & $15(16.5 \%)$ & & $37(23.7 \%)$ \\
\hline Unemployed & $32(49.2 \%)$ & $61(67.0 \%)$ & & $93(59.6 \%)$ \\
\hline Student & $2(3.1 \%)$ & $2(2.2 \%)$ & & $4(2.6 \%)$ \\
\hline Incapacitated & $1(1.5 \%)$ & $0(0 \%)$ & & $1(0.6 \%)$ \\
\hline Other & $7(10.8 \%)$ & $9(9.9 \%)$ & & $16(10.3 \%)$ \\
\hline Income & & & .555 & \\
\hline$<\$ 150$ & $25(29.8 \%)$ & $10(22.7 \%)$ & & $35(27.3 \%)$ \\
\hline$\$ 151-1,000$ & $32(38.1 \%)$ & $16(36.4 \%)$ & & $48(37.5 \%)$ \\
\hline$>\$ 1,000$ & $27(32.1 \%)$ & $18(40.9 \%)$ & & $45(35.2 \%)$ \\
\hline Primary care & & & .200 & \\
\hline Yes & $133(88.1 \%)$ & $124(92.6 \%)$ & & $257(90.2 \%)$ \\
\hline No & $18(11.9 \%)$ & $10(7.4 \%)$ & & $28(9.8 \%)$ \\
\hline
\end{tabular}

Note: $P$ value corresponds to independent samples t test, chi-square test or Fisher's exact test

$* p<.05 ; * * p<.01 ; * * * p<.001$ 
Table 4.2. Participants' stigma by anxiety level

\begin{tabular}{lllll}
\hline \multirow{2}{*}{ Stigma } & \multicolumn{2}{c}{ Anxiety } & p value & \multicolumn{1}{c}{ Total } \\
\cline { 2 - 4 } & \multicolumn{1}{c}{ Low } & \multicolumn{1}{c}{ High } & & \\
\hline Personal & $54.33 \pm 7.94$ & $54.88 \pm 8.40$ & .574 & $54.57 \pm 8.13$ \\
Public & $53.11 \pm 9.27$ & $55.44 \pm 11.31$ & .060 & $54.15 \pm 10.30$ \\
Total & $107.09 \pm 16.14$ & $110.32 \pm 17.50$ & .106 & $108.54 \pm 16.79$ \\
\hline
\end{tabular}


Table 4.3. Participants' Brief COPE scores by anxiety level

\begin{tabular}{|c|c|c|c|c|}
\hline \multirow[t]{2}{*}{ Brief COPE } & \multicolumn{2}{|c|}{ Anxiety } & \multirow[t]{2}{*}{$p$ value } & \multirow[t]{2}{*}{ Total } \\
\hline & Low & High & & \\
\hline \multicolumn{5}{|l|}{ Adaptive coping } \\
\hline Positive reframing & $4.91 \pm 1.70$ & $5.15 \pm 1.85$ & .262 & $5.02 \pm 1.77$ \\
\hline Use of instrumental support & $5.12 \pm 1.82$ & $5.08 \pm 1.96$ & .876 & $5.12 \pm 1.88$ \\
\hline Religion & $5.90 \pm 1.79$ & $6.00 \pm 1.54$ & .653 & $5.94 \pm 1.68$ \\
\hline Use of emotional support & $4.89 \pm 1.67$ & $4.90 \pm 1.85$ & .973 & $4.90 \pm 1.75$ \\
\hline Acceptance & $5.00 \pm 1.57$ & $5.11 \pm 1.71$ & .571 & $5.03 \pm 1.65$ \\
\hline Planning** & $5.07 \pm 1.64$ & $5.70 \pm 1.56$ & .001 & $5.36 \pm 1.62$ \\
\hline Active coping* & $4.95 \pm 1.76$ & $5.41 \pm 1.83$ & .034 & $5.16 \pm 1.80$ \\
\hline Humor & $4.64 \pm 1.65$ & $4.88 \pm 1.85$ & .250 & $4.77 \pm 1.76$ \\
\hline Total adaptive coping & $40.52 \pm 8.95$ & $42.26 \pm 9.40$ & .115 & $41.33 \pm 9.16$ \\
\hline \multicolumn{5}{|l|}{ Maladaptive coping } \\
\hline Self-distraction $* *$ & $4.59 \pm 1.64$ & $5.29 \pm 1.79$ & .001 & $4.92 \pm 1.74$ \\
\hline Denial $^{*} * *$ & $4.54 \pm 1.71$ & $5.51 \pm 1.74$ & .000 & $4.98 \pm 1.79$ \\
\hline Substance use $e^{* * *}$ & $4.11 \pm 2.01$ & $5.21 \pm 1.71$ & .000 & $4.65 \pm 2.15$ \\
\hline Behavioral disengagement $* * *$ & $4.83 \pm 1.84$ & $6.08 \pm 1.84$ & .000 & $5.42 \pm 1.95$ \\
\hline Venting* & $4.85 \pm 1.73$ & $5.36 \pm 1.77$ & .016 & $5.07 \pm 1.77$ \\
\hline Self-blame $* * *$ & $4.90 \pm 1.92$ & $5.92 \pm 1.82$ & .000 & $5.39 \pm 1.94$ \\
\hline Total maladaptive coping*** & $27.84 \pm 7.55$ & $33.41 \pm 7.46$ & .000 & $30.44 \pm 7.99$ \\
\hline Total coping $* * *$ & $68.36 \pm 14.83$ & $75.67 \pm 15.48$ & .000 & $71.78 \pm 15.50$ \\
\hline
\end{tabular}


Table 4.4. Participants' treatment adherence by anxiety level

Treatment

adherence

Adherence*

$* p<.05$ $p$ value

High

$53.11 \pm 7.96 \quad 50.15 \pm 9.04$

.011

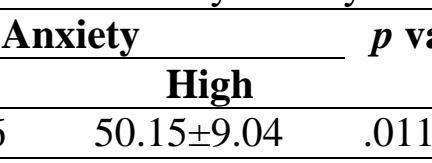


Table 4.5. Correlation between anxiety, adherence, perceived stigma, and coping

\begin{tabular}{|c|c|c|c|c|c|c|c|c|}
\hline & 1 & 2 & 3 & 4 & 5 & 6 & 7 & 8 \\
\hline 1. Anxiety & --- & & & & & & & \\
\hline 2. Adherence & $-.141 *$ & --- & & & & & & \\
\hline 3.Personal view & .079 & -.08 & --- & & & & & \\
\hline 4.Public view & $.132 *$ & -.081 & $.562 * *$ & --- & & & & \\
\hline 5. Perceived stigma & $.123^{*}$ & -.093 & $.850 * *$ & $.912 * *$ & --- & & & \\
\hline 6. Adaptive coping & .048 & -.025 & $-.324 * *$ & $-.271 * *$ & $-.333 * *$ & --- & & \\
\hline 7. Maladaptive coping & $.398 * *$ & $-.129 *$ & -.101 & -0.051 & -0.083 & $.632 * *$ & --- & \\
\hline 8. Total coping & $-.167 * *$ & .041 & $.182^{* *}$ & $.148 *$ & $.184 * *$ & $-.586 * *$ & $-.542 * *$ & --- \\
\hline
\end{tabular}


Figure 4.1. Path diagram to describe the interrelationship between HIV related stigma, maladaptive coping, anxiety, and HIV treatment adherence

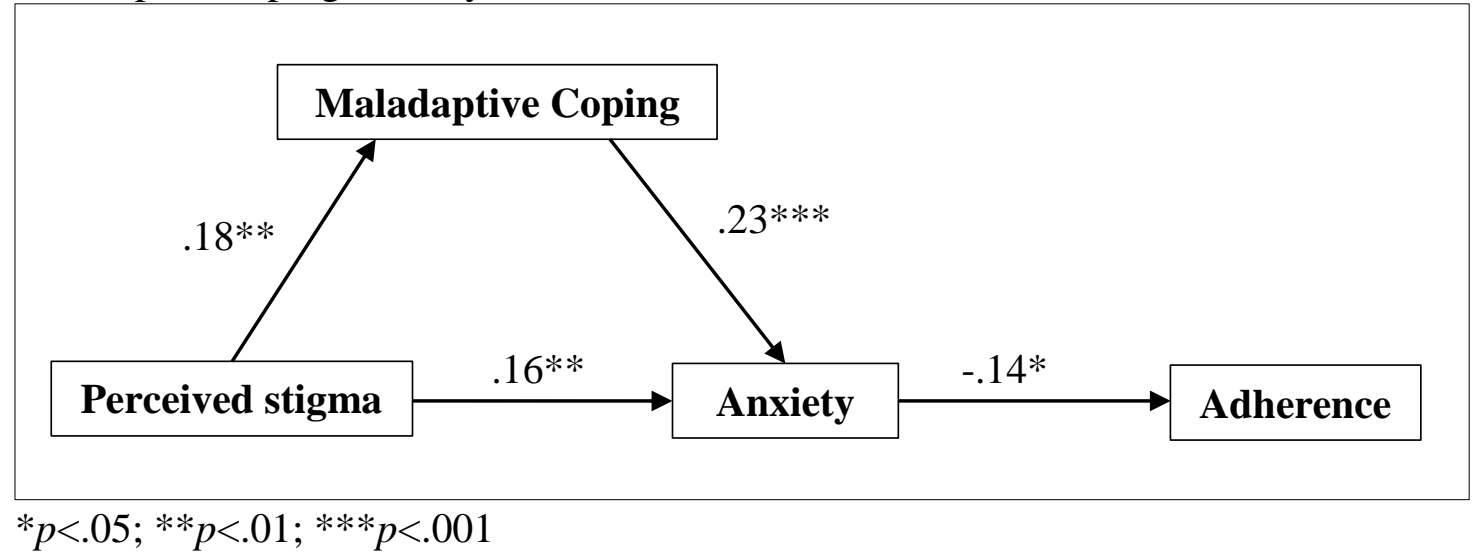




\section{References}

Addolorato, G., Ancona, C., Capristo, E., Graziosetto, R., Di Rienzo, L., Maurizi, M., \& Gasbarrini, G. (1999). State and trait anxiety in women affected by allergic and vasomotor rhinitis. Journal of Psychosomatic Research, 46(3), 283-289.

Ammassari, A., Murri, R., Pezzotti, P., Trotta, M. P., Ravasio, L., De Longis, P., ... Nappa, S. (2001). Self-reported symptoms and medication side effects influence adherence to highly active antiretroviral therapy in persons with HIV infection. JAIDS Journal of Acquired Immune Deficiency Syndromes, 28(5), 445-449.

Bauman, L., Camacho, S., Westbrook, L., \& Forbes-Jones, E. (1997). Correlates of personal stigma and social stigma among mothers with HIV/AIDS. Paper presented at the National Conference on Women and HIV, Pasadena, CA.

Bauman, L., Silver, E., \& Camacho, S. (2000, July). Stigma among mothers with HIV/AIDS. Paper presented at the XIII International AIDS Conference, Durban, South Africa.

Carver, C. S. (1997). You want to measure coping but your protocol's too long: Consider the Brief COPE. International Journal of Behavioral Medicine, 4(2), 92-100.

Chida, Y., \& Vedhara, K. (2009). Adverse psychosocial factors predict poorer prognosis in HIV disease: a meta-analytic review of prospective investigations. Brain, Behavior, and Immunity, 23(4), 434-445.

Campos, L. N., Guimarães, M. D. C., \& Remien, R. H. (2010). Anxiety and depression symptoms as risk factors for non-adherence to antiretroviral therapy in Brazil. AIDS and Behavior, 14(2), 289-299.

Dévieux, J. G., Malow, R. M., Attonito, J. M., Jean-Gilles, M., Rosenberg, R., Gaston, S., ... Deschamps, M. M. (2013). Post-traumatic stress disorder symptomatology and alcohol use among HIV-seropositive adults in Haiti. AIDS care, 25(10), 12101218 .

Earnshaw, V. A., \& Chaudoir, S. R. (2009). From conceptualizing to measuring HIV stigma: a review of HIV stigma mechanism measures. AIDS and Behavior, 13(6), 1160-1177.

Earnshaw, V. A., Smith, L. R., Chaudoir, S. R., Amico, K. R., \& Copenhaver, M. M. (2013). HIV stigma mechanisms and well-being among PLWH: a test of the HIV stigma framework. AIDS and Behavior, 17(5), 1785-1795.

Folkman, S. (1997). Positive psychological states and coping with severe stress. Soc. Sci. Med. 45(8): 1207-1221. 
Gonzalez, A., Solomon, S. E., Zvolensky, M. J., \& Miller, C. T. (2009). The interaction of mindful-based attention and awareness and disengagement coping with HIV/AIDS-related stigma in regard to concurrent anxiety and depressive symptoms among adults with HIV/AIDS. Journal of Health Psychology, 14(3), 403-413.

Gore-Felton, C., Ginzburg, K., Chartier, M., Gardner, W., Agnew-Blais, J., McGarvey, E., ... \& Koopman, C. (2013). Attachment style and coping in relation to posttraumatic stress disorder symptoms among adults living with HIV/AIDS. Journal of Behavioral Medicine, 36(1), 51-60.

Grimm, L. G., \& Yarnold, P. R. (2000). Reading and understanding MORE multivariate statistics. American psychological association.

Holzemer, W. L., Uys, L. R., Chirwa, M. L., Greeff, M., Makoae, L. N., Kohi, T. W., ... Wantland, D. (2007). Validation of the HIV/AIDS Stigma Instrument-PLWA (HASI-P). AIDS Care, 19(8), 1002-1012.

Houston, E., Sandfort, T. G., Watson, K. T., \& Caton, C. L. (2013). Psychological pathways from childhood sexual and physical abuse to HIV/sexually transmitted infection outcomes among homeless women: The role of posttraumatic stress disorder and borderline personality disorder symptoms. Journal of Health Psychology, 18(10), 1330-1340.

Jewkes, R. K., Dunkle, K., Nduna, M., \& Shai, N. (2010). Intimate partner violence, relationship power inequity, and incidence of HIV infection in young women in South Africa: a cohort study. The Lancet, 376(9734), 41-48.

Kagee, A., \& Martin, L. (2010). Symptoms of depression and anxiety among a sample of South African patients living with HIV. AIDS Care, 22(2), 159-165.

Kalichman, S. C., \& Grebler, T. (2010). Stress and poverty predictors of treatment adherence among people with low-literacy living with HIV/AIDS. Psychosomatic Medicine, 72(8), 810.

Kamen, C., Arganbright, J., Kienitz, E., Weller, M., Khaylis, A., Shenkman, T., ... GoreFelton, C. (2015). HIV-related stigma: implications for symptoms of anxiety and depression among Malawian women. African Journal of AIDS Research, 14(1), 67-73.

Katz, I. T., Ryu, A. E., Onuegbu, A. G., Psaros, C., Weiser, S. D., Bangsberg, D. R., \& Tsai, A. C. (2013). Impact of HIV-related stigma on treatment adherence: systematic review and meta-synthesis. Journal of the International AIDS Society, 16(3 Suppl 2):18640. 
Kemppainen, J. K., Holzemer, W. L., Nokes, K., Eller, L. S., Corless, I. B., Bunch, E. H., ... \& Chou, F. Y. (2003). Self-care management of anxiety and fear in HIV disease. Journal of the Association of Nurses in AIDS Care, 14(2), 21-29.

Kline, R. B. (1998). Principles and practice of structural equation modeling. New York: Guilford Press.

Knight, R. G., Waal-Manning, H. J., \& Spears, G. F. (1983). Some norms and reliability data for the State-Trait Anxiety Inventory and the Zung Self-Rating Depression scale. British Journal of Clinical Psychology, 22(4), 245-249.

Kobin, A. B., \& Sheth, N. U. (2011). Levels of adherence required for virologic suppression among newer antiretroviral medications. Annals of Pharmacotherapy, 45(3), 372-379.

Kotzé, M., Visser, M., Makin, J., Sikkema, K., \& Forsyth, B. (2013). Psychosocial variables associated with coping of HIV-positive women diagnosed during pregnancy. AIDS and Behavior, 17(2), 498-507.

Lazarus, R. S., \& Folkman, S. (1984). Stress, appraisal, and coping. New York, NY: Springer.

Mahajan, A. P., Sayles, J. N., Patel, V. A., Remien, R. H., Ortiz, D., Szekeres, G., \& Coates, T. J. (2008). Stigma in the HIV/AIDS epidemic: a review of the literature and recommendations for the way forward. AIDS (London, England), 22(Suppl 2), S67.

Mannheimer, S. B., Morse, E., Matts, J. P., Andrews, L., Child, C., Schmetter, B., ... Terry Beirn Community Programs for Clinical Research on AIDS. (2006). Sustained benefit from a long-term antiretroviral adherence intervention: results of a large randomized clinical trial. Journal of Acquired Immune Deficiency Syndromes, 43, S41-S47.

Mayston, R., Kinyanda, E., Chishinga, N., Prince, M., \& Patel, V. (2012). Mental disorder and the outcome of HIV/AIDS in low-income and middle-income countries: a systematic review. AIDS, 26, S117-S135.

McIntosh, R. C., \& Rosselli, M. (2012). Stress and coping in women living with HIV: a meta-analytic review. AIDS and Behavior, 16(8), 2144-2159.

McIntosh, R. C., \& Rosselli, M. (2012). Stress and coping in women living with HIV: a meta-analytic review. AIDS and Behavior, 16(8), 2144-2159. 
Morrison, S. D., Banushi, V. H., Sarnquist, C., Gashi, V. H., Osterberg, L., Maldonado, Y., \& Harxhi, A. (2011). Levels of self-reported depression and anxiety among HIV-positive patients in Albania: a cross-sectional study. Croatian Medical Journal, 52(5), 622-628.

Moskowitz, J. T., \& Wrubel, J. (2005). Coping with HIV as a chronic illness: Illness appraisals, coping, and well-being. Psychology and Health, 20, 509 -531.

Myer, L., Smit, J., Roux, L. L., Parker, S., Stein, D. J., \& Seedat, S. (2008). Common mental disorders among HIV-infected individuals in South Africa: prevalence, predictors, and validation of brief psychiatric rating scales. AIDS Patient Care and STDs, 22(2), 147-158.

Nachega, J. B., Marconi, V. C., van Zyl, G. U., Gardner, E. M., Preiser, W., Hong, S. Y., ... \& Gross, R. (2011). HIV treatment adherence, drug resistance, virologic failure: evolving concepts. Infectious Disorders-Drug Targets, 11(2), 167-174.

Nilsson Schönnesson, L., Williams, M. L., Ross, M. W., Bratt, G., \& Keel, B. (2007). Factors associated with suboptimal antiretroviral therapy adherence to dose, schedule, and dietary instructions. AIDS and Behavior, 11(2), 175-183.

O’Donnell, J. K., Pence, B. W., Williams, Q., Bengtson, A. M., Modi, R., Shirey, K., \& Gaynes, B. N. (2013). Coping style as a modifier of the relationship between severe life stressors and suicidal ideation among HIV-positive individuals with depression. Age, 45, 35-51.

Olley, B. O., Gxamza, F., Seedat, S., Theron, H., Stein, D. J., Taljaard, J., ... Reuter, H. (2015). Psychopathology and coping in recently diagnosed HIV/AIDS patientsthe role of gender. South African Journal of Psychiatry, 10(1), 4.

Orban, L. A., Stein, R., Koenig, L. J., Conner, L. C., Rexhouse, E. L., Lewis, J. V., \& LaGrange, R. (2010). Coping strategies of adolescents living with HIV: diseasespecific stressors and responses. AIDS Care, 22(4), 420-430.

Pakenham, K. I., \& Rinaldis, M. (2001). The role of illness, resources, appraisal, and coping strategies in adjustment to HIV/AIDS: The direct and buffering effects. Journal of Behavioral Medicine, 24(3), 259-279.

Parienti, J. J., Das-Douglas, M., Massari, V., Guzman, D., Deeks, S. G., Verdon, R., \& Bangsberg, D. R. (2008). Not all missed doses are the same: sustained NNRTI treatment interruptions predict HIV rebound at low-to-moderate adherence levels. PloS One, 3(7), e2783. 
Pence, B. W., Miller, W. C., Whetten, K., Eron, J. J., \& Gaynes, B. N. (2006). Prevalence of DSM-IV-defined mood, anxiety, and substance use disorders in an HIV clinic in the Southeastern United States. Journal of Acquired Immune Deficiency Syndromes, 42(3), 298-306.

Shuter, J., Sarlo, J. A., Kanmaz, T. J., Rode, R. A., \& Zingman, B. S. (2007). HIVinfected patients receiving lopinavir/ritonavir-based antiretroviral therapy achieve high rates of virologic suppression despite adherence rates less than $95 \%$. Journal of Acquired Immune Deficiency Syndromes, 45(1), 4-8.

Sinclair, V. G., \& Wallston, K. A. (2004). The development and psychometric evaluation of the Brief Resilient Coping Scale. Assessment, 11(1), 94-101.

Spielberger, R., Gorsuch, R., \& Lushene, R. (1970). Manual for the State-Trait Anxiety Inventory. Palo Alto, CA: Consulting Psychologists.

Springer, S. A., Dushaj, A., \& Azar, M. M. (2012). The impact of DSM-IV mental disorders on adherence to combination antiretroviral therapy among adult persons living with HIV/AIDS: a systematic review. AIDS and Behavior, 16(8), 21192143.

Storholm, E. D., Halkitis, P. N., Kupprat, S. A., Hampton, M. C., Palamar, J. J., BrennanIng, M., \& Karpiak, S. (2013). HIV-related stigma as a mediator of the relation between multiple-minority status and mental health burden in an aging HIVpositive population. Journal of HIV/AIDS \& Social Services, 12(1), 9-25.

Stutterheim, S. E., Bos, A. E., Pryor, J. B., Brands, R., Liebregts, M., \& Schaalma, H. P. (2011). Psychological and social correlates of HIV status disclosure: The significance of stigma visibility. AIDS Education and Prevention, 23(4), 382.

Terry Beirn Community Programs for Clinical Research on AIDS. (2003). Antiretroviral medication self-report: Form 646.

Varni, S. E., Miller, C. T., McCuin, T., \& Solomon, S. E. (2012). Disengagement and engagement coping with HIV/AIDS stigma and psychological well-being of people with HIV/AIDS. Journal of Social and Clinical Psychology, 31(2), 123.

Vranceanu, A. M., Safren, S. A., Lu, M., Coady, W. M., Skolnik, P. R., Rogers, W. H., \& Wilson, I. B. (2008). The relationship of post-traumatic stress disorder and depression to antiretroviral medication adherence in persons with HIV. AIDS Patient Care and STDs, 22(4), 313-321. 
Weiser, S. D., Palar, K., Frongillo, E. A., Tsai, A. C., \& Kumbakumba, E. (2014). Longitudinal assessment of associations between food insecurity, antiretroviral adherence and HIV treatment outcomes in rural Uganda. AIDS (London, England), 28(1), 115.

Westbrook, L., \& Bauman, L. (1996). The perceived stigma of AIDS: Personal view and public view scales. Bronx, NY: Albert Einstein College of Medicine.

Willie, T. C., Overstreet, N. M., Sullivan, T. P., Sikkema, K. J., \& Hansen, N. B. (2015). Barriers to HIV medication adherence: examining distinct anxiety and depression symptoms among women living with HIV who experienced childhood sexual abuse. Behavioral Medicine, 42(2), 120-127.

Yi, S., Chhoun, P., Suong, S., Thin, K., Brody, C., \& Tuot, S. (2015). AIDS-related stigma and mental disorders among people living with HIV: a cross-sectional study in Cambodia. PloS One, 10(3), e0121461. 


\section{CHAPTER V: Relationships between Depression, Social Support and HIV-Related Stigma in Alcohol Using PLWH in Haiti}

\section{Introduction}

It has long been recognized that people living with HIV (PLWH) face significant psychosocial challenges that often result in complex mental health problems (Mellins \& Malee, 2013; Petersen, et al., 2010; Tucker et al., 2004). Many studies on the health challenges faced by PLWH identify mental health problems as one of the most common comorbidities associated with HIV (Edmiston, Passmore, Smith, \& Petoumenos, 2015; Kendall et al., 2014). Among these, depression is the most widespread (Choi, 2013), affecting PLWH at a rate nearly double that of the general population (Ciesla \& Roberts, 2001). Even the presence of depressive symptoms that do not meet the clinical criteria for depressive disorders result in impaired immunological responses and higher mortality rates (Ironson et al., 2005).

One of the most significant risk factors for mental health problems (including depression) among PLWH includes HIV-related stigma. Stigma is a complex social process involving stereotyping, status loss, and discrimination (Mahajan et al., 2008). HIV-related stigma has been linked to the creation and maintenance of social inequalities, often along the lines of race, class, gender, and sexual orientation (Parker \& Aggleton, 2003). This is additionally complicated by stigmas related to drug useand homosexuality (Reidpath \& Chan, 2005). Several studies have shown that HIV-related stigma is more intense when compared to the stigmas associated with other illnesses such as herpes, cancer, tuberculosis etc. (Hatzenbuehler, Phelan \& Link, 2013; Breet, Kagee \& Seedat, 2014; Crawford, 1996). Research has consistently shown that higher levels of stigma are 
associated with lower levels of mental health in PLWH (Logie \& Gadall, 2009) and HIVrelated stigma is said to be one of the greatest barriers towards providing adequate support and treatment to PLWH (Aggleton, 2002).

When faced with situations of acute/ongoing stress or the challenges of stigma and discrimination, individuals engage in coping processes that include behavioral as well as psychological adaptations aimed at overcoming the stressors or challenges (Taylor \& Stanton, 2007). Among PLWH, stigma constitutes an important cause of stress, anxiety, panic and depression and PLWHs are exposed and forced to cope with it. The notion of "resilience resources" was constructed to identify the modifiable and strength-based moderators that have effects on the coping mechanisms adopted by PLWH (Earnshaw et al., 2015). The characteristics associated with resilience may be both individual (e.g. self-esteem, personality traits, coping style, spirituality, etc.) and social (e.g. supportive peer networks, relationship and support from family, friends etc.; Zhang et al., 2015). Research, particularly among PLWH, consistently highlights the instrumental role played by social support in both physical and mental health outcomes (Degroote, Vogelaers, \& Vandijck, 2014). Studies show that social support is particularly effective in coping with depression, improving treatment adherence, and retention in treatment facilities (Yeji et al., 2014). PLWH with greater access to social support systems experience less stigma-related stress which may ultimately protect them from adverse HIV symptoms (Earnshaw, 2015). Evidently, more research is needed to better understand the relationships and interactions between these core aspects of HIV-related stigma, social support and depression. 
The current study aims to understand the relationship between depression, social support and HIV-related stigma in a sample of HIV positive alcohol users living in resource limited settings such as Haiti. Studying the interrelationships between these variables will allow a greater understanding of the role played by each of these variables in influencing the health care outcomes in PLWH.

\section{Methods}

\section{Study Design and Population}

The current study was a secondary analyses of data from the parent study entitled, “Intervening with Haitian HIV Positive Alcohol Users: An Environmental Psychosocial Framework." The parent study was a randomized controlled trial that examined the effectiveness of the adapted CBSM-A intervention in simultaneously reducing risk behaviors, improving ART adherence and mood. Participants were provided with information on HIV disease and its treatment, including currently available ART medications, the negative effects of substance use and high-risk sexual behavior on the immune system and health status, and the nature of stress and coping responses and resources. The skill building aspects of the parent study included: teaching anxiety reduction skills such as progressive muscle relaxation, relaxing imagery and autogenics; modifying maladaptive cognitive appraisals using cognitive restructuring; enhancing interpersonal conflict resolution skills and anger expression via anger management and assertion training; and providing a supportive group environment and increase utilization of social support networks. Data collection for the parent study occurred at the GHESKIO (Groupe Haitien d'Etude du Sarcome de Kaposi et des Infections Opportunistes) Centers in Port-au-Prince, Haiti. The CBSM-A intervention was designed 
to include a combination of problem-focused (e.g., active coping and planning) and emotion-focused (e.g., relaxation training, seeking emotional support) coping strategies.

The parent study included participants who were: between 18 and 60 years of age; fluent in spoken Haitian Creole; documented HIV seropositivity; reported at least one episode of unprotected anal or vaginal sex in the past 90 days; reported recent alcohol consumption; were not cognitively impaired at the time of recruitment; and did not show symptoms of any major psychiatric disorder. The current study included subjects who participated in baseline assessments before the beginning of randomization and interventional follow-up visits. The institutional review board (IRB) at Florida International University approved this secondary analyses study in September, 2015.

\section{Measures}

\section{Cognitive and Affective Symptoms of Depression}

The Centers for Epidemiological Studies Depression Scale (CES-D) is a 20-item questionnaire that assesses symptoms of depression over the past seven days (Radloff \& Locke, 1986; see Appendix III). The somatic depression items in the CES-D overlap with HIV-related symptoms (Kalichman, Rompa, \& Cage, 2000). The parent study administered only 15 questions which measured cognitive and affective symptoms of depression in order to limit confounding between somatic depression variables and HIV disease-related symptoms. Somatic depression questions such as restless sleep, anorexia, lack of energy, fatigue, and poor concentration were not included in the parent study. The resulting 15-item questionnaire measured mood related and attitudinal aspects of depression. Because the questionnaire was truncated to only 15 items, the original scale could not be applied to the parent study or current study and the scale was re-categorized 
based on mean and standard deviation. Subjects were categorized as affectively depressed if they scored greater than one SD above the mean total scores on mood related and attitudinal aspects of depression. Cronbach's alpha of the instrument was 0.749 .

\section{Stigma of HIV/AIDS}

HIV/AIDS-related stigma was measured using the Perceived Stigma of HIV/AIDS scale (Bauman, Camacho, Westbrook, \& Forbes-Jones, 1997; Bauman, Silver, \& Camacho, 2000; Westbrook \& Bauman, 1996; see Appendix I). This scale measures stigma in terms of two components - internalized stigma and externalized stigma. In order to measure these two parameters, the questionnaire includes two subsections - personal view and public view. The personal view subscale includes questions related to shame, guilt, blame, embarrassment, and poor self-worth due to HIV. The public view subscale includes questions related to participant's perception about social stigma, for example, what the respondent thinks about other people's attitudes and beliefs towards his/her disease condition. The questions in the subscales are both positively and negatively phrased to increase the specificity of the responses. Both subscales have 24 questions measured by four-point Likert-type scale $(1=$ strongly agree to $4=$ strongly disagree). The total score of each subscale ranges between 24 and 96 and higher scores represent higher levels of personal or public stigma. Cronbach's alpha of the instrument was 0.867 .

\section{Social Support}

Modified Medical Outcome Study Social Support Survey (mMOS-SSS) was used to assess the levels of social support received by the participants (Sherbourne \& Stewart, 1991; see Appendix VI). The mMOS-SSS questionnaire was developed to measure 
medical outcome in the year 1991 and reported good internal validity (Cronbach's alpha of the instrument was 0.787 ). This questionnaire includes an 8-item survey of perceived availability of social support and includes two subscales - emotional/informational social support and tangible/instrumental social support. The emotional/informational social support subscale measures empathy, love, trust and caring received by the participants. The tangible/instrumental social support subscale measures tangible benefits and services received by the participants. Each of the two subscales are measured in terms of a 5-point scale $(1=$ None of the time, $2=$ A little of the time, $3=$ Some of the time, $4=$ Most of the time, and $5=$ All of the time) and the total scores range from 8 to 40 and higher scores represents higher levels of social support.

\section{Data Analyses}

IBM SPSS Statistics (Version 23) and IBM SPSS Analysis of Moment Structures (AMOS; Version 23) were used for data analysis (Armonk, NY: IBM Corp.). Frequencies, means, standard deviations, t tests, chi-square tests and Fisher's exact tests were used to describe the demographic characteristics. Independent samples t tests were used to compare perceived stigma and social support variables between depressed and non-depressed participants. Pearson correlations were used to find associations between perceived stigma, depression, and social support variables. Multivariable linear regressions were used to estimate the predictors of depression with demographics, stigma and social support as independent variables. In the regressions analysis, crude models were initially used and subsequently adjusted for associated covariates. The covariates were also tested for significant associations with the outcome variable using bivariate analysis before being incorporated into the final model. To increase the validity of the 
model, multicollinearity among covariates was tested prior to regression analyses. Adjusted models included non-missing values for all independent variables included in the models. Structural equation modeling (SEM) was used to test the hypothesis whether the relationship between HIV-related stigma and depression was mediated by social support variables. SEM accounts for multiple interactive relationships and variances and explores for directional associations between them leading to delineation of the mediators (Grimm \& Yarnold, 2000; Kline, 1998). Maximum-likelihood estimation methods were used for AMOS modules in the analyses. Statistical significance was set at $p<0.05$ for all the analyses.

\section{Results}

\section{Demographic and socio-economic characteristics}

A total of 362 participants were included in the secondary analyses and 135 (37.0\%) were men (Table 1). The mean age of the sample was 35.72 $\pm 8.50(\mathrm{Mean} \pm \mathrm{SD})$ years. Approximately $61 \%$ of the participants had a $6^{\text {th }}$ grade or less education. About $58 \%$ reported that they were married and about $59.7 \%$ were unemployed. The majority of the participants reported having primary care physicians (89.0\%). Except for age, there were no significant differences in other socio-demographic variables between depressed and non-depressed participants.

\section{Stigma and depression}

Depressed participants reported higher levels of perceived stigma than nondepressed participants $(p=.034$; Table 2). Similarly, depressed participants reported higher levels of perceived stigma-public view than non-depressed participants $(p=.039)$. 
However, there were no significant differences in perceived stigma-personal view between depressed and non-depressed participants.

\section{Social Support and depression}

Depressed participants reported lower levels of both components of social support as well as total social support (emotional/informational social support, $p=.002$; tangible/instrumental social support, $p=.000$; and total social support, $p=.000$; Table 3 ).

\section{Relationships Between Perceived Stigma, Depression, and Social Support}

Significant positive correlations were observed between depression, and total social support $(r=-0.199, p<0.01)$, emotional/informational social support $(r=-0.162, p$ $<0.01)$, and tangible/informational social support $(\mathrm{r}=-0.189, \mathrm{p}<0.01)$. Significant negative correlations were observed between depression and perceived stigma-public view $(\mathrm{r}=0.104, \mathrm{p}<0.05 ;$ Table 4).

\section{Predictors of HIV treatment adherence}

In the adjusted multivariable linear regression model, being female (Beta $=3.076$, $p=.001)$, having lower tangible/informational social support $($ Beta $=-0.309, p=.020)$, and having higher perceived stigma-public view (Beta $=1.877, p=.037$ ) were significantly associated with higher levels of depression. The beta estimates and standard errors for each of the predictors are presented in Table 5.

\section{Mediation analysis}

In the mediation analysis, coefficients for all the variables including perceived stigma-personal view, perceived stigma-public view, emotional/informational social support, tangible/informational social support, and depression were estimated simultaneously. However, no significant associations were found between these variables 
in our mediator analyses. Figure 1 shows the path diagram for the variables which showed significance in the regression analyses. In this model, there were significant associations between perceived stigma-public view and depression $($ Beta $=2.398, p=$ $.021)$ and tangible/informational social support and depression (Beta $=-0.412, p=.000$ ). However, there were no associations between perceived stigma-public view and tangible/informational social support $($ Beta $=0.023, p=.531)$. These findings suggest that the effect of stigma on HIV treatment adherence is not mediated by social support.

\section{Discussion}

Similar to many other populations, Haitian PLWH are exposed to challenges such as limited social support, HIV-related stigma, and mental health problems (Vanable et al., 2006). While these challenges are often addressed independently in many studies, our study is unique in integrating these complex variables. Our results show that perceived stigma-public view and tangible social support were significant predictors of depressive symptoms. Mediation analyses, however, showed that tangible social support did not act as a mediator between perceived stigma-public view and depressive symptoms. This could be due to the stronger effects of perceived stigma-public view on depressive symptoms. Social support could not alleviate the effect of stigma on depressive symptoms.

About $45.6 \%$ of our participants reported depressive symptoms and was slightly greater than the prevalence (41.7\%) reported in the Haitian general population (Wagenaar, 2012). Supporting the findings in our study, many other studies have reported higher levels of clinical depression in PLWH. For example, in a study done by Nakasujja et al. (2010) among PLWH in Uganda, about 53.9\% reported higher levels of depressive 
symptoms (CES-D scores $\geq 16$ ). Similarly, in a study done among Kenyan PLWH, Monahan et al. (2009) found that about 34\% of PLWH reported some form of depressive disorders.

A significant number of our participants (47.8\%) reported experiencing high levels of perceived stigma. A number of studies have reported that PLWH experience significant levels of perceived stigma. For example, in a study done by Kalichman et al. (2005) among 2,306 South African PLWH, 27\% believed that they were dirty, 38\% reported being ashamed of their condition, and $41 \%$ felt guilty of having acquired HIV. Similarly, in a Ugandan study, high levels of stigma were reported by PLWH and the levels of stigma increased over time (Chan et al., 2015).

Our study found that being female, having higher perceived stigma-public view and lower tangible social support were associated with higher levels of depression. Consistent with other studies, PLWH in our study who perceived being more stigmatized reported higher levels depressive symptoms (Berger et al., 2001; Lee et al., 2002). The strong associations between perceived stigma-public view and depressive symptoms highlight the prominent role played by self-perceived stigma in aggravating mental health problems. Depression is characterized by a negative pattern of thinking, in which unfortunate events are associated with personal faults (for example, something bad happened to me because of my own mistake), and positive events are believed to be governed by extracorporeal forces (for example, something good happened to me because of sheer luck). Internalized stigma reinforces depressive feelings because it characterizes similar conceptualizations wherein unfortunate events are associated with personal faults 
(for example, one deserves to be the target of prejudice because one possesses the discriminatory negative attribute; Peterson, 1988; Peterson, Seligman, \& Vaillant, 1988). In our study, tangible/instrumental social support significantly and negatively predicted depressive symptoms. Tangible/instrumental social support can range from making a meal for someone to driving that person to the doctor's office. In some situations, individuals need material goods or tangible actions to help them overcome challenging circumstances (Sherbourne \& Stewart, 1991). Many other studies have highlighted the importance of tangible social support in chronic disease states. For example, in a randomized controlled trial done in Uganda, participants who received tangible/instrumental social support in terms of treatment support personnel had 4 times higher odds of achieving optimum HIV treatment adherence when compared to those without support personnel (Kunutsor, 2011). Similarly, many studies have documented a direct relationship between tangible/instrumental social support and increased adherence to ART (Gonzalez et al., 2004, Ulett et al., 2009 and Vyavaharkar et al., 2010). However, similar studies associating the effects of tangible/instrumental social support in alleviating the effects of depressive symptoms in PLWH are sparse. Nevertheless, many studies exist about the beneficial effects of total social support (encompassing emotional/informational and tangible/instrumental social support) in minimizing psychological stressors in PLWH. For example, social support is particularly important in women because they rely on social interactions and acquaintances for reliving their stressors (Hurdle, 2001). Many studies also report inverse associations between total social support and depression in PLWH (Catz, Gore-Felton, \& McClure, 2002;

McDowell \& Serovich, 2007). However, in our study, though there were inverse and 
beneficial associations between tangible/instrumental social support and depression, similar findings were not evident for emotional/informational arm of the social support variable.

In the current study, men relied less on social support and reported lower levels of depressive symptoms when compared to women. This is consistent with abundant literature on gender differences in the prevalence of depression as well as the coping mechanisms. Women generally tend to have greater depression levels and rely more on social support for coping with their stressors. For example, in a review about gender differences in depression, Nolen-Hoeksema (2001) reported that women in general were twice as likely to suffer from depression when compared to men, irrespective of nationalities, cultural affiliations and ethnicities. In a Rwandan study on female PLWH, women with HIV reported extremely high prevalence (81\%) of depressive disorders (Cohen, 2011). Nolen-Hoeksema et al. (1999) proposed the Response Style Theory (RST), wherein women were more likely to ruminate in response to dysphoric or depressive moods, reinforcing the negative spiral of acute and chronic depressive states. Men on the contrary adopt distraction techniques to cope with depressed or dysphoric states thereby overcoming it. These inherent gender differences in coping mechanisms has been proposed as one of the reasons for greater prevalence of depressive disorders in females. This could also be the reason why social support mechanisms are more relied upon by women as a means of distraction to overcome their depressed states. However, studies have also suggested that men resort to harmful distractions such as substance use, risky sexual behaviors and risk seeking behaviors to overcome their dysphoric states (McBride \& Bagby, 2006). 
Irrespective of the significant findings in the study, there are some limitations. The parent study enrolled a consecutive convenience sample of PLWH attending the GHESKIO centers in Haiti. This sample of frequent health care users could be significantly different from the general population of PLWH in Haiti. As the parent study did not employ a random sampling technique for selecting participants from the total population of PLWH in Haiti, the findings in the current study are not generalizable, thereby limiting the external validity. The current study constituted a secondary analyses of variables collected for the parent study. This could be responsible for some surrogate information biases in the current study. This study was a cross-sectional analyses of baseline data collected for the parent study. Because of the cross-sectional nature of the study, only associations could be derived and causal relationships could not be established. Furthermore, this study did not have an HIV-negative comparison group to eliminate the effects of confounders influencing the relationship between independent and outcome variables in the study.

\section{Conclusion}

Our results suggest that comprehensive care for PLWH in Haiti should consider the relationship between intrapersonal (e.g. depression, stigma) and interpersonal (i.e., social support) variables. Such efforts should also encompass gender-based adaptations to account for the higher prevalence of depression in female PLWH. Our findings also suggest that improving social support and reducing stigma could be very useful in decreasing the prevalence as well as the adverse effects of depressive disorders in PLWH. Such multilevel efforts incorporating many interrelated constructs could bring significant changes in health status and general well-being of Haitian PLWH. 


\section{Acknowledgements}

I would like to thank Dr. Jessy G. Dévieux, my major professor, for providing access to the parent study data repository, as well as her entire research group especially Dr. Michele Jean-Gilles for heling me extracting the data. I would also like to thank Dr. H. Virginia McCoy, Dr. Consuelo M. Beck-Sagué, and Dr. Florence George for the intellectual content of this manuscript. I acknowledge the valuable support provided by the University Graduate School, Florida International University, in terms of Doctoral Year Fellowship. Above all, I am very grateful to the GHESKIO Centers, Port-au-Prince, Haiti, who collaborated enthusiastically for this project. 
Table 5.1. Demographic characteristics of the participants

\begin{tabular}{|c|c|c|c|c|}
\hline \multirow[t]{2}{*}{ Characteristics } & \multicolumn{2}{|c|}{$\begin{array}{l}\text { Mood related and attitudinal } \\
\text { depression }\end{array}$} & \multirow[t]{2}{*}{$\begin{array}{c}p \\
\text { value }\end{array}$} & \multirow{2}{*}{$\begin{array}{c}\text { Total } \\
(\mathrm{n}=362, \\
100 \%)\end{array}$} \\
\hline & $\begin{array}{c}\text { Non-depressed } \\
(\mathrm{n}=197, \\
\mathbf{5 4 . 4 \%})\end{array}$ & $\begin{array}{c}\text { Depressed } \\
(\mathbf{n = 1 6 5}, \\
\mathbf{4 5 . 6 \%})\end{array}$ & & \\
\hline Age & $35.92 \pm 8.36$ & $35.48 \pm 8.68$ & .629 & $35.72 \pm 8.50$ \\
\hline Gender** & & & .008 & \\
\hline Male & $85(43.1 \%)$ & $49(29.7 \%)$ & & $\begin{array}{l}135 \\
(37.0 \%)\end{array}$ \\
\hline Female & $112(56.9 \%)$ & $116(70.3 \%)$ & & $\begin{array}{l}228 \\
(63.0 \%)\end{array}$ \\
\hline Education & & & .074 & \\
\hline $6^{\text {th }}$ grade or less & $112(56.9 \%)$ & $109(66.1 \%)$ & & $\begin{array}{l}221 \\
(61.0 \%)\end{array}$ \\
\hline $\begin{array}{l}\text { Some high school or } \\
\text { higher }\end{array}$ & $85(43.1 \%)$ & $56(33.9 \%)$ & & $\begin{array}{l}141 \\
(39.0 \%)\end{array}$ \\
\hline Marital status & & & .221 & \\
\hline $\begin{array}{l}\text { Single or living as } \\
\text { single }\end{array}$ & $77(39.1 \%)$ & $75(45.5 \%)$ & & $\begin{array}{l}152 \\
(42.0 \%)\end{array}$ \\
\hline Married & $120(60.9 \%)$ & $90(54.5 \%)$ & & $\begin{array}{l}210 \\
(58.0 \%)\end{array}$ \\
\hline Employment & & & .110 & \\
\hline Full time job & $3(3.1 \%)$ & $2(1.9 \%)$ & & $5(2.5 \%)$ \\
\hline Seasonal job & $24(24.5 \%)$ & $22(21.4 \%)$ & & $46(22.9 \%)$ \\
\hline Unemployed & $52(53.1 \%)$ & $68(66.0 \%)$ & & $\begin{array}{l}120 \\
(59.7 \%)\end{array}$ \\
\hline Student & $5(5.1 \%)$ & $0(0 \%)$ & & $5(2.5 \%)$ \\
\hline Incapacitated & $0(0 \%)$ & $1(1.0 \%)$ & & $1(0.5 \%)$ \\
\hline Other & $14(14.3 \%)$ & $10(9.7 \%)$ & & $24(11.9 \%)$ \\
\hline Income & & & .807 & \\
\hline$<\$ 150$ & $27(28.1 \%)$ & $17(27.4 \%)$ & & $44(27.8 \%)$ \\
\hline$\$ 151-1,000$ & $38(39.6 \%)$ & $22(35.5 \%)$ & & $60(38.0 \%)$ \\
\hline$>\$ 1,000$ & $31(32.3 \%)$ & $23(37.1 \%)$ & & $54(34.2 \%)$ \\
\hline Primary care & & & .452 & \\
\hline Yes & $173(87.8 \%)$ & $149(90.3 \%)$ & & $\begin{array}{l}322 \\
(89.0 \%)\end{array}$ \\
\hline No & $24(12.2 \%)$ & $16(9.7 \%)$ & & $40(11.0 \%)$ \\
\hline
\end{tabular}

Note: $P$ value corresponds to independent samples t test, chi-square test or Fisher's exact test

${ }^{*} p<.05 ; * * p<.01 ; * * * p<.001$ 
Table 5.2. Comparison of perceived stigma by mood related and attitudinal depression among participants

\begin{tabular}{|c|c|c|c|c|}
\hline \multirow[t]{2}{*}{ Perceived stigma } & \multicolumn{2}{|c|}{$\begin{array}{c}\text { Mood related and attitudinal } \\
\text { depression }\end{array}$} & \multirow[t]{2}{*}{$p$ value } & \multirow[t]{2}{*}{ Total } \\
\hline & Non-depressed & Depressed & & \\
\hline Personal view & $53.75 \pm 7.89$ & $55.17 \pm 8.25$ & .095 & $54.39 \pm 8.07$ \\
\hline Public view* & $52.76 \pm 9.97$ & $55.02 \pm 10.77$ & .039 & $53.79 \pm 10.38$ \\
\hline Total* & $106.51 \pm 15.80$ & $110.19 \pm 17.16$ & .034 & $108.18 \pm 16.51$ \\
\hline
\end{tabular}

$* p<.05 ; * * p<.01 ; * * * p<.001$ 
Table 5.3. Comparison of social support by mood related and attitudinal depression among participants

\begin{tabular}{|c|c|c|c|c|}
\hline \multirow[t]{2}{*}{ Social support } & \multicolumn{2}{|c|}{$\begin{array}{c}\text { Mood related and attitudinal } \\
\text { depression }\end{array}$} & \multirow[t]{2}{*}{$p$ value } & \multirow[t]{2}{*}{ Total } \\
\hline & Non-depressed & Depressed & & \\
\hline $\begin{array}{l}\text { Emotional/informational } \\
\text { support** }\end{array}$ & $12.88 \pm 3.80$ & $11.52 \pm 4.48$ & .002 & $12.26 \pm 4.17$ \\
\hline Tangible support*** & $11.61 \pm 3.51$ & $10.01 \pm 3.83$ & .000 & $10.88 \pm 3.74$ \\
\hline Total $* * *$ & $24.50 \pm 6.22$ & $21.53 \pm 7.42$ & .000 & $23.14 \pm 6.94$ \\
\hline
\end{tabular}


Table 5.4. Correlations among perceived stigma, depression, social support and demographic characteristics

\begin{tabular}{llllllll}
\hline & $\mathbf{1}$ & $\mathbf{2}$ & $\mathbf{3}$ & $\mathbf{4}$ & $\mathbf{5}$ & $\mathbf{6}$ & $\mathbf{7}$ \\
\hline 1.Depression & --- & & & & & & \\
2.Perceived stigma & .085 & --- & & & & \\
3. Personal view & .039 & $.862 * *$ & --- & & & \\
4.Public view & $.104 *$ & $.919 * *$ & $.594 * *$ & --- & & \\
5. Social support & $-.199 * *$ & -.077 & -.058 & -.077 & --- & \\
$\begin{array}{l}\text { 6. Emotional/ } \\
\quad \text { informational }\end{array}$ & $-.162 * *$ & -.103 & -.071 & $-.108 *$ & $.891 * *$ & --- \\
$\quad$ support & & & & & & & \\
7. Tangible support & $-.189 * *$ & -.028 & -.028 & -.022 & $.862 * *$ & $.537 * *$ & --- \\
\hline$* p<.05 ; * * p<.01 ; * * * p<.001$ & & & & & &
\end{tabular}


Table 5.5. Multivariable linear regression predicting depression

\begin{tabular}{lllll}
\hline Independent variables & Estimate & $\begin{array}{c}\text { Standard } \\
\text { error }\end{array}$ & Beta & $\boldsymbol{p}$ value \\
\hline Age & .053 & .051 & .055 & .302 \\
Sex** & 3.076 & .907 & .182 & .001 \\
Education & -1.351 & .878 & -.081 & .125 \\
Marital status & -.394 & .856 & -.024 & .645 \\
Primary care physician & -.390 & 1.323 & -.015 & .769 \\
Emotional/informational & -.124 & .118 & -.063 & .295 \\
support & & & & \\
Tangible support* & -.309 & .132 & -.142 & .020 \\
Personal view & .191 & .884 & .012 & .829 \\
Public view* & 1.877 & .898 & .115 & .037 \\
\hline
\end{tabular}

$* p<.05 ; * * p<.01 ; * * * p<.001$

Adjusted R-squared value $=.26$ 
Figure 5.1. Path diagram to describe the interrelationship between HIV related stigma, social support and depression

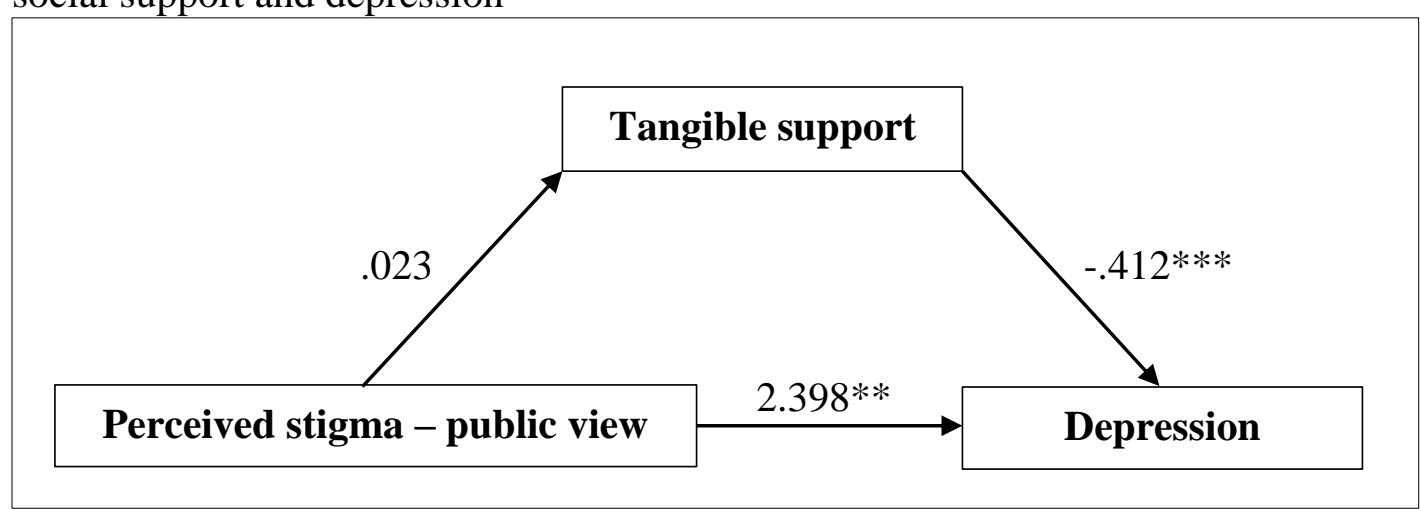

${ }^{*} p<.05 ; * * p<.01 ; * * * p<.001$ 


\section{References}

Aggleton, P., \& Parker, R. (2002). World AIDS Campaign 2002-3. A Conceptual Framework and Basis for Action. HIV/AIDS Stigma and Discrimination. UNAIDS, Geneva, Switzerland.

Bauman, L., Camacho, S., Westbrook, L., \& Forbes-Jones, E. (1997). Correlates of personal stigma and social stigma among mothers with HIV/AIDS. Paper presented at the National Conference on Women and HIV, Pasadena, CA.

Bauman, L., Silver, E., \& Camacho, S. (July, 2000). Stigma among mothers with HIV/AIDS. Paper presented at the XIII International AIDS Conference, Durban, South Africa.

Berger, B. E., Ferrans, C. E., \& Lashley, F. R. (2001). Measuring stigma in people with HIV: Psychometric assessment of the HIV stigma scale. Research in Nursing \& Health, 24, 518-529.

Breet, E., Kagee, A., \& Seedat, S. (2014). HIV-related stigma and symptoms of posttraumatic stress disorder and depression in HIV-infected individuals: does social support play a mediating or moderating role? AIDS Care, 26(8), 947-951.

Catz, S. L., Gore-Felton, C., \& McClure, J. B. (2002). Psychological distress among minority and low-income women living with HIV. Behavioral Medicine, 28(2), 53-60.

Chan, B. T., Weiser, S. D., Boum, Y., Siedner, M. J., Mocello, A. R., Haberer, J. E., ... Tsai, A. C. (2015). Persistent HIV-related stigma in rural Uganda during a period of increasing HIV incidence despite treatment expansion. AIDS (London, England), 29(1), 83-90.

Choi, J. Y. (2013). Mental health of HIV-infected patients: a severe, but overlooked problem. Infection \& Chemotherapy, 45(2), 239-240.

Ciesla, J. A., \& Roberts, J. E. (2001). Meta-analysis of the relationship between HIV infection and risk for depressive disorders. American Journal of Psychiatry, $158(5), 725-30$

Cohen, M. H., Fabri, M., Cai, X., Shi, Q., Hoover, D. R., Binagwaho, A., ... Anastos, K. (2009). Prevalence and predictors of posttraumatic stress disorder and depression in HIV-infected and at-risk Rwandan women. Journal of Women's Health, 18(11), 1783-1791.

Crawford, A. M. (1996). Stigma Associated with AIDS: A Meta-Analysis1. Journal of Applied Social Psychology, 26(5), 398-416. 
Degroote, S., Vogelaers, D., \& Vandijck, D. M. (2014). What determines health-related quality of life among people living with HIV: an updated review of the literature. Archives of Public Health, 72(1), 1-10.

Earnshaw, V. A., Lang, S. M., Lippitt, M., Jin, H., \& Chaudoir, S. R. (2015). HIV stigma and physical health symptoms: do social support, adaptive coping, and/or identity centrality act as resilience resources? AIDS and Behavior, 19(1), 41-49.

Gonzalez, J. S., Penedo, F. J., Antoni, M. H., Durán, R. E., McPherson-Baker, S., Ironson, G., ... \& Schneiderman, N. (2004). Social support, positive states of mind, and HIV treatment adherence in men and women living with HIV/AIDS. Health Psychology, 23(4), 413-418.

Grimm, L. G., \& Yarnold, P. R. (Eds.). (2000). Reading and understanding MORE multivariate statistics. Washington, DC: American Psychological Association.

Hatzenbuehler, M. L., Phelan, J. C., \& Link, B. G. (2013). Stigma as a fundamental cause of population health inequalities. American Journal of Public Health, 103(5), 813-821.

Hurdle, D. E. (2001). Social support: A critical factor in women's health and health promotion. Health and Social Work, 26(2), 72-79.

Ironson, G., O’Cleirigh, C., Fletcher, M. A., Laurenceau, J. P., Balbin, E., Klimas, N., ... Solomon, G. (2005). Psychosocial factors predict CD4 and viral load change in men and women with human immunodeficiency virus in the era of highly active antiretroviral treatment. Psychosomatic Medicine, 67(6), 1013-1021.

Lee, R. S., Kochman, A., \& Sikkema, K. J. (2002). Internalized stigma among people living with HIV-AIDS. AIDS and Behavior, 6(4), 309-319.

Kalichman, S. C., Rompa, D., \& Cage, M. (2000). Distinguishing between overlapping somatic symptoms of depression and HIV disease in people living with HIVAIDS. Journal of Nervous and Mental Diseases, 188, 662-670.

Kalichman, S. C., Simbayi, L., Jooste, S., Toefy, Y., Cain, D., Cherry, C., et al. (2005). Development of a brief scale to measure AIDS-related stigmas in South Africa. AIDS and Behavior, 9, 135-143.

Kline, R. B. (1998). Principles and practice of structural equation modeling. New York: Guilford Press. 
Kunutsor, S., Walley, J., Katabira, E., Muchuro, S., Balidawa, H., Namagala, E., \& Ikoona, E. (2011). Improving clinic attendance and adherence to antiretroviral therapy through a treatment supporter intervention in Uganda: a randomized controlled trial. AIDS and Behavior, 15(8), 1795-1802.

Logie, C., \& Gadalla, T. M. (2009). Meta-analysis of health and demographic correlates of stigma towards people living with HIV. AIDS Care, 21(6), 742-753.

Mahajan, A. P., Sayles, J. N., Patel, V. A., Remien, R. H., Ortiz, D., Szekeres, G., \& Coates, T. J. (2008). Stigma in the HIV/AIDS epidemic: a review of the literature and recommendations for the way forward. AIDS (London, England), 22(Suppl 2), S67-79.

McDowell, T. L., \& Serovich, J. M. (2007). The effect of perceived and actual social support on the mental health of HIV-positive persons. AIDS Care, 19(10), 12231229.

McBride, C., \& Bagby, R. M. (2006). Rumination and interpersonal dependency: Explaining women's vulnerability to depression. Canadian Psychology, 47(3), 184-194.

Mellins, C. A., \& Malee, K. M. (2013). Understanding the mental health of youth living with perinatal HIV infection: lessons learned and current challenges. Journal of the International AIDS Society, 16(1), 18593.

Monahan, P. O., Shacham, E., Reece, M., Kroenke, K., Ong'or, W. O., Omollo, O., ... Ojwang, C. (2009). Validity/reliability of PHQ-9 and PHQ-2 depression scales among adults living with HIV/AIDS in western Kenya. Journal of General Internal Medicine, 24(2), 189-197.

Nakasujja, N., Skolasky, R. L., Musisi, S., Allebeck, P., Robertson, K., Ronald, A., ... Sacktor, N. (2010). Depression symptoms and cognitive function among individuals with advanced HIV infection initiating HAART in Uganda. $B M C$ Psychiatry, 10(1), 1.

Nolen-Hoeksema, S., \& Davis, C. G. (1999). "Thanks for sharing that": ruminators and their social support networks. Journal of Personality and Social Psychology, 77(4), 801-814.

Nolen-Hoeksema, S. (2001). Gender differences in depression. Current Directions in Psychological Science, 10(5), 173-176.

Parker, R., \& Aggleton, P. (2003). HIV and AIDS-related stigma and discrimination: a conceptual framework and implications for action. Social Science \& Medicine, 57(1), 13-24. 
Peterson, C. (1988). Explanatory style as a risk factor for illness. Cognitive Therapy and Research, 12, 119-132.

Peterson, C., Seligman, M.E.P., \& Vaillant, G.E. (1988). Pessimistic explanatory style is a risk factor for physical illness: A thirty-five-year longitudinal study. Journal of Personality and Social Psychology, 55, 23-27.

Petersen, I., Bhana, A., Myeza, N., Alicea, S., John, S., Holst, H., ... Mellins, C. (2010). Psychosocial challenges and protective influences for socio-emotional coping of HIV+ adolescents in South Africa: a qualitative investigation. AIDS Care, 22(8), 970-978.

Radloff, L. S., \& Locke, B. Z. (1986). The community mental health assessment survey and CES-D Scale. In M. M. Weissman, J. K. Meyers, \& C. E. Ross (Eds.), Community Surveys of Psychiatric Disorders (pp. 177-187). New Brunswick, NJ: Rutgers University Press.

Reidpath, D. D., \& Chan, K. Y. (2005). A method for the quantitative analysis of the layering of HIV-related stigma. AIDS Care, 17(4), 425-432.

Sherbourne, C. D., \& Stewart, A. L. (1991). The MOS social support survey. Social Science \& Medicine, 32(6), 705-714.

Taylor, S. E., \& Stanton, A. L. (2007). Coping resources, coping processes, and mental health. Annu. Rev. Clin. Psychol., 3, 377-401.

Tucker, J. S., Orlando, M., Burnam, M. A., Sherbourne, C. D., Kung, F. Y., \& Gifford, A. L. (2004). Psychosocial mediators of antiretroviral nonadherence in HIVpositive adults with substance use and mental health problems. Health Psychology, 23(4), 363-70.

Ulett, K. B., Willig, J. H., Lin, H. Y., Routman, J. S., Abroms, S., Allison, J., ... Mugavero, M. J. (2009). The therapeutic implications of timely linkage and early retention in HIV care. AIDS Patient Care and STDs, 23(1), 41-49.

Vanable, P. A., Carey, M. P., Blair, D. C., \& Littlewood, R. A. (2006). Impact of HIVrelated stigma on health behaviors and psychological adjustment among HIVpositive men and women. AIDS and Behavior, 10(5), 473-482.

Vyavaharkar, M., Moneyham, L., Corwin, S., Saunders, R., Annang, L., \& Tavakoli, A. (2010). Relationships between stigma, social support, and depression in HIVinfected African American women living in the rural Southeastern United States. Journal of the Association of Nurses in AIDS Care, 21(2), 144-152. 
Wagenaar, B. H., Hagaman, A. K., Kaiser, B. N., McLean, K. E., \& Kohrt, B. A. (2012). Depression, suicidal ideation, and associated factors: a cross-sectional study in rural Haiti. BMC Psychiatry, 12(1), 1.

Westbrook, L., \& Bauman, L. (1996). The perceived stigma of AIDS: Personal view and public view scales. Bronx, NY: Albert Einstein College of Medicine.

Yeji, F., Klipstein-Grobusch, K., Newell, M. L., Hirschhorn, L. R., Hosegood, V., \& Bärnighausen, T. (2014). Are social support and HIV coping strategies associated with lower depression in adults on antiretroviral treatment? Evidence from rural KwaZulu-Natal, South Africa. AIDS Care, 26(12), 1482-1489.

Zhang, L., Li, X., Qiao, S., Zhou, Y., Shen, Z., Tang, Z., ... Stanton, B. (2015). The mediating role of individual resilience resources in stigma-health relationship among people living with HIV in Guangxi, China. AIDS Care, 27(10), 13171325 . 


\section{CHAPTER VI: Summary, Limitations and Future Extensions}

\section{Summary of the Study}

The present study was a secondary analyses of baseline data collected from a convenience sample of 389 alcohol using PLWH who attended the GHESKIO Centers in Port-au-Prince, Haiti. The parent study was a randomized controlled trial that evaluated the effectiveness of an adapted CBSM-A intervention. This secondary analyses examined the effects of HIV-related stigma on treatment adherence and how factors like depression, social support, coping, and anxiety mediated this relationship.

The mean age of the cohort was $35.72 \pm 8.50($ Mean $\pm \mathrm{SD})$ years. About $37.0 \%$ were male participants. About 59\% reported a 6th grade or less level of education. More than half of them were unemployed (59.2\%). Approximately $27 \%$ of the participants reported income less than $\$ 150$ per annum. These characteristics represent the general levels of poverty prevalent in Haiti (Farmer, 2006). Albeit, the majority of the participants reported having primary care physicians $(91.2 \%)$ strikingly higher than the health care characteristics of PLWH in Haiti (Peck et al., 2003). The mean treatment adherence was $93.1 \%$, and this included $100 \%$ adherence reported by $71.9 \%$ of the cohort. About $50.2 \%$ reported high levels of total perceived stigma, $47.2 \%$ reported high levels of perceived stigma-public view, and 48.7\% reported high levels of perceived stigma-personal view. About 58.1\% received high levels of tangible/informational social support and 53.9\% received high levels of emotional/informational social support. Slightly greater than half of all participants (51.1\%) reported high levels of total coping, 50.2\% reported high levels of adaptive coping, and 51.6\% reported high levels of maladaptive coping. About 
45.6\% reported clinical depression and $47.2 \%$ reported clinically significant symptoms for the state anxiety.

Significant positive correlations were observed between treatment adherence and satisfaction of quality of care scores $(p<0.01)$. Many studies have documented that treatment adherence is improved by increasing the quality of health care through higher levels of comprehensiveness, competence, continuity of care, consistency, and compassion demonstrated by the health care personnel during clinical encounters (Bristow, Chang, Ziogas \& Anton-Culver, 2013; Ratanawongsa et al., 2013; Williams \& Friedland, 1997). Higher levels of anxiety were associated with higher levels of total perceived stigma $(p<0.05)$, perceived stigma-public view $(p<0.05)$, and maladaptive coping $(p<0.01)$. Similar associations were observed in other studies where higher levels of anxiety and other psychiatric disorders were associated with higher levels of stigma and maladaptive coping mechanisms (Alonzo \& Reynolds, 1995; Gonzalez, Solomon, Zvolensky \& Miller, 2009; Varni, Miller, McCuin \& Solomon, 2012).

Significant negative correlations were observed between treatment adherence and total perceived stigma $(p<0.05)$, maladaptive coping $(p<0.05)$, and anxiety levels $(p$ $<0.05)$. Stigma, maladaptive coping, and anxiety levels have adversely affected treatment adherence in similar other studies (Katz et al., 2013). In the current study, we found that higher levels of perceived stigma-public view $(p<0.05)$, lower levels of total social support $(p<0.01)$, emotional/informational social support $(p<0.01)$ and tangible/informational social support $(p<0.01)$ were associated with higher levels of depression. In the adjusted multivariable linear regression model predicting depression, 
being female ( $p=.001)$, having lower tangible/informational social support $(p=.020)$, and having higher perceived stigma-public view $(p=.037)$ were significantly associated with higher levels of depression. In the adjusted multivariable linear regression model for predicting HIV treatment adherence, perceived stigma $(p=.031)$, showed significant negative associations with treatment adherence, whereas, satisfaction of quality of care scores $($ Beta $=.032, p=.041)$ showed positive association with treatment adherence. $\mathrm{A}$ number of studies have demonstrated the determinants of depression which include stigma, female gender, and lack of social support in several other populations (Simbayi et al., 2007; Li, Lee, Thammawijaya, Jiraphongsa \& Rotheram-Borus, 2009). In addition, studies have also documented that these factors adversely affected treatment adherence (Rintamaki, Davis, Skripkauskas, Bennett \& Wolf, 2006; Uthman, Magidson, Safren \& Nachega, 2014; Horvath et al., 2013).

In the mediation analysis looking for the mediator effects of maladaptive coping on the relationship between stigma and anxiety, there were significant associations between perceived sigma and coping (Beta $=.175, p=.003$ ), perceived sigma and anxiety $($ Beta $=.164, p=.005)$, coping and anxiety $($ Beta $=.229, p<.001)$, and anxiety and treatment adherence $($ Beta $=-.140, p=.018)$. These observations suggest that maladaptive coping acted as a mediator between stigma and anxiety levels which in turn had significant effects on treatment adherence. However, in the mediation analysis looking for the mediator effects of maladaptive coping on the relationship between HIVrelated stigma and treatment adherence, there were no significant mediator effects. Similarly, in the mediation analysis looking for the mediator effects of social support on 
the effects of stigma on depression, there were no significant mediator effects. The lack of mediating effects could be due to the limited variability associated with only using baseline data as well as participants using the GHESKIO Centers in Haiti. Further longitudinal studies could unfold these associations.

\section{Strengths and Limitations}

The greatest strength of our study is in filling the gap in literature on the associations between stigma, depression, anxiety, coping, social support and treatment adherence among PLWH in Haiti. For the first time, we identified that maladaptive coping mediated the relationship between stigma and anxiety in Haitian PLWH population. A number of associations were found in the study between outcome variables such as treatment adherence, depression and anxiety opening up newer hypothesis for further long term experimental studies in this population. The current study will serve as a link joining the findings in other studies applied to the Haitian PLWH population.

Irrespective of many salient findings, this study had certain limitations. The parent study recruited a convenience sample of HIV positive participants attending the GHESKIO Centers in Haiti. The parent study was a randomized controlled trial and had an experimental and control arm thereby eliminating this selection bias. However, the current study only cross-sectionally analyzed baseline data of the parent study and did not have a control group. This group of participants attended the GHESKIO Centers and complied with the rules and protocols of the parent study and did not absolutely represent the entire population of disadvantaged and resource poor HIV positive participants in 
Haiti. Thus, the results of the current study cannot be extrapolated to the entire population, thereby compromising some of its external validity.

This study included only participants reporting ART and did not include ART naive participants. Thus, the results observed in this dissertation cannot be generalized to the entire population of HIV positive individuals in Haiti, because only $53 \%$ of all HIV positive patients in Haiti receive ART (UNICEF, 2013). Longitudinal studies and clinical trials can establish causal relationships, whereas the current dissertation was a crosssectional study and enabled an examination of only existing associations at a point in time and causal associations could not be determined.

Data used for the current study were collected for the specific aims of the parent study and would not have absolutely complied with the specific aims of the current study. This could be responsible for some surrogate information biases in the current study. The variables that were collected in the parent study were secondarily analyzed and adjusted in the current study. There could be a number of other unaccounted factors affecting the outcome variables in the current study. However, the current study is a secondary analysis and the confounders cannot be estimated, thus limiting the results of the study.

The majority of the questionnaires including the CPCRA Antiretroviral Medication Self-Report questionnaire, Perceived Stigma of HIV/AIDS, STAI, Brief COPE, mMOS-SSS, and CES-D were self-reported questionnaires and therefore susceptible to memory and recall biases. These questionnaires are also susceptible to social desirability bias wherein the participants respond to the questions in a favorable and socially desirable ways. This bias interferes with the interpretation of average 
tendencies and individual differences. Such biases could decrease the internal validity of the study.

\section{Future Extensions}

PLWH often have complicated past histories including depression, anxiety, stigmatic experiences, and inadequate social support (Vyavaharkar et al, 2010; Charles et al., 2012). These factors can adversely affect treatment adherence, risk behaviors, and quality of life. Outcomes from this study may be informative in developing successful strategies for stigma, coping, anxiety and depression and planning effective interventions for improving treatment adherence in HIV positive populations. The findings in this study may significantly contribute towards fueling future research on the same topic. This cross-sectional analyses may serve as a basis for future large scale studies on the association between stigma and treatment adherence. Several other factors that could not be measured in this study can be progressively determined, measured and analyzed in future large scale longitudinal and randomized trials. Successive large scale research on this topic can help in stimulating empowerment programs and legislation, thereby empowering HIV-positive community against stigma and discrimination. Healthcare providers should be made aware that anxiety, depression, coping and stigma could act as barriers and should be addressed in any standard HIV care services. This can alleviate the already failing health conditions of these patients due to impoverishment and natural disasters and contribute to significant immune recuperation and general well-being. 


\section{References}

Alonzo, A. A., \& Reynolds, N. R. (1995). Stigma, HIV and AIDS: An exploration and elaboration of a stigma trajectory. Social Science \& Medicine, 41(3), 303-315.

Bristow, R. E., Chang, J., Ziogas, A., \& Anton-Culver, H. (2013). Adherence to treatment guidelines for ovarian cancer as a measure of quality care. Obstetrics \& Gynecology, 121(6), 1226-1234.

CDC. (2013). Global HIV/AIDS - Haiti. Retrieved from http://www.cdc.gov/globalaids/global-hiv-aids-at-cdc/countries/haiti/default.html

Charles, B., Jeyaseelan, L., Pandian, A. K., Sam, A. E., Thenmozhi, M., \& Jayaseelan, V. (2012). Association between stigma, depression and quality of life of people living with HIV/AIDS (PLHA) in South India-a community based cross sectional study. BMC Public Health, 12(1), 1.

Farmer, P. (2006). AIDS and Accusation: Haiti and the Geography of Blame. Univ of California Press.

Gonzalez, A., Solomon, S. E., Zvolensky, M. J., \& Miller, C. T. (2009). The interaction of mindful-based attention and awareness and disengagement coping with HIV/AIDS-related stigma in regard to concurrent anxiety and depressive symptoms among adults with HIV/AIDS. Journal of Health Psychology, 14(3), 403-413.

Horvath, K. J., Oakes, J. M., Rosser, B. S., Danilenko, G., Vezina, H., Amico, K. R., ... Simoni, J. (2013). Feasibility, acceptability and preliminary efficacy of an online peer-to-peer social support ART adherence intervention. AIDS and Behavior, 17(6), 2031-2044.

Katz, I. T., Ryu, A. E., Onuegbu, A. G., Psaros, C., Weiser, S. D., Bangsberg, D. R., \& Tsai, A. C. (2013). Impact of HIV-related stigma on treatment adherence: systematic review and meta-synthesis. Journal of the International AIDS Society, 16(3), 18640.

Li, L., Lee, S. J., Thammawijaya, P., Jiraphongsa, C., \& Rotheram-Borus, M. J. (2009). Stigma, social support, and depression among people living with HIV in Thailand. AIDS Care, 21(8), 1007-1013.

Magidson, J. F., Safren, S. A., \& Nachega, J. B. (2014). Depression and adherence to antiretroviral therapy in low-, middle-and high-income countries: A systematic review and meta-analysis. Current HIV/AIDS Reports, 11(3), 291-307. 
Peck, R., Fitzgerald, D. W., Liautaud, B., Deschamps, M. M., Verdier, R. I., Beaulieu, M. E., ... \& Wright, P. (2003). The feasibility, demand, and effect of integrating primary care services with HIV voluntary counseling and testing: evaluation of a 15-year experience in Haiti, 1985-2000. Journal of Acquired Immune Deficiency Syndromes (1999), 33(4), 470-475.

Ratanawongsa, N., Karter, A. J., Parker, M. M., Lyles, C. R., Heisler, M., Moffet, H. H., ... Schillinger, D. (2013). Communication and medication refill adherence: the Diabetes Study of Northern California. JAMA Internal Medicine, 173(3), 210218.

Rintamaki, L. S., Davis, T. C., Skripkauskas, S., Bennett, C. L., \& Wolf, M. S. (2006). Social stigma concerns and HIV medication adherence. AIDS Patient Care \& STDs, 20(5), 359-368.

Simbayi, L. C., Kalichman, S., Strebel, A., Cloete, A., Henda, N., \& Mqeketo, A. (2007). Internalized stigma, discrimination, and depression among men and women living with HIV/AIDS in Cape Town, South Africa. Social Science \& Medicine, 64(9), 1823-1831.

Varni, S. E., Miller, C. T., McCuin, T., \& Solomon, S. E. (2012). Disengagement and engagement coping with HIV/AIDS stigma and psychological well-being of people with HIV/AIDS. Journal of Social and Clinical Psychology, 31(2), 123.

Vyavaharkar, M., Moneyham, L., Corwin, S., Saunders, R., Annang, L., \& Tavakoli, A. (2010). Relationships between stigma, social support, and depression in HIVinfected African American women living in the rural Southeastern United States. Journal of the Association of Nurses in AIDS Care, 21(2), 144-152.

Williams, A., \& Friedland, G. (1997). Adherence, compliance, and HAART. AIDS Clinical Care, 9(7), 51. 
Appendices 


\section{Appendix I}

\section{Perceived Stigma of HIV/AIDS}

\section{Perceived Stigma of HIV/AIDS: Personal View}

Let's go over the instructions together.

\section{[READ INSTRUCTIONS TOGETHER.]}

Let's do the first item together.

\section{[GO OVER THE FIRST ITEM.]}

If you have any questions, please feel free to ask me.

Here are some statements that people with HIV have made about themselves. For each statement, circle the answer that comes closest to the way you feel about yourself.

\begin{tabular}{|c|c|c|c|c|}
\hline & 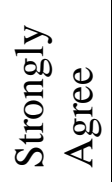 & 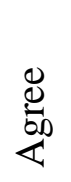 & 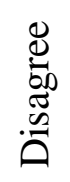 & 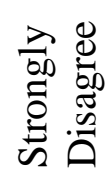 \\
\hline $\begin{array}{l}\text { 1. When people know I have HIV I feel } \\
\text { uncomfortable around them. }\end{array}$ & 1 & 2 & 3 & 4 \\
\hline 2. I feel ashamed that I have HIV. & 1 & 2 & 3 & 4 \\
\hline $\begin{array}{l}\text { 3. Because I have HIV, I should not take care of other } \\
\text { people's children. }\end{array}$ & 1 & 2 & 3 & 4 \\
\hline 4. I have been brave in handling my HIV. & 1 & 2 & 3 & 4 \\
\hline $\begin{array}{l}\text { 5. I must have done something to deserve getting } \\
\text { HIV. }\end{array}$ & 1 & 2 & 3 & 4 \\
\hline $\begin{array}{l}\text { 6. I should not share dishes or glasses just in case } \\
\text { someone might catch HIV from me. }\end{array}$ & 1 & 2 & 3 & 4 \\
\hline $\begin{array}{l}\text { 7. If I applied for a job, and someone else also applied } \\
\text { who did not have HIV, the employer should hire the } \\
\text { other person. }\end{array}$ & 1 & 2 & 3 & 4 \\
\hline $\begin{array}{l}\text { 8. Although I have HIV, I am a person who deserves } \\
\text { as much respect as anyone else. }\end{array}$ & 1 & 2 & 3 & 4 \\
\hline 9. I feel that it was my fault that I got HIV. & 1 & 2 & 3 & 4 \\
\hline $\begin{array}{l}\text { 10. People are right to be afraid of me because I have } \\
\text { HIV. }\end{array}$ & 1 & 2 & 3 & 4 \\
\hline $\begin{array}{l}\text { 11. Because of my HIV, I feel I am less attractive to } \\
\text { those who might want to date me. }\end{array}$ & 1 & 2 & 3 & 4 \\
\hline $\begin{array}{l}\text { 12. I have a lot to teach people about life through } \\
\text { having HIV. }\end{array}$ & 1 & 2 & 3 & 4 \\
\hline
\end{tabular}




\begin{tabular}{|l|c|c|c|c|}
\hline 13. I am embarrassed about having HIV. & 1 & 2 & 3 & 4 \\
\hline $\begin{array}{l}\text { 14. I feel it is completely safe for me to care for other } \\
\text { people's children even though I have HIV. }\end{array}$ & 1 & 2 & 3 & 4 \\
\hline $\begin{array}{l}\text { 15. I deserve a lot of credit for how well I have coped } \\
\text { with HIV. }\end{array}$ & 1 & 2 & 3 & 4 \\
\hline 16. I feel guilty about having HIV. & 1 & 2 & 3 & 4 \\
\hline $\begin{array}{l}\text { 17. I agree with mothers who do not want their children } \\
\text { to play with my children because of my HIV. }\end{array}$ & & & & \\
\hline $\begin{array}{l}\text { 18. I understand why people would reject my } \\
\text { friendship because I have HIV. }\end{array}$ & 1 & 2 & 3 & 4 \\
\hline 19. I think I am a person of good moral character. & 1 & 2 & 3 & 4 \\
\hline 20. I feel ashamed about the way I got HIV. & 1 & 2 & 3 & 4 \\
\hline 21. Because of my HIV, I should not hold a new infant. & 1 & 2 & 3 & 4 \\
\hline $\begin{array}{l}\text { 22. My neighbors would be right to be upset if they } \\
\text { learned I had HIV. }\end{array}$ & 1 & 2 & 3 & 4 \\
\hline 23. I think less of myself because I have HIV. & 1 & 2 & 3 & 4 \\
\hline $\begin{array}{l}\text { 24. I think that my getting HIV was just a matter of bad } \\
\text { luck. }\end{array}$ & 1 & 2 & 3 & 4 \\
\hline
\end{tabular}




\section{Perceived Stigma of HIV/AIDS: Public View}

Let's go over the instructions together.

\section{[READ INSTRUCTIONS TOGETHER.]}

Let's do the first item together.

\section{[GO OVER THE FIRST ITEM.]}

If you have any questions, please feel free to ask me.

The general public has a wide range of beliefs about people who have AIDS or HIV. Here is a list of some examples of these beliefs and attitudes. For each statement, circle the answer that best describes what you think other people's beliefs and attitudes are about HIV.

\begin{tabular}{|c|c|c|c|c|}
\hline & 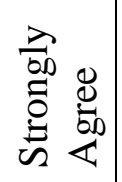 & 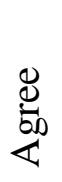 & 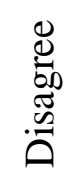 & 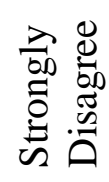 \\
\hline $\begin{array}{l}\text { 1. Most people believe that if you have HIV, you must } \\
\text { have done something to deserve it. }\end{array}$ & 1 & 2 & 3 & 4 \\
\hline $\begin{array}{l}\text { 2. Most people are afraid to be around a person with } \\
\text { HIV. }\end{array}$ & 1 & 2 & 3 & 4 \\
\hline $\begin{array}{l}\text { 3. Most people are uncomfortable around people who } \\
\text { have HIV. }\end{array}$ & 1 & 2 & 3 & 4 \\
\hline 4. Most people think less of a person who has HIV. & 1 & 2 & 3 & 4 \\
\hline $\begin{array}{l}\text { 5. Most people think that people with HIV are of good } \\
\text { moral character. }\end{array}$ & 1 & 2 & 3 & 4 \\
\hline $\begin{array}{l}\text { 6. Most people think that someone with HIV should } \\
\text { not take care of } \\
\text { 7. other people's children. }\end{array}$ & 1 & 2 & 3 & 4 \\
\hline $\begin{array}{l}\text { 8. Most people think that people with HIV deserve } \\
\text { respect as much as anyone else. }\end{array}$ & 1 & 2 & 3 & 4 \\
\hline $\begin{array}{l}\text { 9. Most people feel that if you have HIV, it is your } \\
\text { own fault. }\end{array}$ & 1 & 2 & 3 & 4 \\
\hline $\begin{array}{l}\text { 10. Most mothers would allow their children to play } \\
\text { with a child whose mother has HIV. }\end{array}$ & 1 & 2 & 3 & 4 \\
\hline $\begin{array}{l}\text { 11. Most people would reject the friendship of a person } \\
\text { with HIV. }\end{array}$ & 1 & 2 & 3 & 4 \\
\hline $\begin{array}{l}\text { 12. Most people think that if you have HIV you are not } \\
\text { as good as everyone else. }\end{array}$ & 1 & 2 & 3 & 4 \\
\hline $\begin{array}{l}\text { 13. Most people think you should be embarrassed about } \\
\text { having HIV. }\end{array}$ & 1 & 2 & 3 & 4 \\
\hline
\end{tabular}




\begin{tabular}{|c|c|c|c|c|}
\hline $\begin{array}{l}\text { 14. Most people would not share dishes or glasses with } \\
\text { someone who has HIV because they are afraid they } \\
\text { will catch it. }\end{array}$ & 1 & 2 & 3 & 4 \\
\hline $\begin{array}{l}\text { 15. Most people would be upset if someone with HIV } \\
\text { moved in next door. }\end{array}$ & 1 & 2 & 3 & 4 \\
\hline $\begin{array}{l}\text { 16. Most people believe that having HIV is something } \\
\text { to be ashamed about. }\end{array}$ & 1 & 2 & 3 & 4 \\
\hline $\begin{array}{l}\text { 17. Most people think that people with HIV should be } \\
\text { admired for their bravery in the face of the illness. }\end{array}$ & 1 & 2 & 3 & 4 \\
\hline \multicolumn{5}{|l|}{$\begin{array}{l}\text { 18. Most people think that people with HIV should feel } \\
\text { guilty about it. }\end{array}$} \\
\hline $\begin{array}{l}\text { 19. Most mothers would not want someone with HIV to } \\
\text { hold their new infant. }\end{array}$ & 1 & 2 & 3 & 4 \\
\hline $\begin{array}{l}\text { 20. Most people feel less attracted (as a date) to } \\
\text { someone with HIV. }\end{array}$ & 1 & 2 & 3 & 4 \\
\hline $\begin{array}{l}\text { 21. Most people believe that people with HIV deserve a } \\
\text { lot of credit for how well they cope with the } \\
\text { disease. }\end{array}$ & 1 & 2 & 3 & 4 \\
\hline $\begin{array}{l}\text { 22. Most people feel that how you get HIV is } \\
\text { something to be ashamed about. }\end{array}$ & 1 & 2 & 3 & 4 \\
\hline $\begin{array}{l}\text { 23. Most people think that getting HIV is just a matter } \\
\text { of bad luck. }\end{array}$ & 1 & 2 & 3 & 4 \\
\hline $\begin{array}{l}\text { 24. Most employers would hire someone with HIV to } \\
\text { work for them. }\end{array}$ & 1 & 2 & 3 & 4 \\
\hline $\begin{array}{l}\text { 25. Most people think that people with HIV can teach } \\
\text { us a lot about life. }\end{array}$ & 1 & 2 & 3 & 4 \\
\hline
\end{tabular}

The Perceived Stigma of HIV/AIDS (Bauman, Camacho, Westbrook, \& ForbesJones, 1997; Bauman, Silver, \& Camacho, 2000; Westbrook \& Bauman, 1996) scale is based on the conceptualization of stigma as having internalized as well as externalized components. The authors, Westbrook and Bauman, hypothesize that stigma will cause greater distress and lower self-esteem when the stigmatizing beliefs of others, the externalized dimension, is internalized. The instrument has two scales. The Perceived Stigma of HIV/AIDS: Personal View subscale is a 24-item instrument including stigma items that reflect shame, guilt, blame, embarrassment, and poor self-worth because of HIV. The Perceived Stigma of HIV/AIDS: Public View subscale contains 24 items designed to obtain the participant's perception of social stigma, i.e., what the respondent thinks other people's attitudes and beliefs are about HIV.

The items are phrased positively and negatively, and respondents indicate level of agreement on a four-point Likert-type scale (1=Strongly agree to $4=$ Strongly disagree). On the Personal View scale, recode items 1-3, 5-7, 9-11, 13, 16-18, and 20-24 as (4=1) 
$(3=2)(2=3)(1=4)$ and on the Public View subscale reverse items 1-4, 6, 8, 10-15, 17-19, 21-22. Sum the item values to create the subscale score. You may use mean substitution for missing items. Higher subscale scores indicate a higher level of personal or public stigma.

\section{References}

Bauman, L.J, Camacho, S., Westbrook, L.E., \& Forbes-Jones, E. (1997). Correlates of personal stigma and social stigma among mothers with HIV/AIDS. Presented at the National Conference on Women and HIV, Los Angeles, CA.

Bauman, L.J, Silver, E.J, \& Camacho, S. (2000). Stigma among mothers with HIV/AIDS. Presented at the XIII International AIDS Conference. Durban, South Africa.

Westbrook, L.E. \& Bauman, L.J. (1996). The Perceived Stigma of AIDS: Personal View and Public View scales. Bronx, NY: Albert Einstein College of Medicine. 


\section{Appendix II}

\section{Community Programs for Clinical Research on AIDS (CPCRA) Adherence Self- Report Questionnaire}

FORM 646

(Attach CPCRA PID Label Here)
ANTIRETROVIRAL MEDICATION SELF-REPORT
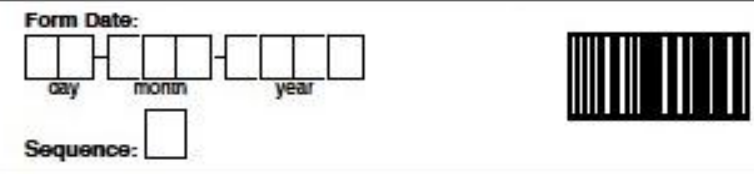

Instructions - RESEARCH STAFF.

Attach a PID label and record the form date on both pages of this form. Mark the "Sequence" box with 7.

Check Method of Data Collection for Sections B and C. If no AR drugs are prescribed check box 3, skip sections A-C, and FAX this page to the SDMC.

If AR drugs are prescribed complete Section A of this form with the patient. If more than 7 AR drugs are prescribed, include another copy of page 1 of this form, marking the "Sequence" box with 2 "

Method of Data collection for Sections $B$ and $c$.

1 Pattent niled out these sections

$2 \square$ staft member (or other person) assisted patent wth completion of these sections

$\square$ Not completed because patient not prescribed any AR drugs. (Do not check this box for patents lost to follow-up.) Skip Sections A-C. FAX this page to the SDMC.

\section{SECTION A}

TO BE COMPLETED BY RESEARCH STAFF WITH

STUDY PARTICIPANT.

Complete the following information with the patient for each antiretroviral drug prescribed during any of the past 7 days. Please write in the name of the drug that the patient uses and the drug code from the key below. For liquid ritonavir. alpha interferon and T-20, record Drug Name," "Drug Code," to ensure the patient's prescribed regimen is well understood. (Do net put atickers on this form.) For drugs that are

temporarily discontinued, record " $00^{\prime}$ for "Total No. of Pills

Per Day." discontinued, record " $00^{\prime}$ for "Total No. of Pills

Drug No. Pills Doses No. Pills

Drug Name Code Per Doee Per Day Per Day SECTION B

TO BE COMPLETED BY STUDY PARTICIPANT

Many people have trouble taking all their pills all of the time. For each drug listed in Section A, indicate how many of your pills you took during the last 7 days (check only one answer for each drug listed). Please answer all of the questions as honestly and carefully as possible. How you answer these questions will not affect your care or participation in this study. If you are unsure about a question, please give the best answer you can.

\begin{tabular}{|c|c|c|c|c|}
\hline \multicolumn{5}{|c|}{ During the last 7 days, I took: } \\
\hline $\begin{array}{l}\text { ALL } \\
\text { my pills } \\
\text { very day }\end{array}$ & $\begin{array}{l}\text { MOST } \\
\text { of my } \\
\text { pills }\end{array}$ & $\begin{array}{c}\text { About } \\
\text { ONE-HALF } \\
\text { of my pills }\end{array}$ & $\begin{array}{l}\text { VERY FEW } \\
\text { of my pills }\end{array}$ & $\begin{array}{l}\text { NONE of } \\
\text { my pills }\end{array}$ \\
\hline
\end{tabular}

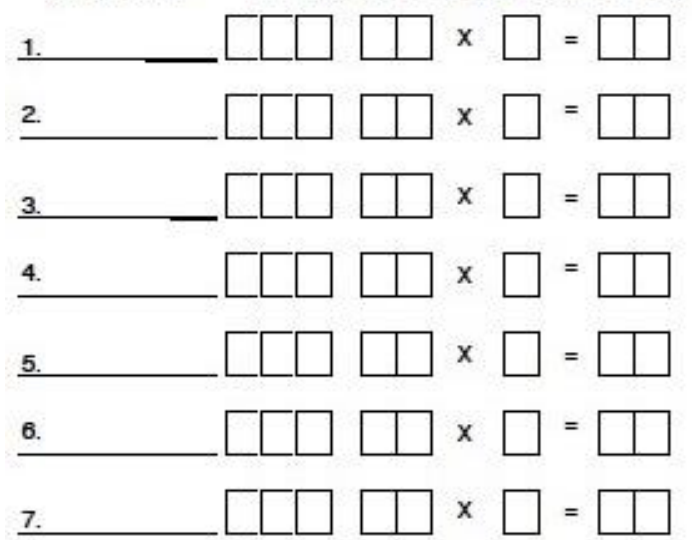

\begin{tabular}{|c|c|c|c|c|c|}
\hline & & & $\begin{array}{l}\text { If you took all your pill } \\
\text { every drug listed, DO I } \\
\text { Otherwise, go to Secti }\end{array}$ & $\begin{array}{l}3 \text { every day duri } \\
\text { IOT ANSWER A } \\
\text { In C on the last }\end{array}$ & $\begin{array}{l}\text { ng the last } 7 \text { days for } \\
\text { NY MORE QUESTIONS. } \\
\text { page. }\end{array}$ \\
\hline $\begin{array}{l}\text { "Drug Codes: } \\
\text { ABC-abacavir } \\
\text { ADV-adefovir dlpivoodl } \\
\text { APV-amprenavir } \\
\text { AZV-Atazanavir } \\
\text { CBV-Comblvir }\end{array}$ & $\begin{array}{l}\text { DDI-didanosine } \\
\text { DDC-zaicliabine } \\
\text { DLV-delavirdine } \\
\text { D4T-stavudine } \\
\text { EFV-efavirenz }\end{array}$ & $\begin{array}{l}\text { EMV-Emivirine } \\
\text { FTC-Coviracil } \\
\text { HDU-hydroxyurea } \\
\text { IDV-Indinavir } \\
\text { IFN-r } a \text {-interferon }\end{array}$ & $\begin{array}{l}\text { IL.2-interleukin } 2 \\
\text { LPV-Iopinavinintonawir (Kaletra) } \\
\text { NFV-neinnavir } \\
\text { NVP-nevirapine } \\
\text { RTV-ritonavir }\end{array}$ & $\begin{array}{l}\text { SQV-saquinavir } \\
\text { 3TC-lamiludine } \\
\text { TNV-Tenofovir } \\
\text { TPV-Thpranavir } \\
\text { TZV-Trizlir }\end{array}$ & $\begin{array}{l}\text { T20-T-20 (Fuzeon) } \\
\text { ZDV-Zidovudine } \\
\text { OAR-Other antiretrowirat }\end{array}$ \\
\hline
\end{tabular}

CPCRA Form 646 V4 (1-2) AUG 2003 


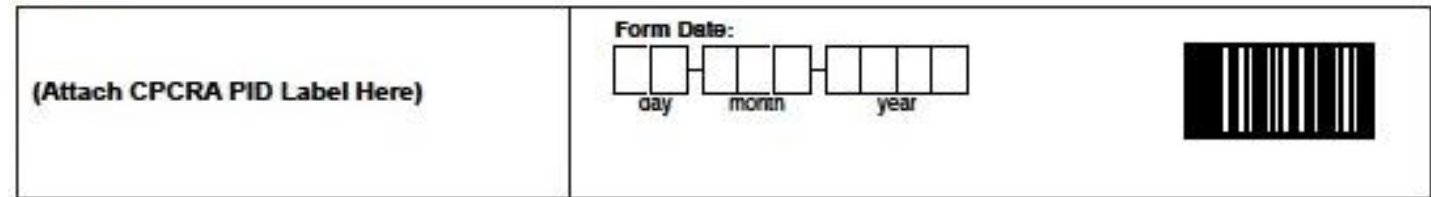

\section{SECTION C}

TO BE COMPLETED BY STUDY PARTICIPANT. Do not answer these questions if you took all your pills every day during the last 7 days for every drug listed.

1. During the last 7 days, what part of the day did you usually MISS taking your antiretroviral drugs? (Check all that apply.)

$1 \square$ In the morning (upon waking until 12 noon)

$1 \square$ In the afternoon (between 12 noon and 5 p.m.)

$1 \square$ In the evening (between 5 and 9 p.m.)

$1 \square$ At night (9 p.m. until waking the next morning)

2. Below are some reasons why people miss taking their antiretroviral drugs. Check "Yes" or "No" to indicate whether or not each of the following reasons describes why you usually MISSED taking your antiretroviral drugs during the last 7 days:
a. I feel worse when I take the pills
$1 \square$ Yes $2 \square$ No
b. There are too many pills to take
$1 \square Y_{\theta e}=\square$ No
c. I forget to take the pills
$1 \square Y_{e s}=\square$ No
d. I ran out of pills
e. I don't think I need the pills
$1 \square Y_{\text {es }} 2 \square$ No
f. I was away from home
$1 \square Y_{\theta e}=\square$ No
g. I did not want others to notice
$1 \square$ Yes $2 \square$ No
h. I am too busy
$1 \square Y_{\text {es }}=\square$ No i. I had problems taking pills at
specified times (with meals, on
$1 \square Y_{\theta e} 2 \square$ No empty stomach, etc.)
j. I was confused or uncertain about how to take the pills
$1 \square Y_{e s}=\square$ No
k. Other (please explain): 


\section{Appendix III}

\section{Center for Epidemiological Studies - Depression (CES-D) Affective Depression (15-item)}

\begin{tabular}{|c|c|c|c|c|}
\hline & 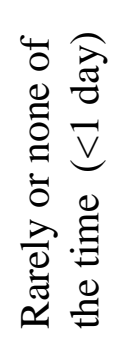 & 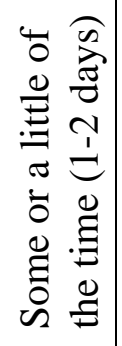 & 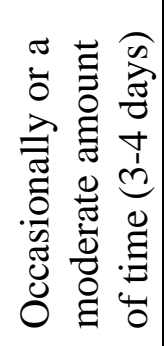 & 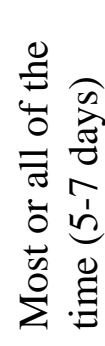 \\
\hline $\begin{array}{l}\text { 1. How often did you feel bothered by } \\
\text { things that don't usually bother you? }\end{array}$ & 0 & 1 & 2 & 3 \\
\hline $\begin{array}{l}\text { 2. How often did you feel that you could } \\
\text { not shake off the blues even with help } \\
\text { from family or friends? }\end{array}$ & 0 & 1 & 2 & 3 \\
\hline $\begin{array}{l}\text { 3. How often did you feel that you were } \\
\text { just as good as other poople? }\end{array}$ & 0 & 1 & 2 & 3 \\
\hline 4. How often did you feel depressed? & 0 & 1 & 2 & 3 \\
\hline $\begin{array}{l}\text { 5. How often did you feel hopeful about } \\
\text { the future? }\end{array}$ & 0 & 1 & 2 & 3 \\
\hline $\begin{array}{l}\text { 6. How often did you feel that your life } \\
\text { had been a failure? }\end{array}$ & 0 & 1 & 2 & 3 \\
\hline 7. How often did you feel fearful? & 0 & 1 & 2 & 3 \\
\hline 8. How often did you feel happy? & 0 & 1 & 2 & 3 \\
\hline 9. How often did you talk less than usual? & 0 & 1 & 2 & 3 \\
\hline 10. How often did you feel lonely? & 0 & 1 & 2 & 3 \\
\hline $\begin{array}{l}\text { 11. How often did you feel that people } \\
\text { were unfriendly? }\end{array}$ & 0 & 1 & 2 & 3 \\
\hline 12. How often did you enjoy life? & 0 & 1 & 2 & 3 \\
\hline 13. How often did you have crying spells? & 0 & 1 & 2 & 3 \\
\hline 14. How often did you feel sad? & 0 & 1 & 2 & 3 \\
\hline $\begin{array}{l}\text { 15. How often did you feel that people } \\
\text { disliked you? }\end{array}$ & 0 & 1 & 2 & 3 \\
\hline
\end{tabular}




\section{Appendix IV}

\section{Brief COPE}

\begin{tabular}{|c|c|c|c|c|}
\hline & $\begin{array}{l}\text { I haven't } \\
\text { been } \\
\text { doing } \\
\text { this at all }\end{array}$ & $\begin{array}{l}\text { I've } \\
\text { been } \\
\text { doing } \\
\text { this a } \\
\text { little bit }\end{array}$ & $\begin{array}{l}\text { I've been } \\
\text { doing this } \\
\text { a medium } \\
\text { amount }\end{array}$ & $\begin{array}{l}\text { I've } \\
\text { been } \\
\text { doing } \\
\text { this a } \\
\text { lot }\end{array}$ \\
\hline $\begin{array}{l}\text { 1. I've been turning to work or other } \\
\text { activities to take my mind off things. }\end{array}$ & 1 & 2 & 3 & 4 \\
\hline $\begin{array}{l}\text { 2. I've been concentrating my efforts on } \\
\text { doing something about the situation } \\
\text { I'm in. }\end{array}$ & 1 & 2 & 3 & 4 \\
\hline $\begin{array}{l}\text { 3. I've been saying to myself "this isn't } \\
\text { real.". }\end{array}$ & 1 & 2 & 3 & 4 \\
\hline $\begin{array}{l}\text { 4. I've been using alcohol or other drugs } \\
\text { to make myself feel better. }\end{array}$ & 1 & 2 & 3 & 4 \\
\hline $\begin{array}{l}\text { 5. I've been getting emotional support } \\
\text { from others. }\end{array}$ & 1 & 2 & 3 & 4 \\
\hline $\begin{array}{l}\text { 6. I've been giving up trying to deal } \\
\text { with it. }\end{array}$ & 1 & 2 & 3 & 4 \\
\hline $\begin{array}{l}\text { 7. I've been taking action to try to make } \\
\text { the situation better. }\end{array}$ & 1 & 2 & 3 & 4 \\
\hline $\begin{array}{l}\text { 8. I've been refusing to believe that it } \\
\text { has happened. }\end{array}$ & 1 & 2 & 3 & 4 \\
\hline $\begin{array}{l}\text { 9. I've been saying things to let my } \\
\text { unpleasant feelings escape. }\end{array}$ & 1 & 2 & 3 & 4 \\
\hline $\begin{array}{l}\text { 10. I've been getting help and advice } \\
\text { from other people. }\end{array}$ & 1 & 2 & 3 & 4 \\
\hline $\begin{array}{l}\text { 11. I've been using alcohol or other drugs } \\
\text { to help me get through it. }\end{array}$ & 1 & 2 & 3 & 4 \\
\hline $\begin{array}{l}\text { 12. I've been trying to see it in a different } \\
\text { light, to make it seem more positive. }\end{array}$ & 1 & 2 & 3 & 4 \\
\hline 13. I've been criticizing myself. & 1 & 2 & 3 & 4 \\
\hline $\begin{array}{l}\text { 14. I've been trying to come up with a } \\
\text { strategy about what to do. }\end{array}$ & 1 & 2 & 3 & 4 \\
\hline $\begin{array}{l}\text { 15. I've been getting comfort and } \\
\text { understanding from someone. }\end{array}$ & 1 & 2 & 3 & 4 \\
\hline $\begin{array}{l}\text { 16. I've been giving up the attempt to } \\
\text { cope. }\end{array}$ & 1 & 2 & 3 & 4 \\
\hline $\begin{array}{l}\text { 17. I've been looking for something good } \\
\text { in what is happening. }\end{array}$ & 1 & 2 & 3 & 4 \\
\hline 18. I've been making jokes about it. & 1 & 2 & 3 & 4 \\
\hline
\end{tabular}




\begin{tabular}{|l|l|l|l|l|}
\hline $\begin{array}{c}\text { 19. I've been doing something to think } \\
\text { about it less, such as going to } \\
\text { movies, watching TV, reading, } \\
\text { daydreaming, sleeping, or shopping. }\end{array}$ & 1 & 2 & 3 & 4 \\
\hline $\begin{array}{l}\text { 20. I've been accepting the reality of the } \\
\text { fact that it has happened. }\end{array}$ & 1 & 2 & 3 & 4 \\
\hline $\begin{array}{l}\text { 21. I've been expressing my negative } \\
\text { feelings. }\end{array}$ & 1 & 2 & 3 & 4 \\
\hline $\begin{array}{l}\text { 22. I've been trying to find comfort in my } \\
\text { religion or spiritual beliefs. }\end{array}$ & 1 & 2 & 3 & 4 \\
\hline $\begin{array}{l}\text { 23. I've been trying to get advice or help } \\
\text { from other people about what to do. }\end{array}$ & 1 & 2 & 3 & 4 \\
\hline 24. I've been learning to live with it. & 1 & 2 & 3 & 4 \\
\hline $\begin{array}{c}\text { 25. I've been thinking hard about what } \\
\text { steps to take. }\end{array}$ & 1 & 2 & 3 & 4 \\
\hline $\begin{array}{l}\text { 26. I've been blaming myself for things } \\
\text { that happened. }\end{array}$ & 1 & 2 & 3 & 4 \\
\hline 27. I've been praying or meditating. & 1 & 2 & 3 & 4 \\
\hline 28. I've been making fun of the situation. & & 2 & 3 & 4 \\
\hline
\end{tabular}

\section{Scales are computed as follows (with no reversals of coding):}

1. Self-distraction, items 1 and 19 (Maladaptive Coping)

2. Active coping, items 2 and 7 (Adaptive Coping)

3. Denial, items 3 and 8 (Maladaptive Coping)

4. Substance use, items 4 and 11 (Maladaptive Coping)

5. Use of emotional support, items 5 and 15 (Adaptive Coping)

6. Use of instrumental support, items 10 and 23 (Adaptive Coping)

7. Behavioral disengagement, items 6 and 16 (Maladaptive Coping)

8. Venting, items 9 and 21 (Maladaptive Coping)

9. Positive reframing, items 12 and 17 (Adaptive Coping)

10. Planning, items 14 and 25 (Adaptive Coping)

11. Humor, items 18 and 28 (Adaptive Coping)

12. Acceptance, items 20 and 24 (Adaptive Coping)

13. Religion, items 22 and 27 (Adaptive Coping)

14. Self-blame, items 13 and 26 (Maladaptive Coping) 


\section{Appendix V}

\section{State-Trait Anxiety Inventory (STAI) Form Y-1}

Please provide the following information:

Name:

Date:

S:

Age:

Gender (Circle): M F

$\mathrm{T}$ :

DIRECTIONS: A number of statements which people have used to describe themselves are given below. Read each statement and then circle the appropriate number to the right of the statement to indicate how you feel right now, that is, at this moment. There are no right or wrong answers. Do not spend too much time on any one statement but give the answer which seems to describe your present feelings best.

\begin{tabular}{|c|c|c|c|c|}
\hline & 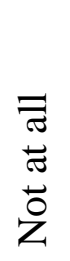 & $\begin{array}{l}\vec{z} \\
\frac{\pi}{3} \\
\text { J } \\
\tilde{0} \\
\text { is }\end{array}$ & 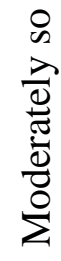 & 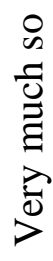 \\
\hline 1. I feel calm & 1 & 2 & 3 & 4 \\
\hline 2. I feel secure & 1 & 2 & 3 & 4 \\
\hline 3. I am tense & 1 & 2 & 3 & 4 \\
\hline 4. I feel strained & 1 & 2 & 3 & 4 \\
\hline 5. I feel at ease & 1 & 2 & 3 & 4 \\
\hline 6. I feel upset & 1 & 2 & 3 & 4 \\
\hline 7. I am presently worrying over possible misfortunes & 1 & 2 & 3 & 4 \\
\hline 8. I feel satisfied & 1 & 2 & 3 & 4 \\
\hline 9. I feel frightened & 1 & 2 & 3 & 4 \\
\hline 10. I feel comfortable & 1 & 2 & 3 & 4 \\
\hline 11. I feel self-confident & 1 & 2 & 3 & 4 \\
\hline 12. I feel nervous & 1 & 2 & 3 & 4 \\
\hline 13. I am jittery & 1 & 2 & 3 & 4 \\
\hline 14. I feel indecisive & 1 & 2 & 3 & 4 \\
\hline 15. I am relaxed & 1 & 2 & 3 & 4 \\
\hline 16. I feel content & 1 & 2 & 3 & 4 \\
\hline 17. I am worried & 1 & 2 & 3 & 4 \\
\hline 18. I feel confused & 1 & 2 & 3 & 4 \\
\hline 19. I feel steady & 1 & 2 & 3 & 4 \\
\hline 20. I feel pleasant & 1 & 2 & 3 & 4 \\
\hline
\end{tabular}


State-Trait Anxiety Inventory for Adults Scoring Key (Form Y-1)

Developed by Charles D. Spielberger in collaboration with R.L. Gorsuch, R. Lushene, P.R. Vagg, and G.A. Jacobs

To use this stencil, fold this sheet in half and line up with the appropriate test side, Form Y-1. Simply total the scoring weights shown on the stencil for each response category. For example, for question \# 1, if the respondent marked 3, then the weight would be 2 . Refer to the manual for appropriate normative data

\begin{tabular}{|c|c|c|c|c|}
\hline & $\begin{array}{l}\bar{\pi} \\
\tilde{\pi} \\
0 \\
z\end{array}$ & $\begin{array}{l}\tilde{J} \\
\frac{\pi}{3} \\
0 \\
\text { Ẽ } \\
\text { is }\end{array}$ & $\begin{array}{l}8 \\
\infty \\
\frac{\lambda}{0} \\
\frac{0}{\pi} \\
\frac{\pi}{8} \\
\sum\end{array}$ & 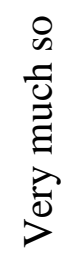 \\
\hline 1. & 4 & 3 & 2 & 1 \\
\hline 2. & 4 & 3 & 2 & 1 \\
\hline 3. & 1 & 2 & 3 & 4 \\
\hline 4. & 1 & 2 & 3 & 4 \\
\hline 5. & 4 & 3 & 2 & 1 \\
\hline 6. & 1 & 2 & 3 & 4 \\
\hline 7. & 1 & 2 & 3 & 4 \\
\hline 8. & 4 & 3 & 2 & 1 \\
\hline 9. & 1 & 2 & 3 & 4 \\
\hline 10. & 4 & 3 & 2 & 1 \\
\hline 11. & 4 & 3 & 2 & 1 \\
\hline 12. & 1 & 2 & 3 & 4 \\
\hline 13. & 1 & 2 & 3 & 4 \\
\hline 14. & 1 & 2 & 3 & 4 \\
\hline 15. & 4 & 3 & 2 & 1 \\
\hline 16. & 4 & 3 & 2 & 1 \\
\hline 17. & 1 & 2 & 3 & 4 \\
\hline 18. & 1 & 2 & 3 & 4 \\
\hline 19. & 4 & 3 & 2 & 1 \\
\hline 20. & 4 & 3 & 2 & 1 \\
\hline
\end{tabular}




\section{Appendix VI}

Modified Medical Outcomes Study Social Support Survey (mMOS-SSS)

\begin{tabular}{|l|c|c|c|c|c|}
\hline \multicolumn{2}{|l|}{} & & & \\
\end{tabular}


VITA

\section{MUNI BALAKRISHNAN RUBENS}

2008-2009

Florida International University, Miami, Florida

Master of Public Health

Research Assistant

Department of Health Promotion and Disease Prevention

Florida International University Miami, Florida

2011-Present

Florida International University, Miami, Florida

Doctoral Candidate

Research Assistant

Department of Health Promotion and Disease Prevention

Florida International University Miami, Florida

\section{PUBLICATIONS}

Rubens M, Ramamoorthy V, Attonito J, Saxena A, Appunni S, Shehadeh N, Dévieux JG. A Review of 5-HT Transporter Linked Promoter Region Polymorphism (5-HTTLPR) and associations with alcohol use problems and sexual risk behaviors. Journal of Community Genetics. 2016;7(1):1-10. PubMed PMID: 26338666.

Dévieux JG, Saxena A, Rosenberg R, Klausner JD, Jean-Gilles M, Madhivanan P, Gaston S, Rubens M, Theodore H, Deschamps M, Koenig SP, Pape JW. Knowledge, Attitudes, Practices and Beliefs about Medical Male Circumcision (MMC) among a Sample of Health Care Providers in Haiti. PLoS One. 2015;10(8):e0134667. PubMed PMID: 26237217.

Rubens M, Ramamoorthy V, Attonito J, Saxena A, Nair RR, Shehadeh N. Health promotion and disease prevention strategies for today's physicians. Am J Med Sci. 2015;349(1):73-9. PubMed PMID: 25559281.

Saxena A, Rubens M, Ramamoorthy V, Khan H. Risk of second cancers in Merkel cell carcinoma: a meta-analysis of population based cohort studies. J Skin Cancer.

2014;184245. PubMed PMID: 25574398.

Rubens M. Political and medical views on medical marijuana and its future. Soc Work Public Health. 2014;29(2):121-31. PubMed PMID: 24405197. 
Rubens M, Ramamoorthy V, Saxena A, Shehadeh N. Public health in the twenty-first century: the role of advanced technologies. Front Public Health. 2014 Nov 10;2:224. eCollection 2014. PubMed PMID: 25426484.

Rubens M, McCoy HV, Shehadeh N. Proficiency in condom use among migrant workers. J Assoc Nurses AIDS Care. 2014 May-Jun;25(3):233-42. PubMed PMID: 23876817.

Rubens M, Shehadeh N. Gun violence in United States: in search for a solution. Front Public Health. 2014 Mar 3;2:17. PubMed PMID: 24624371.

Rubens M. The world of community-based research is a complicated place. J Adolesc Health. 2013 Jul;53(1):146. PubMed PMID: 23791442.

Rubens M, Saxena A, Gaston S, Jean-Gilles M, Madhivanan P, Devieux JG.

Implementing medical male circumcision for HIV/STI risk reduction: exploring acceptability among medical care providers in Haiti. Presented at the 2014 National STD Prevention Conference, CDC, Atlanta, Georgia, June, 2014.

Saxena A, Rubens M, Gaston S, Jean-Gilles M, Rosenberg R, Devieux JG. Cognitive Behavioral Stress Management (CBSM) intervention decreases alcohol use and emotional distress among HIV positive men and women in Haiti. Presented at the 2014 Southern HIV and Alcohol Research Consortium conference, Miami, Florida, January, 2014. 